\title{
Electronically Modified Cobalt Aminopyridine Complexes Reveal an Orthogonal Axis for Catalytic Optimization for $\mathrm{CO}_{2}$ Reduction
}

Alon Chapovetsky, ${ }^{\dagger}$ Jeffrey J. Liu, ${ }^{\dagger}$ Matthew Welborn, ${ }^{\ddagger}$ John M. Luna, ${ }^{+}$Thomas Do, ${ }^{\dagger}$ Ralf Haiges, ${ }^{\dagger}$ Thomas F. Miller III, ${ }^{*,+}$ and Smaranda C. Marinescu ${ }^{*,+}$

${ }^{+}$Department of Chemistry, University of Southern California, Los Angeles, California 90089, United States

${ }^{\ddagger}$ Division of Chemistry and Chemical Engineering, California Institute of Technology, Pasadena, California 91125, United States

*Corresponding Authors: Smaranda C. Marinescu (smarines@usc.edu) and Thomas F. Miller III (thm@caltech.edu) 


\section{Contents}

General Considerations

Page

Calculation of Binding Constant from Cyclic Voltammetry

S2

Calculations of the Hammett Parameters for 1-4

S3

Crystallographic Data

S3

Electrochemical Experiments and Analyses

S4-S6

Hammett Analysis

S7-S14

S15

Density Functional Theory Calculation Details

S16

Synthetic Schemes and Procedures

S16-S26

NMR Spectra

S27-S40

Evans Method Experiments

S41-S43

High Scan Rate Cyclic Voltammetry Scans for Complex 2

S44

Supplementary Cyclic Voltammetry Titration Data

S45-S47

Supplementary CPE Data

S48

Faradic Efficiency Corrected $\left(i_{\text {cat }} / i_{p}\right)^{2}$ Plots

S49

${ }^{1}$ H NMR of Complex 4 with DCM $\quad$ S50

TFE Titration of Complex 1

S51

Calculation of Diffusion Coefficients for Complexes 2-4

S51-S52

Coordinates of Intermediates Examined in Density Functional Theory Studies

S53-S60

References

S61-S62 


\section{General}

All manipulations of air and moisture sensitive materials were conducted under a nitrogen atmosphere in a Vacuum Atmospheres drybox or on a dual manifold Schlenk line. The glassware was oven-dried prior to use. All solvents were degassed with nitrogen and passed through activated alumina columns and stored over $4 \AA$ Linde-type molecular sieves. Deuterated solvents were dried over $4 \AA$ Linde-type molecular sieves prior to use. Proton NMR spectra were acquired at room temperature using Varian (Mercury 400 2-Channel, VNMRS-500 2-Channel, VNMRS- 6003 Channel, and 400-MR 2-Channel) spectrometers and referenced to the residual ${ }^{1} \mathrm{H}$ resonances of the deuterated solvent $\left({ }^{1} \mathrm{H}: \mathrm{CDCl}_{3}, \delta 7.26 ; \mathrm{C}_{6} \mathrm{D}_{6}, \delta 7.16 ; \mathrm{CD}_{2} \mathrm{Cl}_{2}, \delta 5.32 ; \mathrm{CD}_{3} \mathrm{CN}, \delta 1.94\right)$ and are reported as parts per million relative to tetramethylsilane. Elemental analyses were performed using Thermo Scientific ${ }^{\mathrm{TM}}$ FLASH $2000 \mathrm{CHNS} / \mathrm{O}$ Analyzers. All the chemical reagents were purchased from commercial vendors and used without further purification.

\section{Cyclic Voltammetry (CV)}

Electrochemistry experiments were carried out using a Pine potentiostat. The experiments were performed in a single compartment electrochemical cell under nitrogen or $\mathrm{CO}_{2}$ atmosphere using a $3 \mathrm{~mm}$ diameter glassy carbon electrode as the working electrode, a platinum wire as auxiliary electrode and a silver wire as the reference electrode. Ohmic drop was compensated using the positive feedback compensation implemented in the instrument. All reported potentials are referenced relative to ferrocene $(\mathrm{Fc})$ with the $\mathrm{Fe}^{3+/ 2+}$ couple at $0.0 \mathrm{~V}$. Alternatively, in cases when the redox couple of ferrocene overlapped with other redox waves of interested, decamethylferrocene $\left(\mathrm{Fc}^{*}\right)$ was as an internal standard with the $\mathrm{Fe}^{* 3+/ 2+}$ couple at $-0.48 \mathrm{~V}$. All electrochemical experiments were performed with $0.1 \mathrm{M}$ tetrabutylammonium hexafluorophosphate as supporting electrolyte. The concentrations of the cobalt complexes 1-4 were generally at $0.5 \mathrm{mM}$ and experiments with $\mathrm{CO}_{2}$ were performed at gas saturation or varying amounts of $\mathrm{CO}_{2}$ in dimethylformamide (DMF).

\section{Controlled-potential electrolysis (CPE)}

CPE measurements were conducted in a two-chambered $\mathrm{H}$ cell. The first chamber held the working and reference electrodes in $50 \mathrm{~mL}$ of $0.1 \mathrm{M}$ tetrabutylammonium hexafluorophosphate and 1.3 M trifluoroethanol in DMF. The second chamber held the auxiliary electrode in $25 \mathrm{~mL}$ of $0.1 \mathrm{M}$ tetrabutylammonium hexafluorophosphate in DMF. The two chambers were separated by a fine porosity glass frit. The reference electrode was placed in a separate compartment and connected by a Vycor tip. Glassy carbon plate electrodes $(6 \mathrm{~cm} \times 1 \mathrm{~cm} \times 0.3 \mathrm{~cm}$; Tokai Carbon USA) were used as the working and auxiliary electrodes. Using a gas-tight syringe, $10 \mathrm{~mL}$ of gas were withdrawn from the headspace of the $\mathrm{H}$ cell and injected into a gas chromatography instrument (Shimadzu GC-2010-Plus) equipped with a BID detector and a Restek ShinCarbon ST Micropacked column. Faradaic efficiencies were determined by diving the measured CO produced by the amount of $\mathrm{CO}$ expected based on the charge passed during the bulk electrolysis experiment. For each species the controlled-potential electrolysis measurements were performed at least twice, leading to similar behavior. The reported Faradaic efficiencies and mmol of CO produced are average values. 


\section{X-ray Diffraction Data Collection and Processing}

The X-ray intensity data were collected on a Bruker APEX DUO 3-circle platform diffractometer with the $\chi$-axis fixed at $50.74^{\circ}$, and using Mo $K_{\alpha}$ radiation $(\lambda=0.71073 \AA$ ) from a fine-focus tube monochromatized by a TRIUMPH curved-crystal monochromator. ${ }^{1}$ The diffractometer was equipped with an APEX II CCD detector and an Oxford Cryosystems Cryostream 700 apparatus for low-temperature data collection adjusted to $173(2) \mathrm{K}$. The crystal was mounted in a Cryo-Loop using Paratone oil. A complete hemisphere of data was scanned on omega $\left(0.5^{\circ}\right)$ at a detector distance of $50 \mathrm{~mm}$ and a resolution of $512 \times 512$ pixels. The frames were integrated using the SAINT algorithm ${ }^{2}$ to give the hkl files corrected for Lp/decay. Data were corrected for absorption effects using the multi-scan method (SADABS). ${ }^{3}$ The structures were solved by intrinsic phasing and refined with the Bruker SHELXTL Software Package. ${ }^{4-7}$

\section{Calculation of Binding Constant from Cyclic Voltammetry ${ }^{8}$}

The CV's for complex 4 under $\mathrm{N}_{2}$ and $\mathrm{CO}_{2}$ are indicative of $\mathrm{CO}_{2}$ binding to the metal center which can be approximated using the following equation

$$
\Delta E=\left(\frac{R T}{n F}\right) \ln \left(1+\left[\mathrm{CO}_{2}\right] K_{Q}\right)
$$

In $\mathrm{Eq}(6), \Delta \mathrm{E}$ corresponds to the change in potential $(59 \mathrm{mV})$ for the $\mathrm{Co}^{\mathrm{I} / 0}$ couple when the atmosphere is changed from $\mathrm{N}_{2}$ to $\mathrm{CO}_{2}$. $\mathrm{R}$ is the universal gas constant $\left(8.314 \mathrm{~J} \mathrm{~K}^{-1} \mathrm{~mol}^{-1}\right)$, $\mathrm{T}$ is the temperature Kelvin $(298.15 \mathrm{~K}), \mathrm{F}$ is faraday's constant $\left(96,485 \mathrm{C} \mathrm{mol}^{-1}\right), \mathrm{n}$ is the number of electrons involve in the reduction from $\mathrm{Co}^{\mathrm{I}}$ to $\mathrm{Co}^{0}$ (1 electron), $\left[\mathrm{CO}_{2}\right]$ is the concentration of $\mathrm{CO}_{2}$ in $\operatorname{DMF}(0.2 \mathrm{M})$ and $\mathrm{K}_{\mathrm{Q}}$ is the binding constant between $\mathrm{CO}_{2}$ and the cobalt catalyst.

\section{Calculations of the Hammett Parameters for 1-4}

The cumulative Hammett Parameters for 1-4 were calculated by the summation of the individual Hammett constants for each substituent. The literature ${ }^{9}$ values used were:

$\sigma_{\mathrm{p}, \mathrm{H}}=0$

$\sigma_{\mathrm{p}, \mathrm{CF} 3}=0.54$

$\sigma_{\mathrm{p}, \mathrm{NMe} 2}=-0.83$

For complex 1, $0 \times 4=\mathbf{0}$

For complex 2, $0.54 \times 4=\mathbf{2 . 1 6}$

For complex 3, $2 \times 0+2 \times(-0.83)=\mathbf{- 1 . 6 6}$

For complex 4, $2 \times 0.54+2 \times(-0.83)=-\mathbf{0 . 5 8}$ 


\section{Crystallographic data}

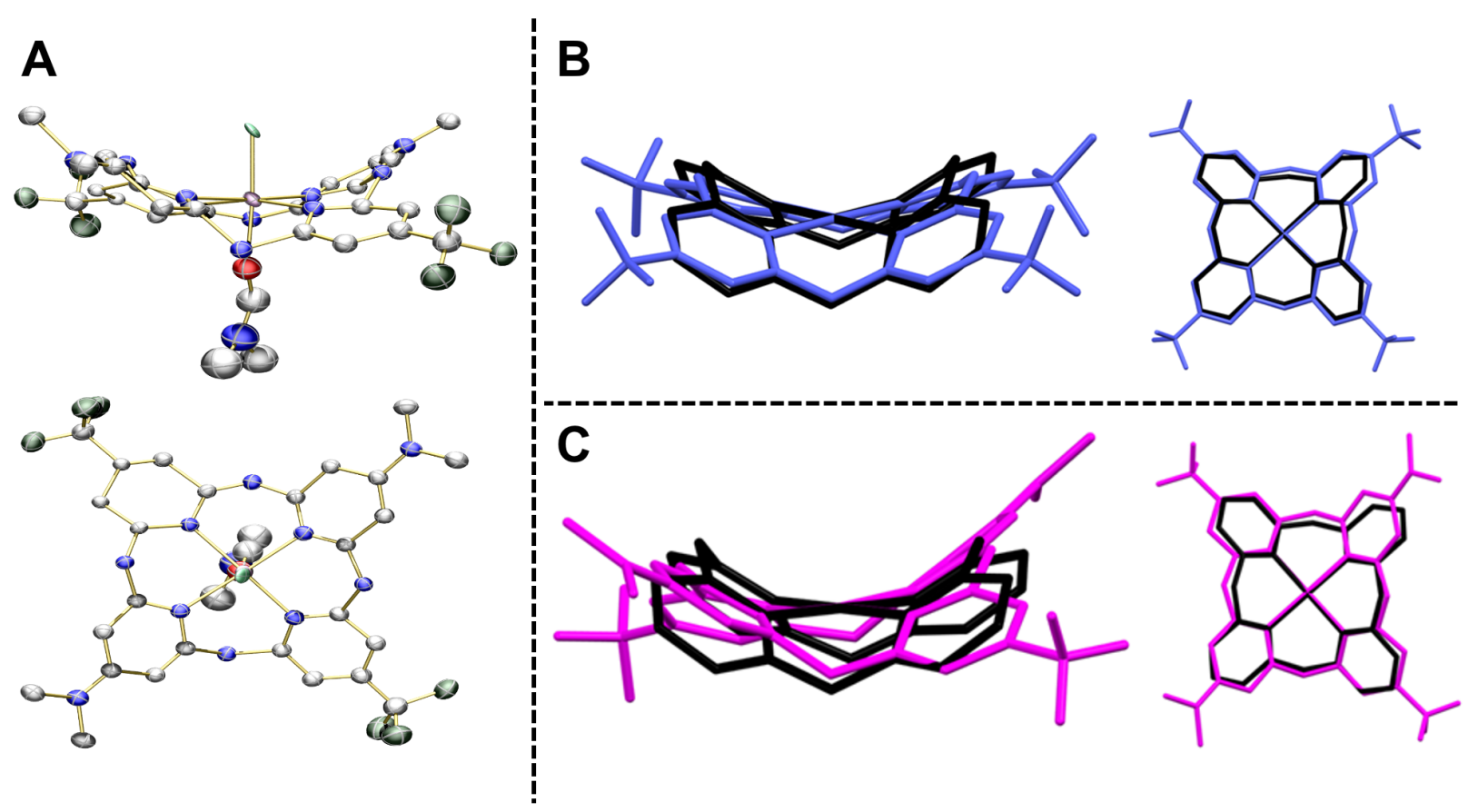

Figure S1. (A) Thermal ellipsoid drawing of complex 4 displayed at 50\% probability level. Hydrogen atoms and $\mathrm{BF}_{4}^{-}$counteranions are omitted for clarity. (B) Overlay of wireframe representations of complexes 2 (blue) and the unsubstituted cobalt aminopyridine $\mathbf{1}$ (black). (C) Overlay of wireframe representations of complexes 4 (blue) and the unsubstituted cobalt aminopyridine $\mathbf{1}$ (black). 


\section{Table S1. Sample and crystal data for 2.}

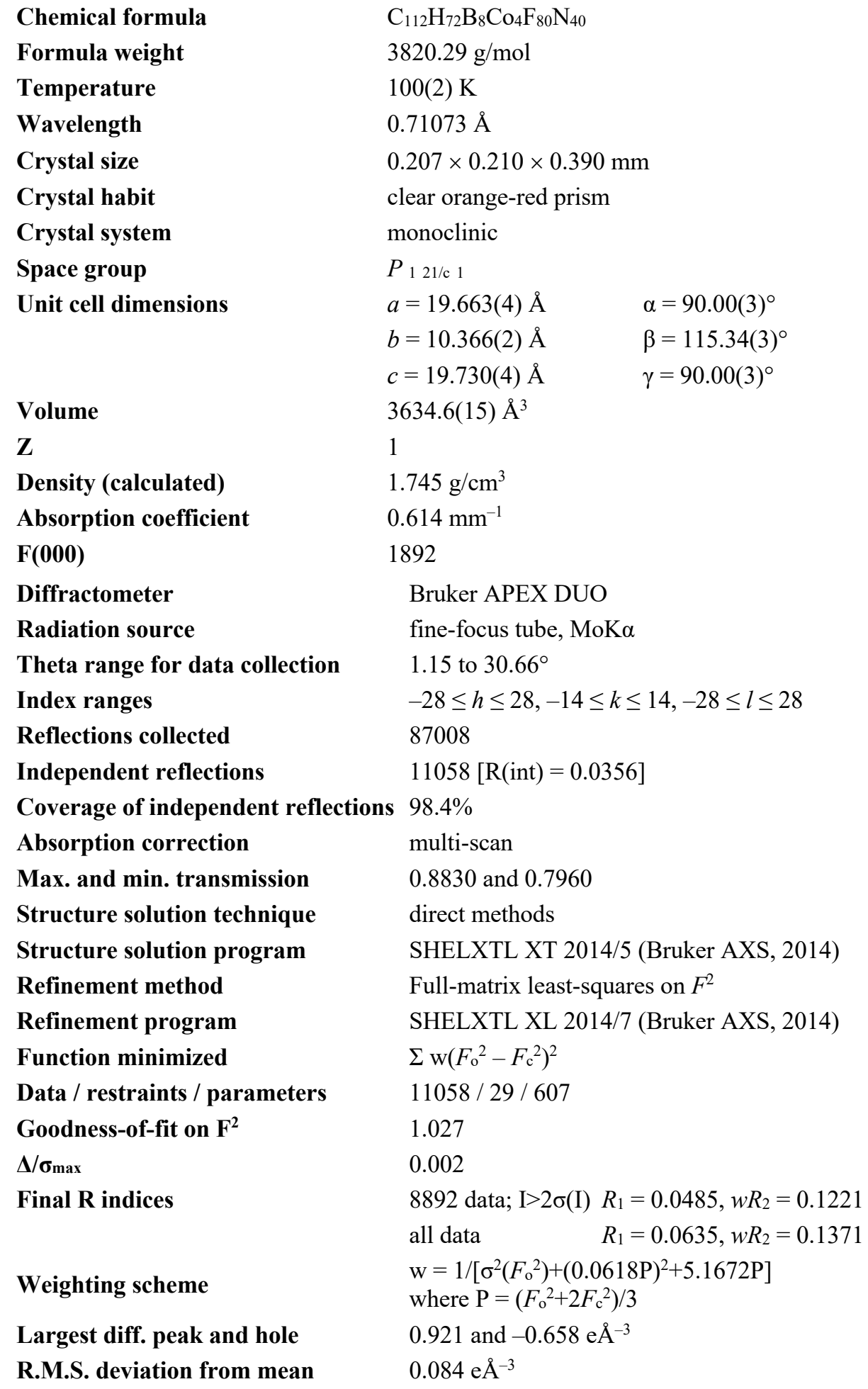




\section{Table S2. Sample and crystal data for 4-Cl.}

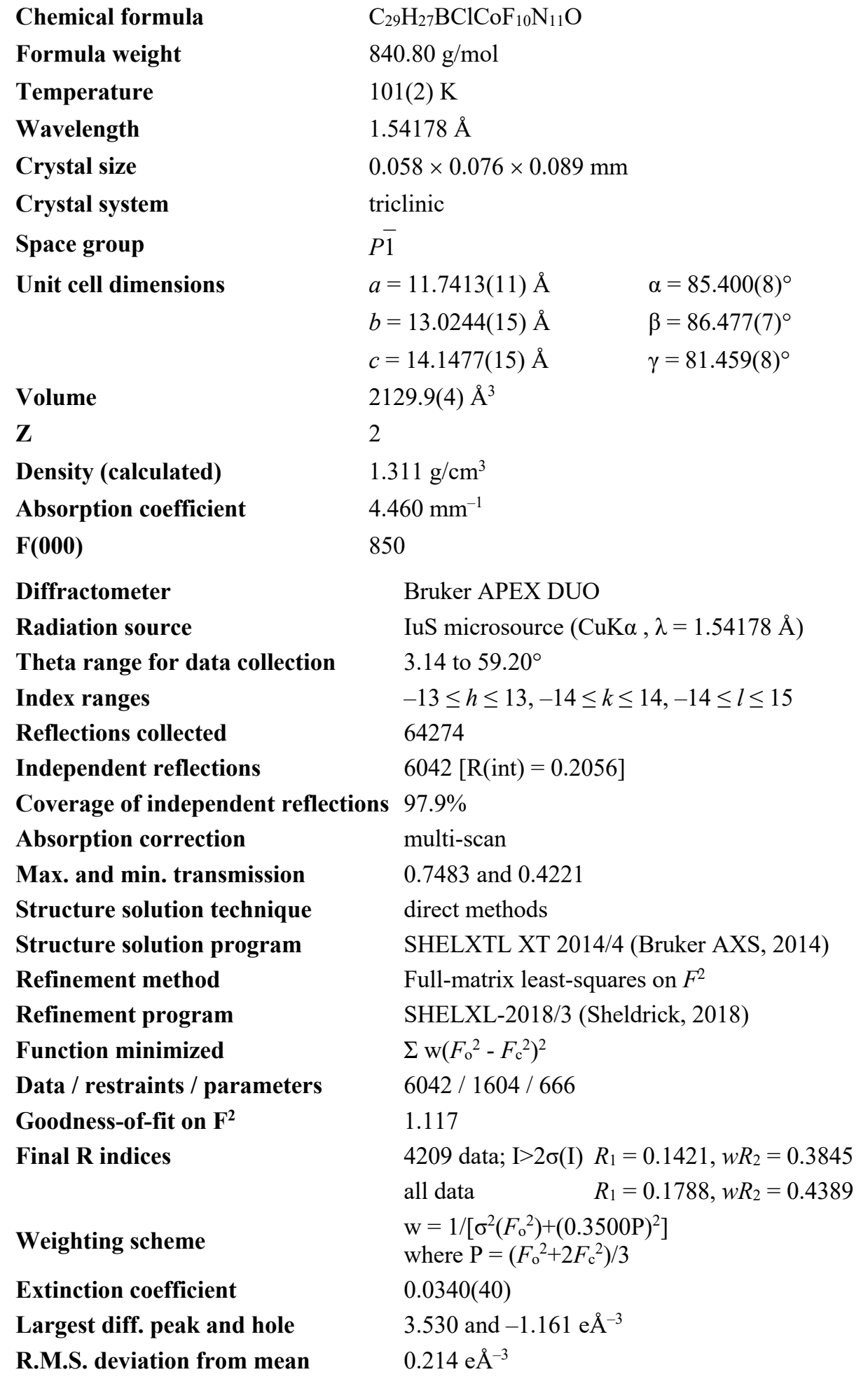




\section{Electrochemical Experiments and Analyses}

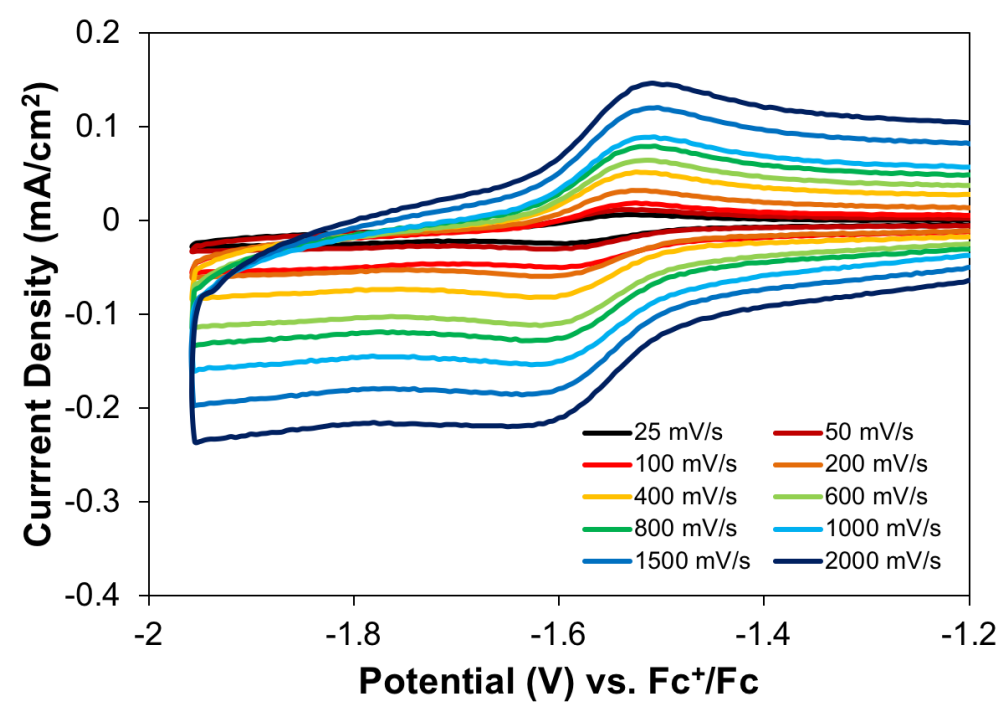

Figure S2. Cyclic voltammograms of complex $2(0.5 \mathrm{mM})$ in a DMF solution containing $0.1 \mathrm{M}$ $\left[n \mathrm{Bu}_{4} \mathrm{~N}\right]\left[\mathrm{PF}_{6}\right]$ under an atmosphere of $\mathrm{N}_{2}$ displaying the reversible one-electron reduction with an $E_{1 / 2}$ of $-1.56 \mathrm{~V}$ vs. $\mathrm{Fc}^{+/ 0}$ and assigned to $\left[\mathrm{Co}\left({ }^{\mathrm{CF} 3} \mathrm{~L}\right)\right]^{2+/+}$ couple. Scan rates vary from 0.025 to $2 \mathrm{~V} / \mathrm{s}$.

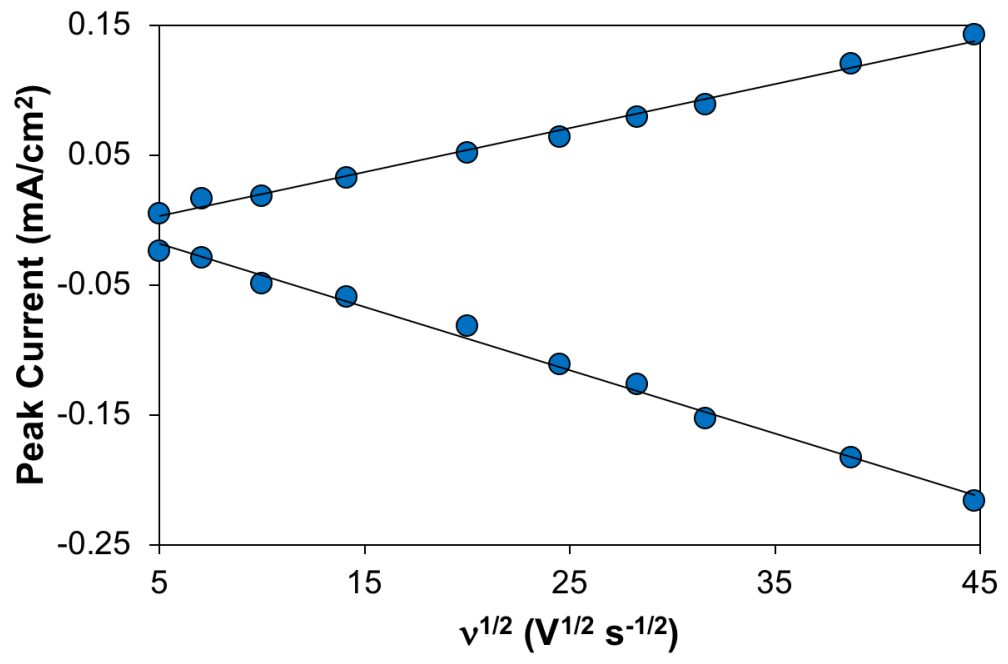

Figure S3. Plot showing the peak current, both cathodic and anodic, of complex $2(0.5 \mathrm{mM}$ in a DMF solution containing $0.1 \mathrm{M}\left[n \mathrm{Bu}_{4} \mathrm{~N}\right]\left[\mathrm{PF}_{6}\right]$ under an atmosphere of $\mathrm{N}_{2}$ ) as a function of the scan rate. The cathodic and anodic peak currents increase linearly with the square root of the scan rate. This behavior is indicative of a freely-diffusing species, where the electrode reaction is controlled by mass transport. 


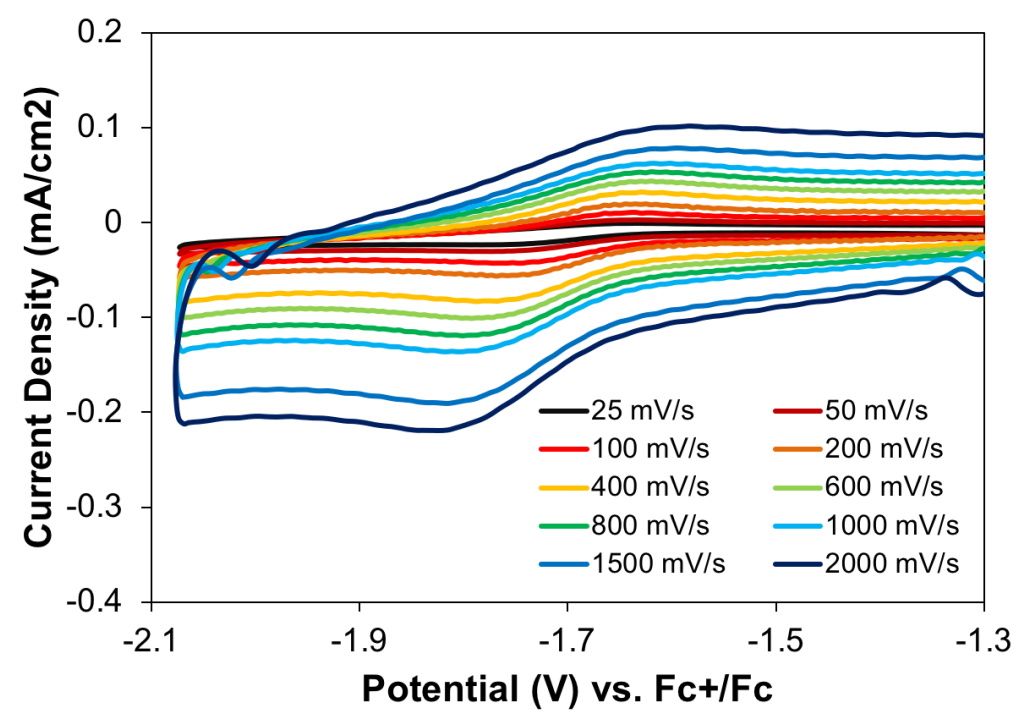

Figure S4. Cyclic voltammograms of complex $3(0.5 \mathrm{mM})$ in a DMF solution containing $0.1 \mathrm{M}$ $\left[n \mathrm{Bu}_{4} \mathrm{~N}\right]\left[\mathrm{PF}_{6}\right]$ under an atmosphere of $\mathrm{N}_{2}$ displaying the reversible one-electron reduction with an $E_{1 / 2}$ of $-1.75 \mathrm{~V}$ vs. $\mathrm{Fc}^{+/ 0}$ and assigned to $\left[\mathrm{Co}\left({ }^{\mathrm{NMe} 2} \mathrm{~L}\right)\right]^{2+/+}$ couple. Scan rates vary from 0.025 to 2 $\mathrm{V} / \mathrm{s}$.

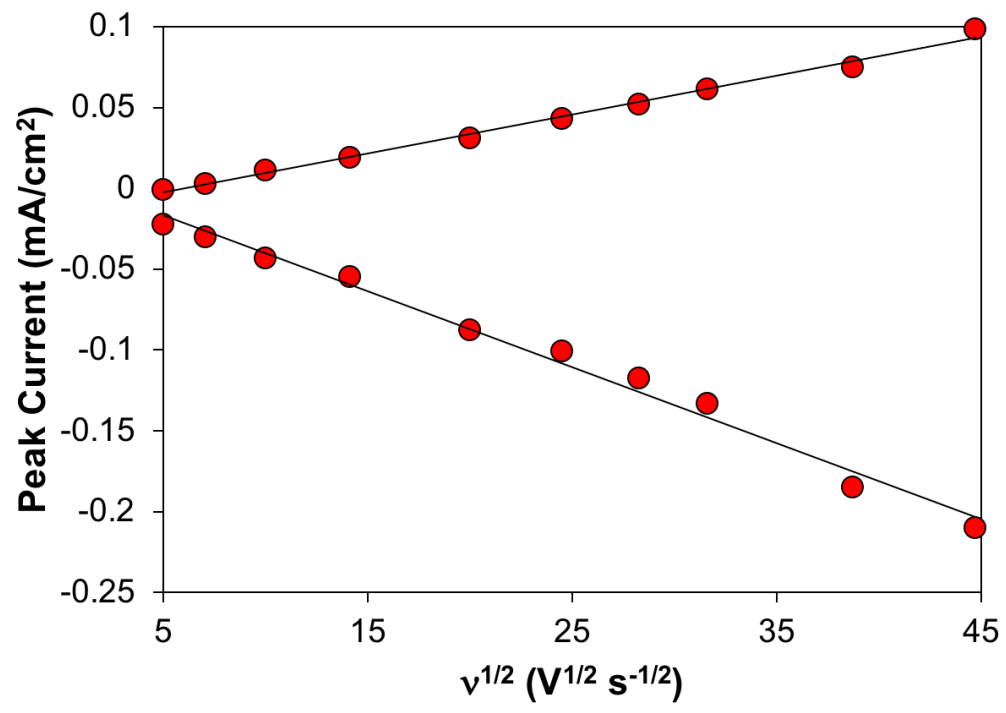

Figure S5. Plot showing the peak current, both cathodic and anodic, of complex $3(0.5 \mathrm{mM}$ in a DMF solution containing $0.1 \mathrm{M}\left[n \mathrm{Bu}_{4} \mathrm{~N}\right]\left[\mathrm{PF}_{6}\right]$ under an atmosphere of $\mathrm{N}_{2}$ ) as a function of the scan rate. The cathodic and anodic peak currents increase linearly with the square root of the scan rate. This behavior is indicative of a freely-diffusing species, where the electrode reaction is controlled by mass transport. 


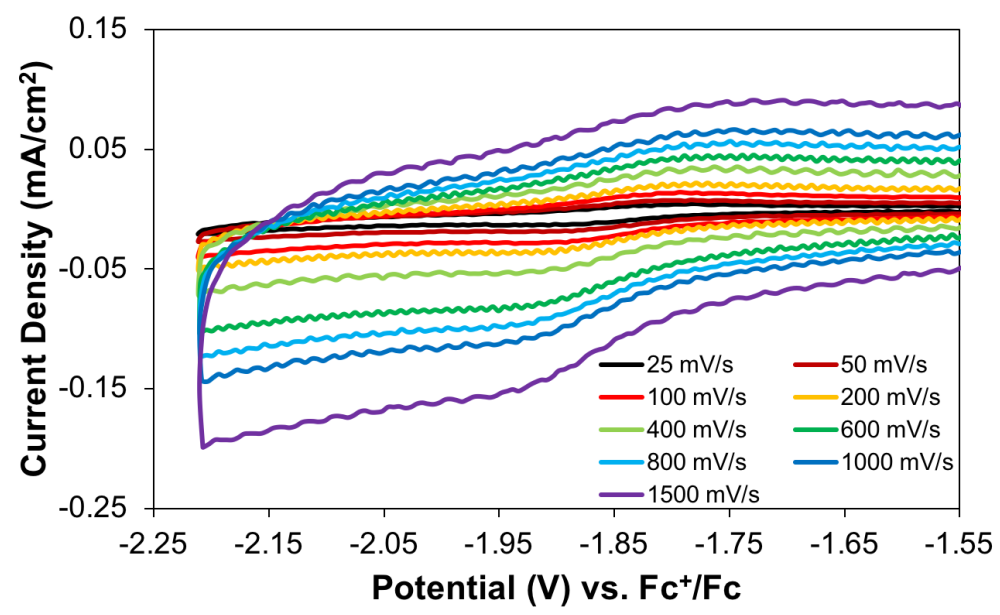

Figure S6. Cyclic voltammograms of complex $4(0.5 \mathrm{mM})$ in a DMF solution containing $0.1 \mathrm{M}$ $\left[n \mathrm{Bu}_{4} \mathrm{~N}\right]\left[\mathrm{PF}_{6}\right]$ under an atmosphere of $\mathrm{N}_{2}$ displaying the reversible one-electron reduction with an $E_{1 / 2}$ of $-1.85 \mathrm{~V}$ vs. $\mathrm{Fc}^{+/ 0}$ and assigned to $\left[\mathrm{Co}\left({ }^{\mathrm{Mix}} \mathrm{L}\right)\right]^{2+/+}$ couple. Scan rates vary from 0.025 to 1.5 $\mathrm{V} / \mathrm{s}$.

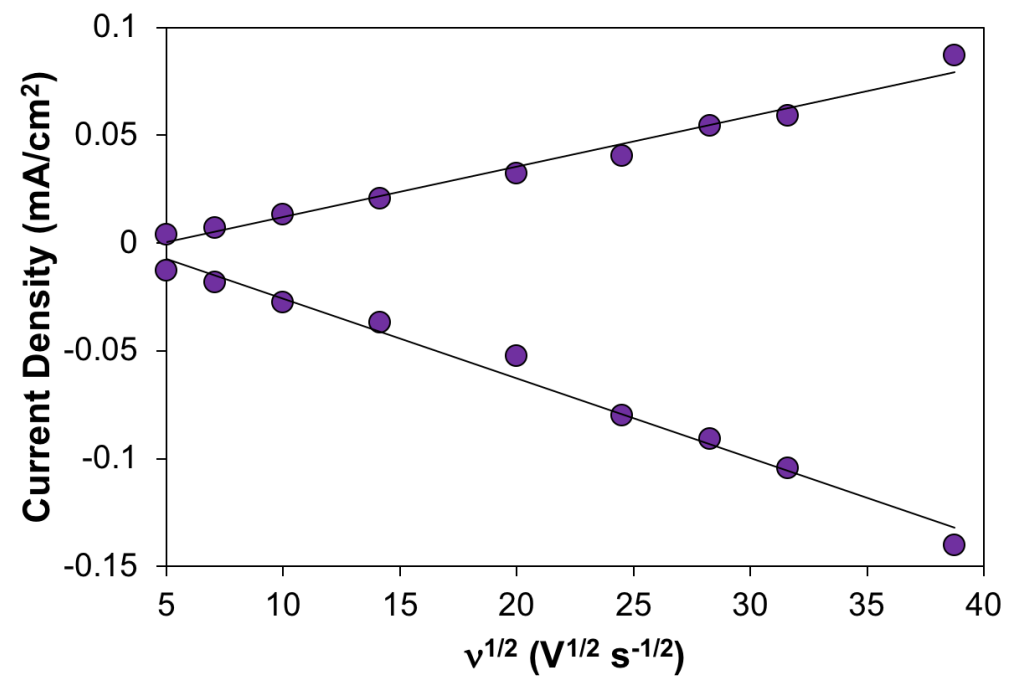

Figure S7. Plot showing the peak current, both cathodic and anodic, of complex $4(0.5 \mathrm{mM}$ in a DMF solution containing $0.1 \mathrm{M}\left[n \mathrm{Bu}_{4} \mathrm{~N}\right]\left[\mathrm{PF}_{6}\right]$ under an atmosphere of $\mathrm{N}_{2}$ ) as a function of the scan rate. The cathodic and anodic peak currents increase linearly with the square root of the scan rate. This behavior is indicative of a freely-diffusing species, where the electrode reaction is controlled by mass transport. 


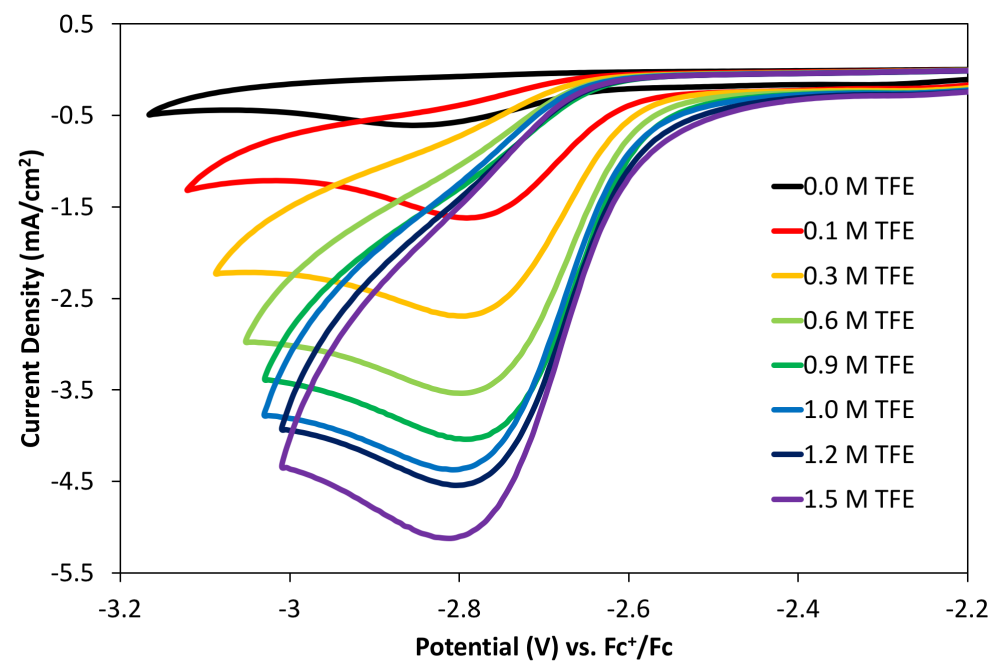

Figure S8. Cyclic voltammograms of complex $2(0.5 \mathrm{mM})$ in a DMF solution containing $0.1 \mathrm{M}$ $\left[n \mathrm{Bu}_{4} \mathrm{~N}\right]\left[\mathrm{PF}_{6}\right]$ under $\mathrm{CO}_{2}$ atmosphere with varying amounts of TFE. The potential at which maximum current is observed is $-2.72 \mathrm{~V}$. Scans are performed at $100 \mathrm{mV} / \mathrm{s}$.

Table S3. Catalytic current for the titration of complex 2 with TFE. $i_{p}=0.0177 \mathrm{~mA} / \mathrm{cm}^{2}$, extrapolated from the reversible $\mathrm{Co}^{\mathrm{II} / \mathrm{I}}$ couple.

\begin{tabular}{ccc}
\hline$[$ TFE $](\mathbf{M})$ & $\boldsymbol{i}_{\text {cat }}\left(\mathbf{m A} / \mathbf{c m}^{2}\right)$ & $\boldsymbol{i}_{\text {cat }} / \boldsymbol{i}_{\boldsymbol{p}}$ \\
\hline $\mathbf{0 . 1}$ & 1.23 & 69.4 \\
$\mathbf{0 . 3}$ & 2.69 & 152.0 \\
$\mathbf{0 . 6}$ & 4.42 & 249.6 \\
$\mathbf{0 . 9}$ & 4.75 & 268.3 \\
$\mathbf{1 . 0}$ & 5.73 & 323.7 \\
$\mathbf{1 . 5}$ & 6.56 & 370.3 \\
\hline
\end{tabular}

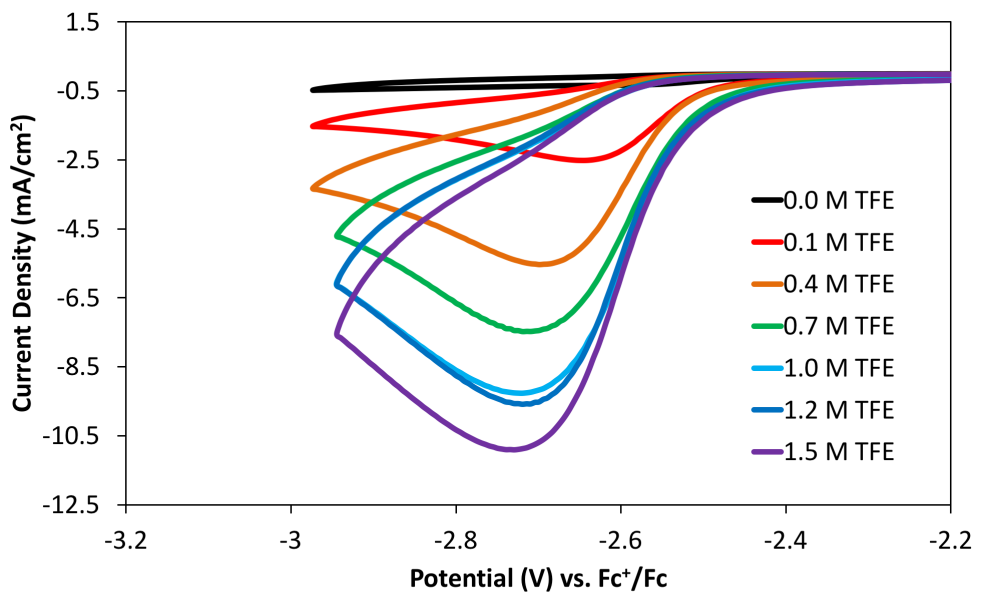

Figure S9. Cyclic voltammograms of complex $3(0.5 \mathrm{mM})$ in a DMF solution containing $0.1 \mathrm{M}$ $\left[n \mathrm{Bu}_{4} \mathrm{~N}\right]\left[\mathrm{PF}_{6}\right]$ under $\mathrm{CO}_{2}$ atmosphere with varying amounts of TFE. The potential at which maximum current is observed is $-2.73 \mathrm{~V}$. Scans are performed at $100 \mathrm{mV} / \mathrm{s}$. 
Table S4. Catalytic current for the titration of complex 3 with TFE. $i_{p}=0.0140 \mathrm{~mA} / \mathrm{cm}^{2}$, extrapolated from the reversible $\mathrm{Co}^{\mathrm{II} / \mathrm{I}}$ couple.

\begin{tabular}{ccc}
\hline$[\mathrm{TFE}](\mathbf{M})$ & $\boldsymbol{i}_{\boldsymbol{c a t}}\left(\mathbf{m A} / \mathbf{c m}^{\mathbf{2}}\right)$ & $\boldsymbol{i}_{\boldsymbol{c a t}} \boldsymbol{i}_{\boldsymbol{p}}$ \\
\hline $\mathbf{0 . 1}$ & 2.47 & 176.8 \\
$\mathbf{0 . 4}$ & 5.51 & 394.1 \\
$\mathbf{0 . 7}$ & 7.47 & 534.8 \\
$\mathbf{1 . 0}$ & 9.20 & 658.9 \\
$\mathbf{1 . 2}$ & 9.57 & 684.9 \\
$\mathbf{1 . 5}$ & 10.91 & 781.1 \\
\hline
\end{tabular}

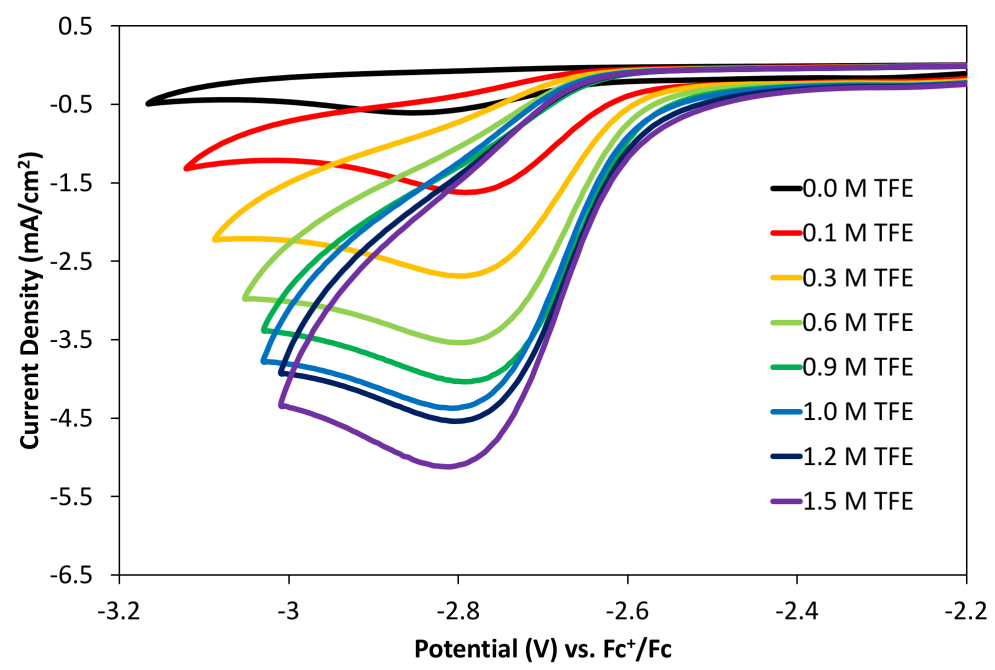

Figure S10. Cyclic voltammograms of complex $4(0.5 \mathrm{mM})$ in a DMF solution containing $0.1 \mathrm{M}$ $\left[n \mathrm{Bu}_{4} \mathrm{~N}\right]\left[\mathrm{PF}_{6}\right]$ under $\mathrm{CO}_{2}$ atmosphere with varying amounts of TFE. The potential at which maximum current is observed is $-2.79 \mathrm{~V}$. Scans are performed at $100 \mathrm{mV} / \mathrm{s}$.

Table S5. Catalytic current for the titration of complex 4 with TFE. $i_{p}=0.0357 \mathrm{~mA} / \mathrm{cm}^{2}$, extrapolated from the reversible $\mathrm{Co}^{\mathrm{I} / \mathrm{I}}$ couple.

\begin{tabular}{ccc}
\hline$[$ TFE] $(\mathbf{M})$ & $\boldsymbol{i}_{\text {cat }}\left(\mathbf{m A} / \mathbf{c m}^{\mathbf{2}}\right)$ & $\boldsymbol{i}_{\text {cat }} / \boldsymbol{i}_{\boldsymbol{p}}$ \\
\hline $\mathbf{0 . 1}$ & 1.62 & 45.4 \\
$\mathbf{0 . 3}$ & 2.69 & 75.4 \\
$\mathbf{0 . 6}$ & 3.53 & 98.9 \\
$\mathbf{0 . 9}$ & 4.00 & 112.1 \\
$\mathbf{1}$ & 4.369 & 122.4 \\
$\mathbf{1 . 2}$ & 4.546 & 127.4 \\
$\mathbf{1 . 5}$ & 5.123 & 143.5 \\
\hline
\end{tabular}




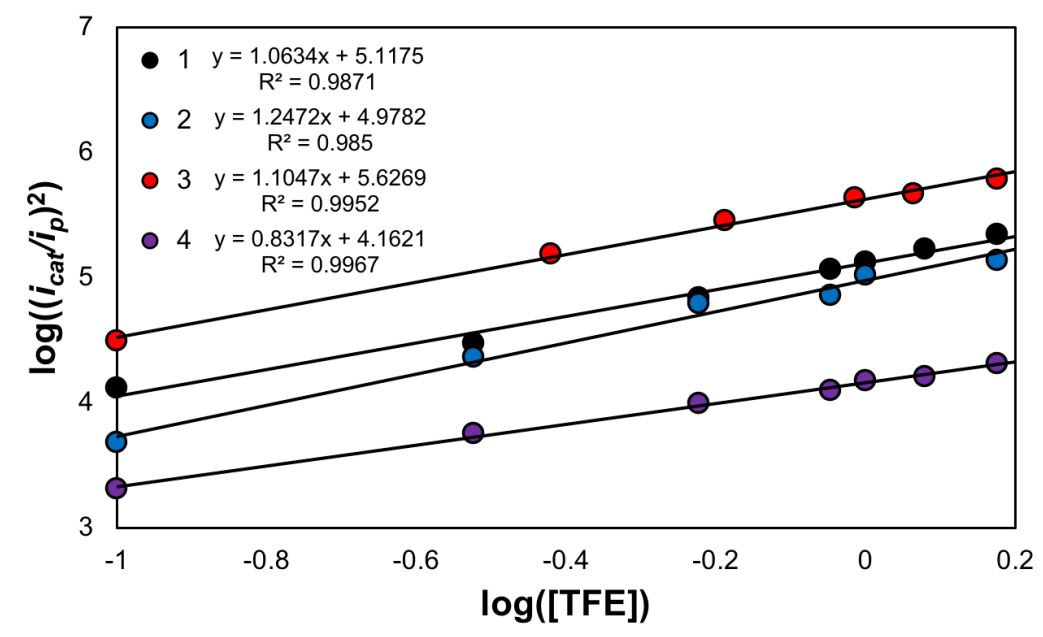

Figure S11. Plot of the $\log$ of $\left(i_{\text {cat }} / i_{p}\right)^{2}$ vs. $\log ([\mathrm{TFE}])$. The slopes of the lines are all approximately equal to one indicating a reaction that is first order in protons.
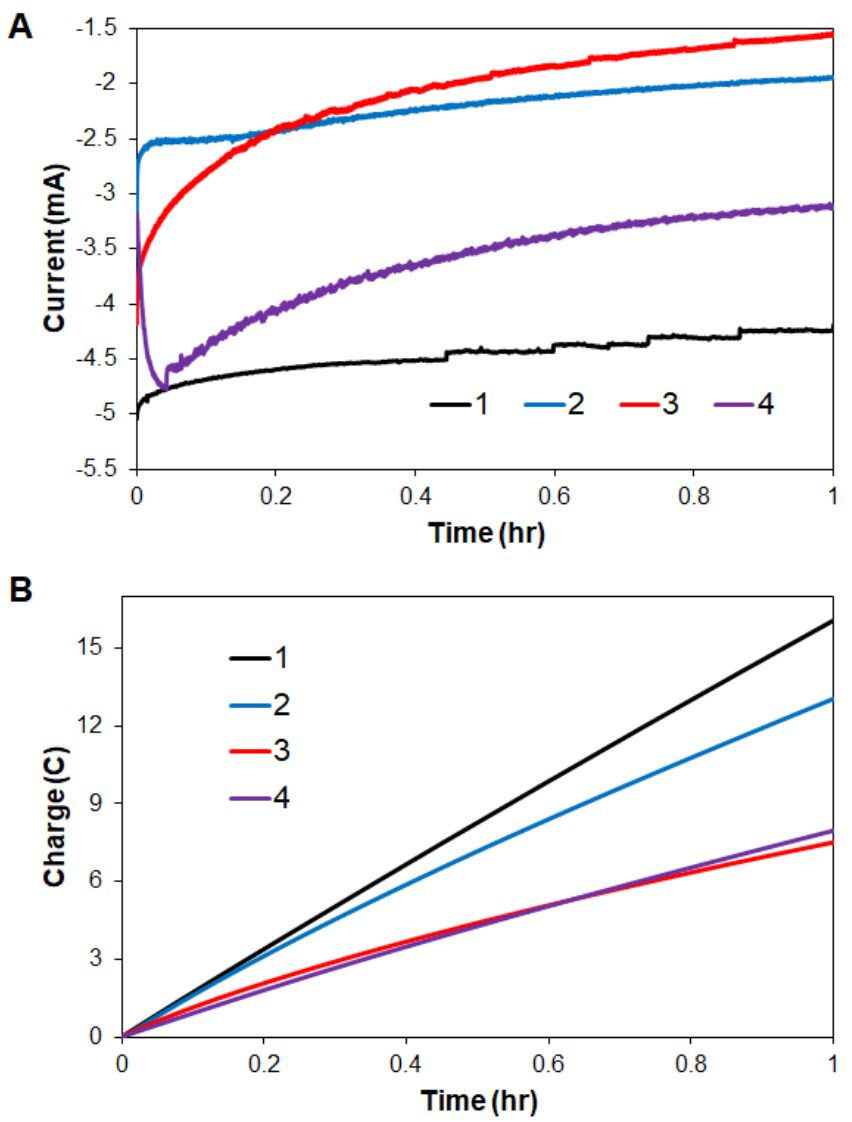

Figure S12. Overlay of the current (A) and charge (B) traces for the controlled potential electrolysis (CPE) experiments for complexes 1-4 measured at $-2.75 \mathrm{~V}$ vs. $\mathrm{Fc}^{+/ 0}$ over one hour. Electrochemical studies are performed in DMF solutions containing $0.1 \mathrm{M}\left[n \mathrm{Bu}_{4} \mathrm{~N}\right]\left[\mathrm{PF}_{6}\right]$ under an atmosphere of $\mathrm{CO}_{2}$ and in the presence of 2,2,2-trifluoroethanol $(1.3 \mathrm{M})$ and catalyst $(0.5 \mathrm{mM})$. 


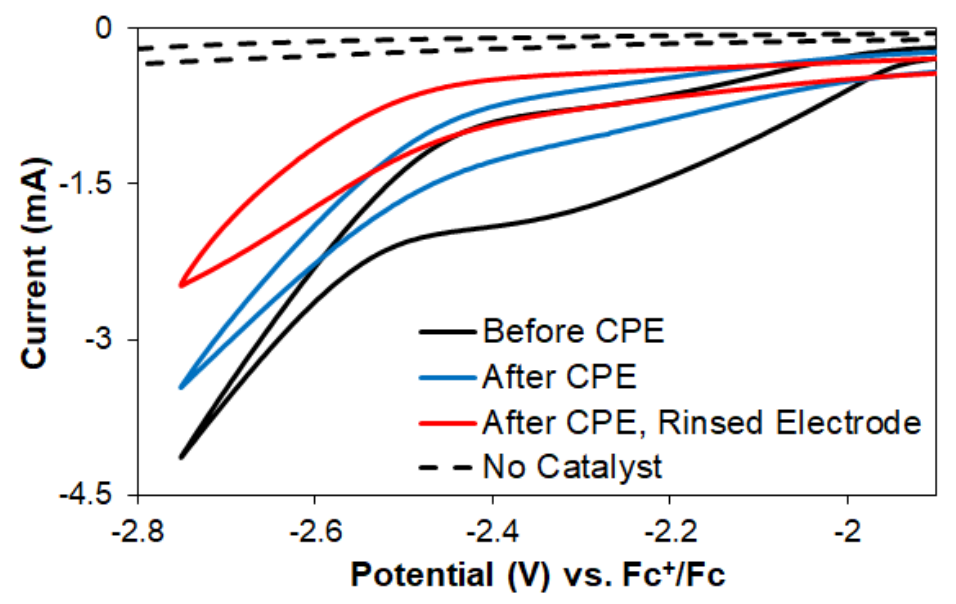

Figure S13. Cyclic voltammograms of complex $2(0.5 \mathrm{mM})$ in a DMF solution containing $\left[n \mathrm{Bu}_{4} \mathrm{~N}\right]\left[\mathrm{PF}_{6}\right](0.1 \mathrm{M}), 2,2,2$-trifluoroethanol $(1.3 \mathrm{M})$, and $\mathrm{CO}_{2}(1 \mathrm{~atm})$ before (black) and after (blue) controlled potential electrolysis (CPE). After the controlled potential electrolysis, the working electrode was rinsed $(3 \times 10 \mathrm{~mL}$ DMF $)$ and its electrochemistry was measured in a fresh DMF solution containing $\left[n \mathrm{Bu}_{4} \mathrm{~N}\right]\left[\mathrm{PF}_{6}\right](0.1 \mathrm{M}), 2,2,2$-trifluoroethanol $(1.3 \mathrm{M})$, and $\mathrm{CO}_{2}(1 \mathrm{~atm})$ - red trace. Scan rate $=100 \mathrm{mV} / \mathrm{s}$.

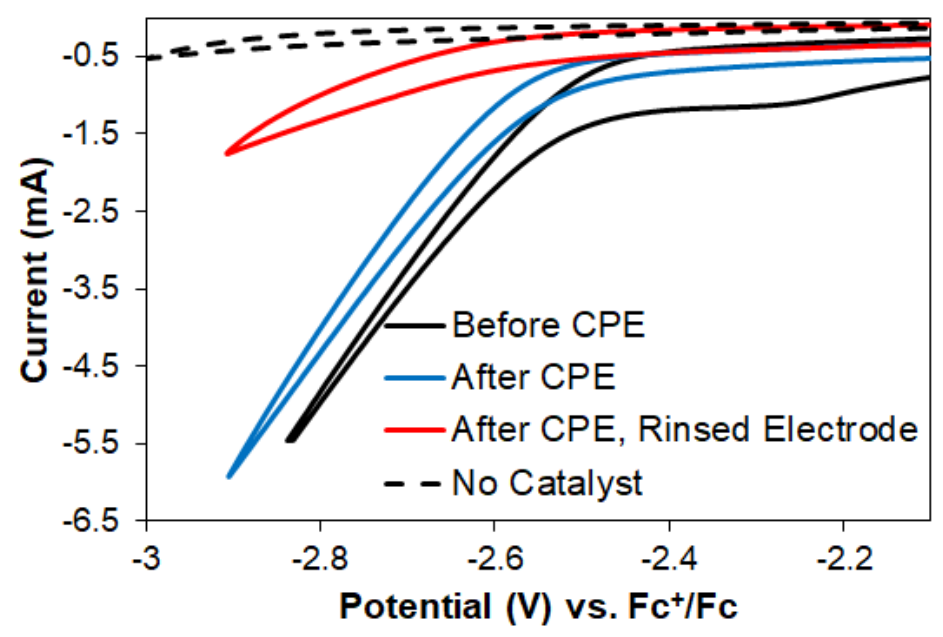

Figure S14. Cyclic voltammograms of complex $3(0.5 \mathrm{mM})$ in a DMF solution containing $\left[n \mathrm{Bu}_{4} \mathrm{~N}\right]\left[\mathrm{PF}_{6}\right](0.1 \mathrm{M}), 2,2,2$-trifluoroethanol $(1.3 \mathrm{M})$, and $\mathrm{CO}_{2}(1 \mathrm{~atm})$ before (black) and after (blue) controlled potential electrolysis (CPE). After the controlled potential electrolysis, the working electrode was rinsed $(3 \times 10 \mathrm{~mL}$ DMF $)$ and its electrochemistry was measured in a fresh DMF solution containing $\left[n \mathrm{Bu}_{4} \mathrm{~N}\right]\left[\mathrm{PF}_{6}\right](0.1 \mathrm{M}), 2,2,2$-trifluoroethanol $(1.3 \mathrm{M})$, and $\mathrm{CO}_{2}(1 \mathrm{~atm})$ - red trace. Scan rate $=100 \mathrm{mV} / \mathrm{s}$. 


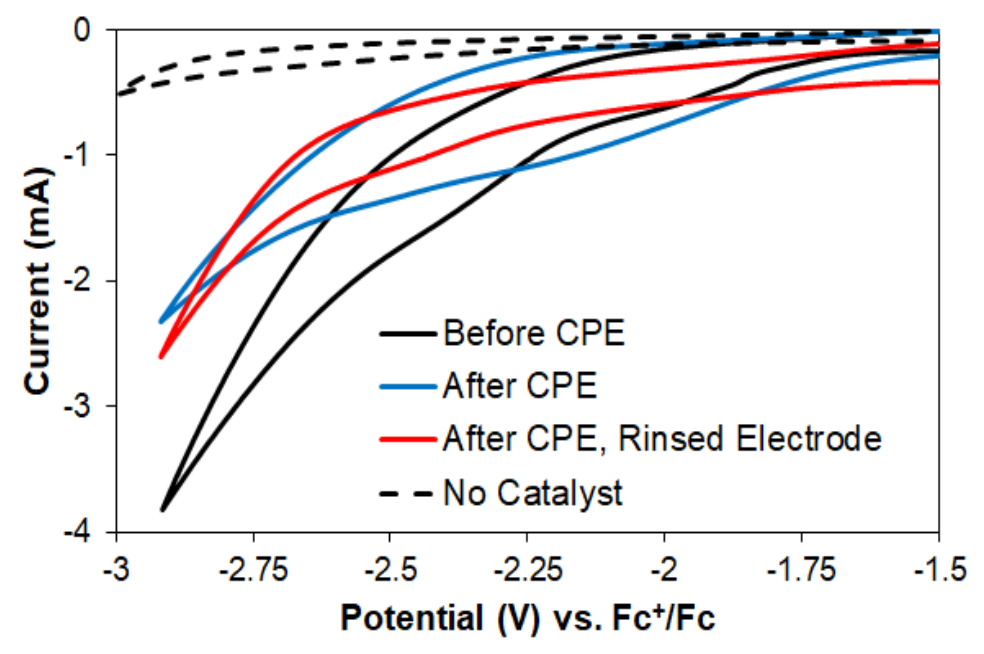

Figure S15. Cyclic voltammograms of complex $4(0.5 \mathrm{mM})$ in a DMF solution containing $\left[n \mathrm{Bu}_{4} \mathrm{~N}\right]\left[\mathrm{PF}_{6}\right](0.1 \mathrm{M}), 2,2,2$-trifluoroethanol $(1.3 \mathrm{M})$, and $\mathrm{CO}_{2}(1 \mathrm{~atm})$ before (black) and after (blue) controlled potential electrolysis (CPE). After the controlled potential electrolysis, the working electrode was rinsed $(3 \times 10 \mathrm{~mL}$ DMF $)$ and its electrochemistry was measured in a fresh DMF solution containing $\left[n \mathrm{Bu}_{4} \mathrm{~N}\right]\left[\mathrm{PF}_{6}\right](0.1 \mathrm{M}), 2,2,2$-trifluoroethanol $(1.3 \mathrm{M})$, and $\mathrm{CO}_{2}(1 \mathrm{~atm})$ - red trace. Scan rate $=100 \mathrm{mV} / \mathrm{s}$. 


\section{Hammett Analysis}
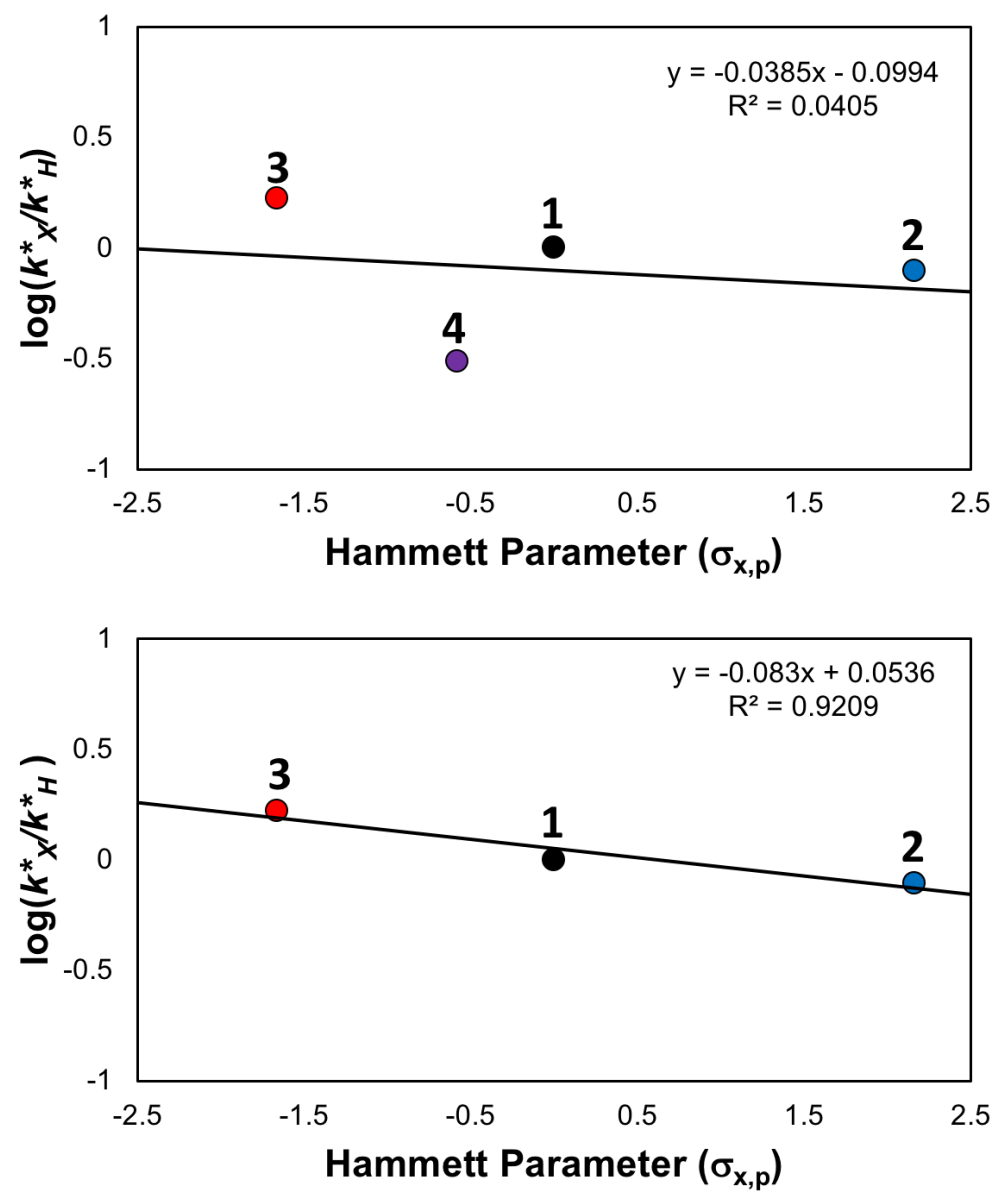

Figure S16. Hammett plot showing a linear free energy correlation between $\log$ of $k^{*} \mathrm{X} / k^{*}{ }_{\mathrm{H}}\left(k^{*}=\right.$ $\left.\left(i_{c a t} / i_{p}\right)^{2}\right)$ and macrocycle substitution. Catalytic currents were measured in the presence of $1.5 \mathrm{M}$ TFE under an atmosphere of $\mathrm{CO}_{2}$. A negative slope indicates that the rate-determining step involves a buildup of positive charge or a decrease in negative charge, consistent with a protonation. While a weak correlation is observed when including the entire series $\left(\mathrm{R}^{2}=0.0405\right)$, removing complex 4, which exhibits significant deposition, results in a strong correlation $\left(\mathrm{R}^{2}=\right.$ 0.9209 ) and a corresponding $\rho$ value of -0.083 . The Hammett parameters for each macrocycle were calculated by summing the individual Hammett constants for each pyridyl group (see page S3). 


\section{Density Functional Theory Calculation Details}

Density Functional Theory (DFT) calculations are performed using the Q-Chem 5.0 software package. ${ }^{10}$ The B3LYP functional is used for all calculations. ${ }^{11-14}$ Calculations are done using the relatively-fine Lebedev exchange correlation grid with 75 radial and 302 points. ${ }^{15}$ The $6-31+g^{*}$ basis set is used for all calculations. ${ }^{16}$ Diffuse functions are included to properly treat the strong anionic character of the bound $\mathrm{CO}_{2}$.

Dimethylformamide solvation energies are computed using the SMD implicit solvent model. ${ }^{17}$ Solvent calculations are done, as recommended, at the gas phase optimized geometries. The SM12 model is also tested and yields similar results, but the CM5 charge component of the model does not converge for all geometries.

Geometry optimizations are started from initial guesses corresponding to the structures of complex 1, and the resulting DFT minima do not deviate qualitatively from these initial guesses. All geometric minima are fully optimized to the default thresholds of the Q-Chem 5.0 software package. Protonation free energies are computed as described in a previous report of closely related cobalt macrocyclic derivatives. ${ }^{18}$

Schemes for ${ }^{\mathrm{CF} 3} \mathrm{~L},{ }^{\mathrm{NMe} 2} \mathrm{~L}$, and ${ }^{\mathrm{Mix}} \mathrm{L}$ Synthesis<smiles>C=CCN(c1cc(C(C)(F)F)cc(Cl)n1)c1cc(C(F)(F)F)cc(N(CC=C)c2cc(C(F)(F)F)cc(Cl)n2)n1</smiles><smiles>C=CCN(c1cc(C(F)(F)F)cc(C(F)(F)F)c1)c1cc(C(F)(F)F)cc(Nc2cc(C(F)(F)F)cc(Nc3cc(C(F)(F)F)cc(Nc4cc(C(F)(F)F)cc(Nc5cc(C(F)(F)F)cc(Nc6cc(C(F)(F)F)cc(N(CC=C)c7cc(C(F)(F)F)cc(C(C)(C)C)n7)n6)n5)n4)n3)n2)n1</smiles>

(D)

CF

Figure S17. Synthetic scheme for the preparation of ${ }^{\mathbf{C F} 3} \mathbf{L}$. (i) Allylamine, $\mathrm{CuBr}$, L-Proline, $\mathrm{K}_{2} \mathrm{CO}_{3}$, 10:1 DMSO: $\mathrm{H}_{2} \mathrm{O}, 135^{\circ} \mathrm{C}, 72 \mathrm{~h}, 50 \%$ yield; (ii) $\mathbf{A}, \mathrm{NaH}, \mathrm{THF}, 80{ }^{\circ} \mathrm{C}, 2 \mathrm{~h}, 80 \%$ yield; (iii) $\mathbf{B}, \mathbf{C}$, $\mathrm{Pd}_{2}(\mathrm{dba})_{3}$, dppf, $\mathrm{NaO} t \mathrm{Bu}$, toluene, $110^{\circ} \mathrm{C}, 1 \mathrm{~h}, 20 \%$ yield; (iv) $\mathrm{Pd}_{2}(\mathrm{dba})_{3}$, dppf, $\mathrm{KO} t \mathrm{Bu}$, toluene, $110{ }^{\circ} \mathrm{C}, 12 \mathrm{~h}, 70 \%$ yield, where $\mathrm{dba}=$ dibenzylacetone, and dppf $=1,1^{\prime}-$ Bis(diphenylphosphino)ferrocene. 
<smiles>C=CCNc1cc(N)cc(NCC=CC#CCCCCC)n1</smiles>

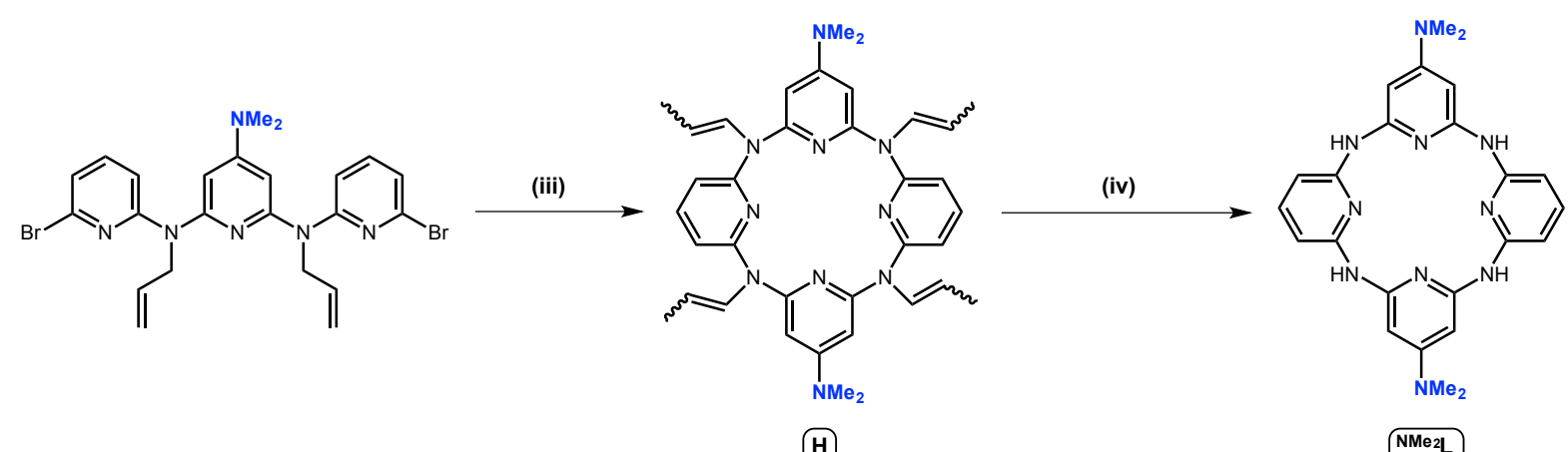

Figure S18. Synthetic scheme for the preparation of ${ }^{\mathbf{N M e} 2} \mathbf{L}$. (i) Allylamine, $\operatorname{Pd}_{2}(\mathrm{dba})_{3}$, dppp, $\mathrm{NaO} t \mathrm{Bu}$, toluene, $110^{\circ} \mathrm{C}, 12 \mathrm{~h}, 30 \%$ yield; (ii) $\mathrm{NaH}$, THF, $80{ }^{\circ} \mathrm{C}, 2,6$-Dibromopyridine, $2 \mathrm{~h}, 65 \%$ yield; (iii) F, G, $\mathrm{Pd}_{2}(\mathrm{dba})_{3}$, dppp, $\mathrm{NaO}^{t} \mathrm{Bu}$, toluene, $110{ }^{\circ} \mathrm{C}, 1 \mathrm{~h}$; (iv) $\mathrm{HCl}, 10: 1 \mathrm{DMSO}: \mathrm{H}_{2} \mathrm{O}, 60$ ${ }^{\circ} \mathrm{C}, 1 \mathrm{~h}, 35 \%$ yield, where $\mathrm{dba}=$ dibenzylacetone, and dppp =1,3-Bis(diphenylphosphino)propane.<smiles>C=CCNc1cc(N(C)C)cc(NCC=C)n1</smiles>

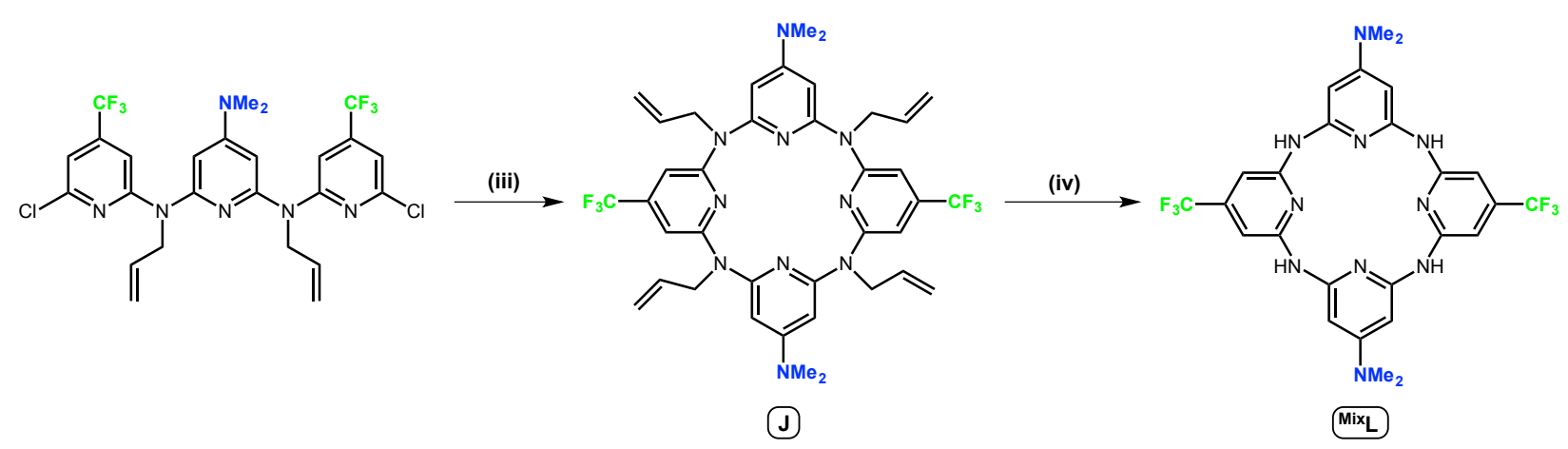

Figure S19. Synthetic scheme for the preparation of ${ }^{M i x} \mathbf{L}$. (i) Allylamine, $\operatorname{Pd}_{2}(\mathrm{dba})_{3}$, dppp, $\mathrm{NaO} t \mathrm{Bu}$, toluene, $110{ }^{\circ} \mathrm{C}, 12 \mathrm{~h}, 30 \%$ yield; (ii) $\mathbf{A}$, NaH, THF, $80{ }^{\circ} \mathrm{C}, 2 \mathrm{~h}, 70 \%$ yield; (iii), I, F, $\mathrm{Pd}_{2}(\mathrm{dba})_{3}, \mathrm{dppp}, \mathrm{NaO} t \mathrm{Bu}$, toluene, $110{ }^{\circ} \mathrm{C}, 1 \mathrm{~h}, 25 \%$ yield; (iv) $\mathrm{Pd}_{2}(\mathrm{dba})_{3}$, dppf, $\mathrm{KO} t \mathrm{Bu}$, toluene, $110{ }^{\circ} \mathrm{C}, \quad 12 \mathrm{~h}, \quad 85 \%$ yield, where $\mathrm{dba}=$ dibenzylacetone, $\mathrm{dppp}=1,3-$ Bis(diphenylphosphino)propane, and dppf = 1,1'-Bis(diphenylphosphino)ferrocene. 


\section{Synthetic Procedures}

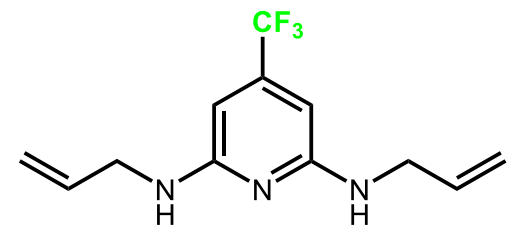

(B)

2,6-(bis)allylamino-4-(trifluromethyl)pyridine (B), 2,6-dichloro-4-(trifluromethyl)pyridine (5 g, $23.1 \mathrm{mmol}$ ), copper iodide (440.8 mg, $2.31 \mathrm{mmol})$, L-proline (532 mg, $4.62 \mathrm{mmol}$ ), and potassium carbonate $(9.60 \mathrm{~g}, 69.4 \mathrm{mmol})$ were added to a nitrogen filled thick walled bomb flask. Degassed DMSO (60 mL), water $(6 \mathrm{~mL})$, and allylamine $(17.36 \mathrm{~mL}, 231.0 \mathrm{mmol})$ were added to the above solids, and the flask was sealed under nitrogen and heated at $120^{\circ} \mathrm{C}$ for 3 days. Upon cooling to room temperature, the red solution was filtered through Celite, and extracted with ethyl acetate $(100 \mathrm{~mL})$ and water $(200 \mathrm{~mL})$. The organic layer was separated and the aqueous layer was extracted with ethyl acetate $(2 \times 100 \mathrm{~mL})$. The combined organic fractions were washed with water $(10 \times 100 \mathrm{~mL})$ and dried with $\mathrm{Na}_{2} \mathrm{SO}_{4}$. Removal of solvent afforded the crude product as a black oil. The oil was chromatographed on a silica gel column using a 3:1 mixture of dichloromethane:hexanes as the mobile phase. After the removal of solvent, a white solid was obtained (51\% yield). ${ }^{1} \mathrm{H}$ NMR $\left(500 \mathrm{MHz} \mathrm{CDCl}_{3}\right) \delta 5.93\left(\mathrm{~m}, 2 \mathrm{H}, H \mathrm{C}=\mathrm{CH}_{2}\right), 5.88(\mathrm{~s}, 2 \mathrm{H}, m-$ $\left.\mathrm{NC}_{5} \mathrm{H}_{2}\right), 5.27-5.16\left(\mathrm{dd}, 4 \mathrm{H}, \mathrm{HC}=\mathrm{CH}_{2}\right), 4.56(\mathrm{~s}, 2 \mathrm{H}, \mathrm{NH}), 3.7\left(\mathrm{~d}, 4 \mathrm{H}, \mathrm{H}_{2} \mathrm{C}-\mathrm{CH}\right) .{ }^{13} \mathrm{C}\left\{{ }^{1} \mathrm{H}\right\} \mathrm{NMR}$ $\left(126 \mathrm{MHz}, \mathrm{CDCl}_{3}\right) \delta 158.36,134.92,116.07,90.77,44.54 .{ }^{19} \mathrm{~F}\left\{{ }^{1} \mathrm{H}\right\} \mathrm{NMR}\left(470 \mathrm{MHz}, \mathrm{CDCl}_{3}\right) \delta-$ 65.46.<smiles>C=CCN(c1cc(C(F)(F)F)cc(C(F)(F)F)c1)c1cc(C(F)(F)F)cc(Cl)n1</smiles>

(c) 


\section{N2,N6-Bis(6-chloro-4-(trifluromethyl)pyridin-2-yl)-N2,N6-diallyl-4-}

(trifluromethyl)pyridine-2,6-diamine (C), $\mathrm{NaH}$ (60 wt\% in paraffin liquid, $0.988 \mathrm{~g}, 24.7 \mathrm{~mol}$ ) and 2,6-(bis)allylamino-4-(trifluromethyl)pyridine (1.06 g, $4.12 \mathrm{mmol}$ ) were added to a stir bar equipped, oven dried $100 \mathrm{~mL}$ 3-neck flask under nitrogen protection. THF (30 mL) was slowly added to generate an amber suspension. The mixture was then refluxed at $80{ }^{\circ} \mathrm{C}$ for one hour and then taken off the heat and allowed to cool. 2,6-dichloro-4-(trifluormethyl)pyridine (2.66 g, 12.3 mmol) was added to the mixture and the solution was brought back to reflux for 1.5 hours. The solution was allowed to cool to room temperature and slowly quenched with cold water. The solvent was removed under vacuum and the residue was dissolved in dichloromethane (50 $\mathrm{mL})$. The organic layer was washed with water $(3 \times 100 \mathrm{~mL})$, dried with $\mathrm{Na}_{2} \mathrm{SO}_{4}$ and concentrated under vacuum to give a brown oil. The oil was chromatographed on a silica gel column using a 2:1 mixture of dichloromethane:hexanes as the mobile phase. The product was the second to elute. After removal of solvent the product was isolated as an orange solid (81\% yield). ${ }^{1} \mathrm{H}$ NMR (500 $\left.\mathrm{MHz}_{2} \mathrm{CDCl}_{3}\right): \delta 7.32\left(\mathrm{~s}, 2 \mathrm{H}\right.$, central $\left.m-\mathrm{NC}_{5} \mathrm{H}_{2}\right), 7.13\left(\mathrm{~s}, 2 \mathrm{H}\right.$, outer $\left.m-\mathrm{NC}_{5} \mathrm{H}_{2}\right), 7.10(\mathrm{~s}, 2 \mathrm{H}$, outer m-NC $\left.\mathrm{H}_{2}\right), 5.92\left(\mathrm{~m}, 2 \mathrm{H} H \mathrm{C}=\mathrm{CH}_{2}\right), 5.17\left(\mathrm{dd}, 4 \mathrm{H}, \mathrm{HC}=\mathrm{CH}_{2}\right), 4.79\left(\mathrm{~m}, 4 \mathrm{H}, H_{2} \mathrm{C}-\mathrm{CH}\right) .{ }^{13} \mathrm{C}\left\{{ }^{1} \mathrm{H}\right\} \mathrm{NMR}$ $\left(126 \mathrm{MHz}, \mathrm{CDCl}_{3}\right): \delta 156.22,154.86,132.64,117.12,112.90,108.75,104.29,50.8 .{ }^{19} \mathrm{~F}\left\{{ }^{1} \mathrm{H}\right\} \mathrm{NMR}$ $\left(470 \mathrm{MHz}, \mathrm{CDCl}_{3}\right) \delta-65.02,-65.26$.

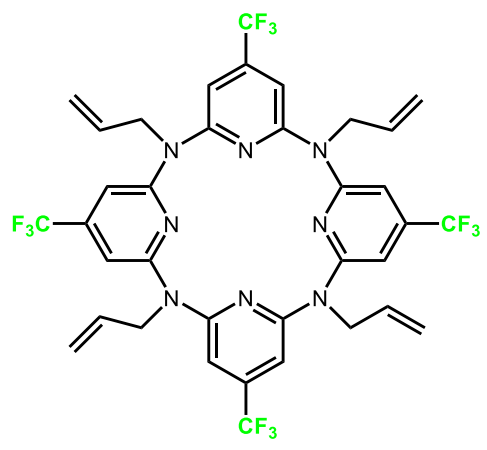

(D)

(NAllyl) $)_{4}$-BridgedCalix[4]-4-(trifluromethyl)pyridine $\left(\mathrm{Py}_{4}\left(\mathrm{CF}_{3}\right)_{4}(\mathrm{NAllyl})_{4}\right)(\mathrm{D}), \mathrm{Pd}_{2}(\mathrm{dba})_{3}(55$ $\mathrm{mg}, 0.06 \mathrm{mmol}), 1,1^{\prime}$-Bis(diphenylphosphino)ferrocene (62.1 mg $\left.0.11 \mathrm{mmol}\right)$, and sodium tertbutoxide (111 mg $1.15 \mathrm{mmol}$ ) were added to a stir bar equipped, oven dried $100 \mathrm{~mL} 3$-neck flask under nitrogen atmosphere. Dry toluene $(100 \mathrm{~mL})$ was syringed into the flask and the resultant red mixture was heated to $60^{\circ} \mathrm{C}$, when $\mathbf{B}(112.2 \mathrm{mg}, 0.43 \mathrm{mmol})$, and $\mathbf{C}(226.3 \mathrm{mg}, 0.37 \mathrm{mmol})$, were added to the suspension, causing a color change from red to orange. The reaction mixture was then 
further heated to $110^{\circ} \mathrm{C}$ and refluxed for 2.5 hours. After cooling to room temperature, the solution was filtered through Celite, reduced under pressure, and re-dissolved in dichloromethane $(50 \mathrm{~mL})$. The solution was washed with water $(5 \times 100 \mathrm{~mL})$ and the aqueous layer was re-extracted with dichloromethane $(2 \times 50 \mathrm{~mL})$. The combined organic layers were dried with $\mathrm{Na}_{2} \mathrm{SO}_{4}$ and eluted through a silica containing fritted glass funnel. The resultant organic fraction was reduced under pressure to give a yellow oil. The residue was chromatographed on a silica gel column using a 3:1 dichloromethane:hexane mobile phase. The desired product was the second compound to elute, and reduction of solvent under reduced pressure yielded a brown solid (20\% yield). ${ }^{1} \mathrm{H}$ NMR (500 $\left.\mathrm{MHz}, \mathrm{CDCl}_{3}\right): \delta 6.62\left(\mathrm{~s}, 8 \mathrm{H}, \mathrm{m}, 2 \mathrm{H}, m-\mathrm{NC}_{5} \mathrm{H}_{2}\right), 5.84\left(\mathrm{~m}, 4 \mathrm{H}, H \mathrm{C}=\mathrm{CH}_{2}\right), 5.26-5.16(\mathrm{dd}, 8 \mathrm{H}$, $\left.\mathrm{HC}=\mathrm{CH}_{2}\right), 4.38-4.20\left(\mathrm{dd}, 8 \mathrm{H}, \mathrm{H}_{2} \mathrm{C}-\mathrm{CH}\right) .{ }^{13} \mathrm{C}\left\{{ }^{1} \mathrm{H}\right\} \mathrm{NMR}\left(126 \mathrm{MHz}, \mathrm{CDCl}_{3}\right): \delta 158.3,133.05$, 116.92, 105.34, 52.51. ${ }^{19} \mathrm{~F}\left\{{ }^{1} \mathrm{H}\right\}$ NMR $\left(470 \mathrm{MHz}, \mathrm{CDCl}_{3}\right): \delta-64.88$.

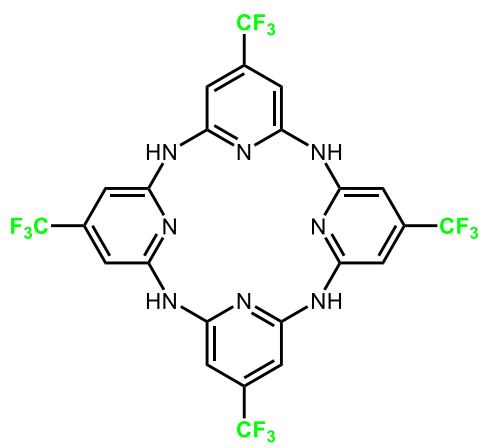

$\mathrm{CF}_{3} \mathrm{~L}$

(NH) 4 -BridgedCalix [4]-4-(trifluromethyl)pyridine $\left(\mathrm{Py}_{4}\left(\mathbf{C F}_{3}\right)_{4} \mathbf{N H}_{4}\right)\left({ }^{\mathrm{CF} 3} \mathbf{L}\right), \mathrm{Pd}_{2}(\mathrm{dba})_{3}(2 \mathrm{mg}$, $2.1 \mathrm{mmol}$ ), 1,1'-Bis(diphenylphosphino)ferrocene ( $24 \mathrm{mg} 4.3 \mathrm{mmol}$ ), and potassium tert-butoxide (37.4 mg, $0.33 \mathrm{mmol}$ ) were added to a stir bar equipped, oven dried $100 \mathrm{~mL}$ 3-neck flask under nitrogen atmosphere. Dry toluene $(30 \mathrm{~mL})$ was syringed into the flask and the resultant red mixture was heated. Upon reaching approximately $60{ }^{\circ} \mathrm{C}, \mathbf{D}(45.0 \mathrm{mg}, 0.056 \mathrm{mmol})$, was added to the suspension, causing a darkening in color. The reaction mixture was then heated to $110{ }^{\circ} \mathrm{C}$ and refluxed for 12 hours. After cooling to room temperature, the solvent was removed under reduced pressure and redissolved in dichloromethane $(20 \mathrm{~mL})$. The solution was washed with water $(3 \times$ $30 \mathrm{~mL}$ ). The organic layers were dried with $\mathrm{Na}_{2} \mathrm{SO}_{4}$ and eluted through a $2.5 \mathrm{~cm} \times 1 \mathrm{~cm}$ silica containing fritted glass funnel. The resultant organic fraction was reduced under pressure to give brown oil. The oil was dissolved in a 10:1 acetone:water mixture $(10 \mathrm{~mL})$ and excess concentrated hydrochloric acid was added. The resultant orange mixture was heated to reflux for an hour. The 
acetone was removed under reduced pressure and $\mathrm{Na}_{2} \mathrm{CO}_{3(\mathrm{aq})}$ was added until the solution reached a $\mathrm{pH}$ of 10 . The solution was filtered and the filtrate was washed with benzene. The filtrate was isolated and dried under vacuum to give $\mathbf{D}$ as an off-white solid (70\% yield). ${ }^{1} \mathrm{H} \mathrm{NMR} \mathrm{(500} \mathrm{MHz}$, acetone-d $\left.d_{6}\right): \delta 6.74\left(\mathrm{~s}, 8 \mathrm{H}, m-\mathrm{NC}_{5} \mathrm{H}_{2}\right), 8.64(\mathrm{~s}, 4 \mathrm{H}, \mathrm{N} H) .{ }^{13} \mathrm{C}\left\{{ }^{1} \mathrm{H}\right\} \mathrm{NMR}\left(126 \mathrm{MHz}, \mathrm{CDCl}_{3}\right): \delta$ $158.31,156.28,150.01,133.54,118.31,115.05,109.35,105.03,50.11 .{ }^{19} \mathrm{~F}\left\{{ }^{1} \mathrm{H}\right\} \mathrm{NMR}(470 \mathrm{MHz}$, $\left.\mathrm{CDCl}_{3}\right): \delta-65.74$.

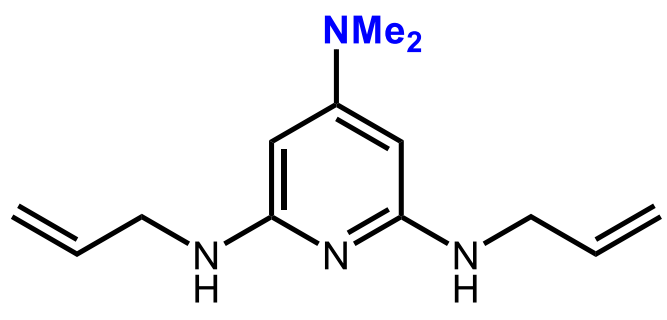

(F)

2,6-(bis)allylamino-4-(dimethylamine)pyridine (F), 2,6-dichloro-4-(dimethylamine)pyridine (E) $\quad(813.2 \quad \mathrm{mg}, \quad 4.28 \quad \mathrm{mmol}), \quad \mathrm{Pd}_{2}(\mathrm{dba})_{3} \quad(177 \quad \mathrm{mg}, \quad 0.19 \quad \mathrm{mmol}), \quad 1,1^{\prime}-$ Bis(diphenylphosphino)ferrocene (193.5 mg, $0.35 \mathrm{mmol})$, and sodium tert-butoxide (1.73 g, 18.0 mmol) were added to an oven dried, stir bar equipped, nitrogen filled thick walled bomb flask. Degassed toluene $(250 \mathrm{~mL})$ was added to the solution, along with allylamine $(17.36 \mathrm{~mL}, 23.1$ mmol). The flask was then sealed under nitrogen and heated at $110{ }^{\circ} \mathrm{C}$ overnight. NOTE: This molecule is air sensitive. Work up must be performed as rapidly as possible. Upon cooling to room temperature, the red solution was filtered through Celite, and the solvent was removed under reduced pressure. The obtained red residue was suspended in hexanes $(80 \mathrm{~mL})$ and sonicated for 25 minutes. The solution was filtered to remove the insoluble impurities. The solids were further washed with hexanes $(2 \times 80 \mathrm{~mL})$ and filtered again. The hexane fractions were combined. Removal of the solvent gave rise to the product as an orange oil. The oil was immediately brought into an inert atmosphere glove box, extracted into pentane $(25 \mathrm{~mL})$ and mixed with crushed activated molecular sieves ( $\sim 10$ sieve spheres). The solution was stirred for 35 minutes before being filtered. The solvent was removed under reduced pressure to give the product as an amber oil in 30\% yield. NOTE: The oil MUST be stored under inert atmosphere. ${ }^{1} \mathrm{H} \mathrm{NMR}(500 \mathrm{MHz}$, $\left.\mathrm{CDCl}_{3}\right): \delta 5.93\left(\mathrm{~m}, 2 \mathrm{H}, H \mathrm{C}=\mathrm{CH}_{2}\right), 5.27-5.16\left(\mathrm{dd}, 4 \mathrm{H}, \mathrm{HC}=\mathrm{CH}_{2}\right), 5.12\left(\mathrm{~s}, 2 \mathrm{H}, m-\mathrm{NC}_{5} \mathrm{H}_{2}\right), 3.83(\mathrm{~m}$, 
4H, $\left.\mathrm{H}_{2} \mathrm{C}-\mathrm{CH}\right), 2.92\left(\mathrm{~s}, 6 \mathrm{H}, \mathrm{N}\left(\mathrm{CH}_{3}\right)_{2}\right){ }^{13} \mathrm{C}\left\{{ }^{1} \mathrm{H}\right\} \mathrm{NMR}\left(126 \mathrm{MHz}, \mathrm{CDCl}_{3}\right): \delta 158.97,158.15,135.95$, $115.53,7.48,45.24,39.48$.<smiles>C=CCN(c1ccccc1)c1cc(N(C)C)cc(N(CC=C)c2cccc(Br)n2)n1</smiles>

N2,N6-diallyl-N2,N6-bis(6-bro-4-(pyridin-2-yl)-N4,N4-dimethylpyridine-2,4,6-triamine (G), $\mathrm{NaH}(60 \mathrm{wt} \%$ in paraffin liquid, $600 \mathrm{mg}, 15.0 \mathrm{mmol})$ and $\mathbf{E}(600 \mathrm{mg}, 3.14 \mathrm{mmol})$ were added to a stir bar equipped, oven dried $100 \mathrm{~mL}$ 3-neck flask under nitrogen atmosphere. THF (30 mL) was slowly added to generate an amber suspension. The mixture was then refluxed at $80{ }^{\circ} \mathrm{C}$ for one hour and was then taken off heat and allowed to cool. 2,6-dibromopyridine (1.83 g, $7.73 \mathrm{mmol})$ was added to the mixture and the solution was brought back to reflux for 1 hour. The solution was cooled to room temperature and slowly quenched with cold water. The solvent was removed under vacuum and the residue was dissolved in dichloromethane $(50 \mathrm{~mL})$. The organic layer was washed with water $(3 \times 100 \mathrm{~mL})$, dried with $\mathrm{Na}_{2} \mathrm{SO}_{4}$ and concentrated under vacuum to give a brown oil. The oil was chromotographed on a silica gel column with a 2:1 mixture of hexanes: dichloromethane as the mobile phase and then washed with diethyl ether to isolate the product as a yellow oil (73\% yield). ${ }^{1} \mathrm{H}$ NMR $\left(500 \mathrm{MHz}, \mathrm{CDCl}_{3}\right) \delta 7.25$ (t, 2H, p-pyridine), 7.03 (d, 2H, $m$ pyridine bromine adjacent), 6.89 (d, 2H, m-pyridine nitrogen adjacent), 6.30 (s, $\mathrm{NMe}_{2}$-pyridine), $5.99\left(\mathrm{~m}, 2 \mathrm{H}, \mathrm{HC}=\mathrm{CH}_{2}\right), 5.22-5.12\left(\mathrm{dd}, 4 \mathrm{H}, \mathrm{HC}=\mathrm{CH}_{2}\right), 4.72\left(\mathrm{~s}, 4 \mathrm{H}, \mathrm{H}_{2} \mathrm{C}-\mathrm{CH}\right) .{ }^{13} \mathrm{C}\left\{{ }^{1} \mathrm{H}\right\} \mathrm{NMR}(126$ $\left.\mathrm{MHz}_{\mathrm{CDCl}}\right): \delta 157.52,157.20,155.81,139.35,138.58,134.80,118.39,116.17,111.35,95.04$, $50.76,39.56$. 


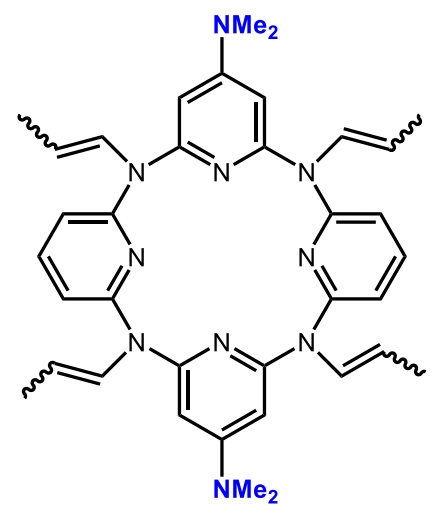

(H)

\section{$\mathrm{N}_{4}{ }_{4}, \mathrm{~N}_{4}{ }_{4}, \mathrm{~N}^{5}{ }_{4}, \mathrm{~N}^{5}$-tetramethyl-2,4,6,8-tetra(prop-1-en-1-yl)-2,4,6,8-tetraaza-1,3,5(2,6)-}

tripyridina-7(1,3)-benzenacyclooctaphane-14,54-diamine (H). $\mathrm{Pd}_{2}(\mathrm{dba})_{3}(35 \mathrm{mg}, 0.038 \mathrm{mmol})$, 1,3-Bis(diphenylphosphino)propane $(31.7 \mathrm{mg}, 0.08 \mathrm{mmol})$, and sodium tert-butoxide (80 $\mathrm{mg}, 0.83$ mmol) were added to a stir bar equipped, oven dried $250 \mathrm{~mL}$ 3-neck flask under nitrogen atmosphere. Dry toluene $(70 \mathrm{~mL})$ was syringed into the flask and the resultant red mixture was heated to $60{ }^{\circ} \mathrm{C}$, when $\mathbf{G}(151.0 \mathrm{mg}, 0.27 \mathrm{mmol})$ and $\mathbf{F}(59.4 \mathrm{mg}, 0.26 \mathrm{mmol})$ were added to the suspension, causing a darkening in color. The reaction mixture was then further heated to $110^{\circ} \mathrm{C}$ and refluxed for twelve hours. After cooling to room temperature, the solvent was removed under reduced pressure and redissolved in diethyl ether. The red solution was filtered through Celite and was used without further purification. Diagnostic proton NMR peaks can be found at 5.85 (singlet) and 6.45 (doublet).

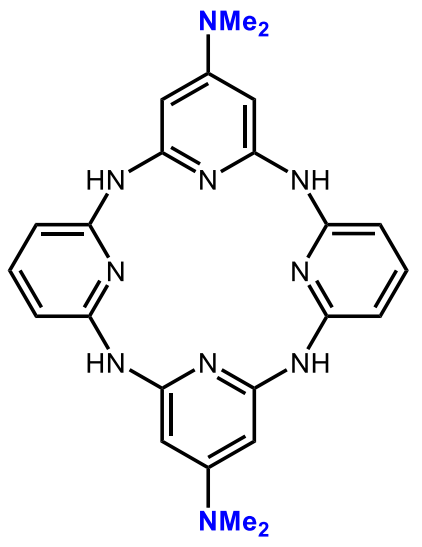

$\mathrm{NMe}_{2} \mathrm{~L}$ 
(NH) $)_{4}$-BridgedCalix[4]-pyridine-(Py(NMe $\left.)_{2}\left(\mathbf{P y}_{2}\right) \quad{ }_{\left({ }^{\mathrm{NMe}} 2\right.} \mathbf{L}\right) . \quad \mathbf{H}$ was dissolved in a 10:1 acetone:water $(11 \mathrm{~mL})$ mixture and concentrated $\mathrm{HCl}$ was added $(5 \mathrm{~mL})$. The solution was refluxed for one hour, after which the volatiles were removed under reduced pressure. $\mathrm{Na}_{2} \mathrm{CO}_{3(\mathrm{aq})}$ was added until the solution reached a $\mathrm{pH}$ of 10 . The solution was filtered and the filtrate was washed with water, dichloromethane, and diethyl ether. The filtrate was isolated and dried under vacuum to give ${ }^{\mathrm{NMe} 2} \mathbf{L}$ as an off-white solid (20\% yield). ${ }^{1} \mathrm{H}$ NMR (500 MHz, $\left.\mathrm{CD}_{3} \mathrm{OD}\right) \delta 7.49$ (t, $2 \mathrm{H}, p$-Py), 6.47 (d, 4H, m-Py), 5.94 (s, 2H, NMe $-\mathrm{Py}$ ), 2.99 (s, 12H, NMe $).{ }^{13} \mathrm{C}\left\{{ }^{1} \mathrm{H}\right\} \mathrm{NMR}(126 \mathrm{MHz}$, $\left.\mathrm{CDCl}_{3}\right): \delta 140.88,133.45,131.83,129.99,107.26,91.93,59.54$.

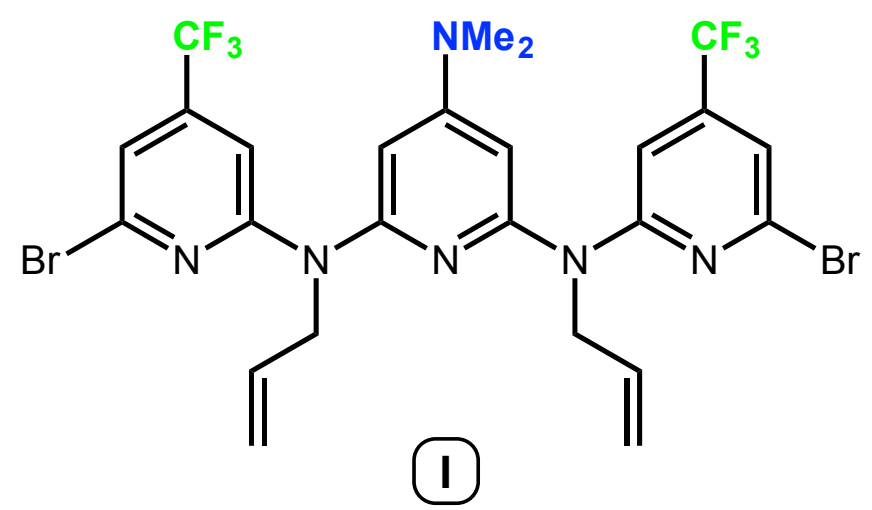

\section{N2,N6-diallyl-N2,N6-bis(6-chloro-4-(trifluoromethyl)pyridin-2-yl)-N4,N4-}

dimethylpyridine-2,4,6-triamine (I), $\mathrm{NaH}(60 \mathrm{wt} \%$ in paraffin oil, $700 \mathrm{mg}, 18.0 \mathrm{mmol}$ ) and $\mathbf{E}$ (700 mg, $3.00 \mathrm{mmol}$ ) were added to a stir bar equipped, oven dried $100 \mathrm{~mL}$ 3-neck flask under nitrogen atmosphere. THF $(30 \mathrm{~mL})$ was slowly added to generate an amber suspension. The mixture was then refluxed at $80{ }^{\circ} \mathrm{C}$ for one hour and was then taken off heat and allowed to cool. 2,6-dichloro-4-(trifluormethyl)pyridine (2.25 g, $10.4 \mathrm{mmol})$ was added to the mixture and the solution was brought back to reflux for 1 hour. The solution was cooled to room temperature and slowly quenched with cold water. The solvent was removed under vacuum and the residue was dissolved in dichloromethane $(50 \mathrm{~mL})$. The organic layer was washed with water $(3 \times 100 \mathrm{~mL})$, dried with $\mathrm{Na}_{2} \mathrm{SO}_{4}$ and concentrated under vacuum to give a brown oil. The oil was chromotographed on a silica gel column with a 2:1 mixture of hexanes:ether as the mobile phase. The product was the first to elute. After removal of solvent the product is isolated as a yellow solid (65\% yield). ${ }^{1} \mathrm{H} \mathrm{NMR}\left(500 \mathrm{MHz}, \mathrm{CDCl}_{3}\right.$ ): $\delta 7.14$ (s, $2 \mathrm{H}, m-\mathrm{CF}_{3}-\mathrm{Py}$ ), 6.89 (s, $2 \mathrm{H}, m-\mathrm{CF}_{3}-\mathrm{Py}$ ), 6.32 (s, $2 \mathrm{H}$, outer $\left.m-\mathrm{NC}_{5} \mathrm{H}_{2}\right), 5.92\left(\mathrm{~m}, 2 \mathrm{H} H \mathrm{C}=\mathrm{CH}_{2}\right), 5.17\left(\mathrm{dd}, 4 \mathrm{H}, \mathrm{HC}=\mathrm{CH}_{2}\right), 4.72\left(\mathrm{~m}, 4 \mathrm{H}, \mathrm{H}_{2} \mathrm{C}-\mathrm{CH}\right)$. 
${ }^{13} \mathrm{C}\left\{{ }^{1} \mathrm{H}\right\}$ NMR (126 MHz, $\left.\mathrm{CDCl}_{3}\right): \delta 157.83,157.25,150.10,133.77,116.72,109.74,106.42,96.8$, 51.07, 39.54. ${ }^{19} \mathrm{~F}\left\{{ }^{1} \mathrm{H}\right\}$ NMR $\left(470 \mathrm{MHz}, \mathrm{CDCl}_{3}\right) \delta-64.9$.

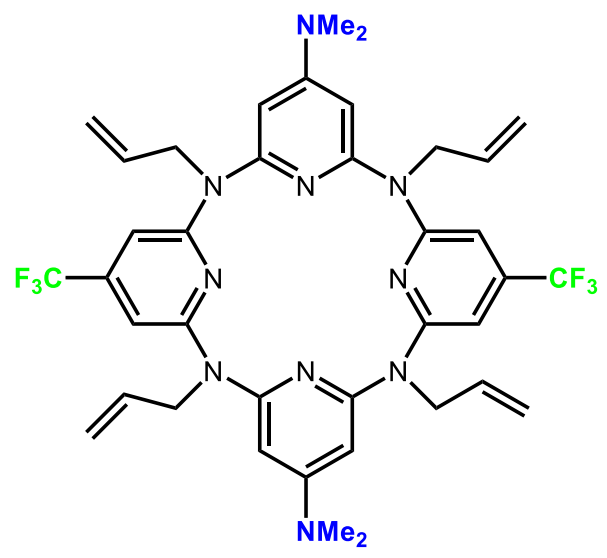

(J)

2,4,6,8-tetraallyl- $\mathrm{N}_{4}{ }_{4}, \mathrm{~N}^{1}{ }_{4}, \mathrm{~N}^{5}{ }_{4}, \mathrm{~N}^{5}{ }_{4}$-tetramethyl-34,75-bis(trifluoromethyl)-2,4,6,8-tetraaza1,3,5(2,6)-tripyridina-7(1,3)-benzenacyclooctaphane-14,54-diamine (J) $\mathrm{Pd}_{2}(\mathrm{dba})_{3}(137.8 \mathrm{mg}$, $0.15 \mathrm{mmol}$ ), 1,3-Bis(diphenylphosphino)propane (124 mg, $0.30 \mathrm{mmol}$ ), and sodium tert-butoxide (300 mg, $3.12 \mathrm{mmol}$ ) were added to a stir bar equipped, oven dried $500 \mathrm{~mL}$ 3-neck flask under nitrogen protection. Dry toluene $(250 \mathrm{~mL})$ was syringed into the flask and the resultant red mixture was heated to $60{ }^{\circ} \mathrm{C}$, when $\mathbf{E}(591.2 \mathrm{mg}, 3.09 \mathrm{mmol})$ and $\mathbf{F}(232 \mathrm{mg}, 1.00 \mathrm{mmol})$ were added to the suspension, causing a darkening in color. The reaction mixture was further heated to $110{ }^{\circ} \mathrm{C}$ and refluxed for one hour. After cooling to room temperature, the solvent was removed under reduced pressure and redissolved in dichloromethane $(20 \mathrm{~mL})$. The solution was washed with water $(3 \times 30 \mathrm{~mL})$. The organic layers were dried with $\mathrm{Na}_{2} \mathrm{SO}_{4}$ and eluted through a 2:1 hexane:ether column (last spot to elute collected) followed by a 1:1:1 hexane:ether:dichloromethane column (first sport collected) to give $\mathbf{G}$ as an off-white solid (30\% yield). Note: this was not fully purified as evident from the NMR spectra. We believe that the impurities are various isomers in which the allyl bond is isomerized. These impurities do not inhibit subsequent synthetic steps. ${ }^{1} \mathrm{H}$ NMR $\left(500 \mathrm{MHz}, \mathrm{CDCl}_{3}\right) \delta 6.15\left(\mathrm{~s}, 4 \mathrm{H}, m-\mathrm{CF}_{3}-\mathrm{Py}\right), 6.04$ (s, 4H, $m$-NMe $-\mathrm{Py}), 5.91\left(\mathrm{~m}, 4 \mathrm{H}, H \mathrm{C}=\mathrm{CH}_{2}\right), 5.33-5.14\left(\mathrm{dd}, 8 \mathrm{H}, \mathrm{HC}=\mathrm{CH}_{2}\right), 4.38-4.12(\mathrm{dd}, 8 \mathrm{H}$, $\left.\mathrm{H}_{2} \mathrm{C}-\mathrm{CH}\right), 2.89$ (s, $\left.12 \mathrm{H}, \mathrm{N}\left(\mathrm{CH}_{3}\right)_{2}\right) .{ }^{13} \mathrm{C}\left\{{ }^{1} \mathrm{H}\right\}$ NMR $\left(126 \mathrm{MHz}, \mathrm{CDCl}_{3}\right)$ 8158.42, 134.38, 115.89, 104.87, 91.78, 52.54. ${ }^{19} \mathrm{~F}\left\{{ }^{1} \mathrm{H}\right\} \mathrm{NMR}\left(470 \mathrm{MHz}, \mathrm{CDCl}_{3}\right) \delta-68.92\left(\mathrm{~s}, 6 \mathrm{~F}, \mathrm{CF}_{3}\right)$. 


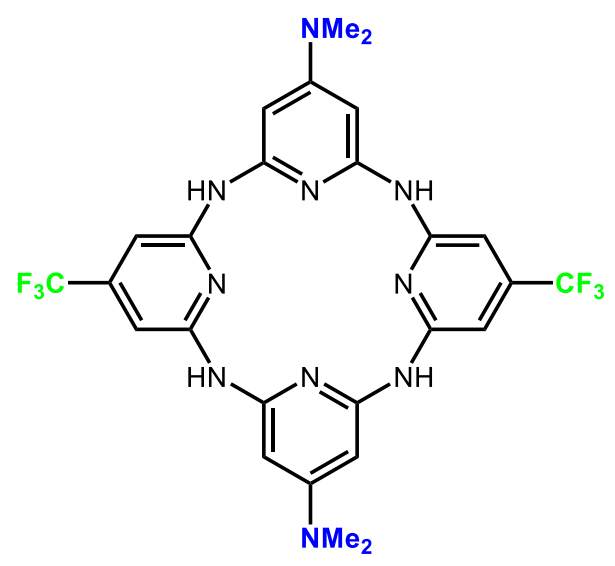

Mix L

(NH) $)_{4}$-BridgedCalix[4]-pyridine $\left.\left(\mathbf{P y}_{4}\left(\mathbf{N M e}_{2}\right)_{2}\left(\mathbf{C F}_{3}\right)_{2} \mathbf{N H}_{4}\right) \quad{ }^{{ }^{\mathrm{Mix}} \mathbf{L}}\right), \mathrm{Pd}_{2}(\mathrm{dba})_{3}(7.0 \mathrm{mg}, 0.008$ $\mathrm{mmol}), 1,1$ '-Bis(diphenylphosphino)ferrocene $(5.5 \mathrm{mg} 0.010 \mathrm{mmol})$, and potassium tert-butoxide (55 mg $0.49 \mathrm{mmol}$ ) were added to a stir bar equipped, oven dried $100 \mathrm{~mL}$ 3-neck flask under nitrogen atmosphere. Dry toluene $(100 \mathrm{~mL})$ was syringed into the flask and the resultant red mixture was heated. Upon reaching approximately $60^{\circ} \mathrm{C}, \mathbf{C}(56.9 \mathrm{mg}, 0.074 \mathrm{mmol})$, was added to the suspension, causing a darkening in color. The reaction mixture was heated to $110{ }^{\circ} \mathrm{C}$ and refluxed for one hour. After cooling to room temperature, the solvent was removed under reduced pressure and redissolved in diethyl ether $(20 \mathrm{~mL})$. The solution was washed with water $(3 \times 30$ $\mathrm{mL}$ ). The organic layers were dried with $\mathrm{Na}_{2} \mathrm{SO}_{4}$ and filtered through a $2.5 \mathrm{~cm} \times 1 \mathrm{~cm}$ silica containing fritted glass funnel. The resultant organic fraction was reduced under pressure to give brown oil. The oil was dissolved in a 10:1 acetone:water mixture $(10 \mathrm{~mL})$ and excess concentrated hydrochloric acid was added. The resultant orange mixture was heated to reflux for an hour. The acetone was removed under reduced pressure and $\mathrm{Na}_{2} \mathrm{CO}_{3(\mathrm{aq})}$ was added until the solution reached a $\mathrm{pH}$ of 10. The solution was filtered and the filtrate was washed with benzene. The filtrate was isolated and dried under vacuum to give $\mathbf{D}$ as an off-white solid ( $85 \%$ yield). ${ }^{1} \mathrm{H}$ NMR (500 MHz, acetone- $\left.d_{6}\right): \delta 7.94(\mathrm{~s}, 4 \mathrm{H}, \mathrm{N} H), 6.42$ (s, 4H, $\left.m-\mathrm{CF}_{3}-\mathrm{Py}\right), 6.00$ (s, 4H, $\left.m-\mathrm{NMe}_{2}-\mathrm{Py}\right), 2.93$ (s, 12H, $\left.\mathrm{N}\left(\mathrm{CH}_{3}\right)_{2}\right) .{ }^{13} \mathrm{C}\left\{{ }^{1} \mathrm{H}\right\} \mathrm{NMR}\left(126 \mathrm{MHz}, \mathrm{CDCl}_{3}\right): \delta 13.50,129.46,129.39,88.20,77.18,64.04,24.85$. ${ }^{19} \mathrm{~F}\left\{{ }^{1} \mathrm{H}\right\}$ NMR $\left(470 \mathrm{MHz}, \mathrm{CDCl}_{3}\right) \delta-65.75$. 
NMR Spectra

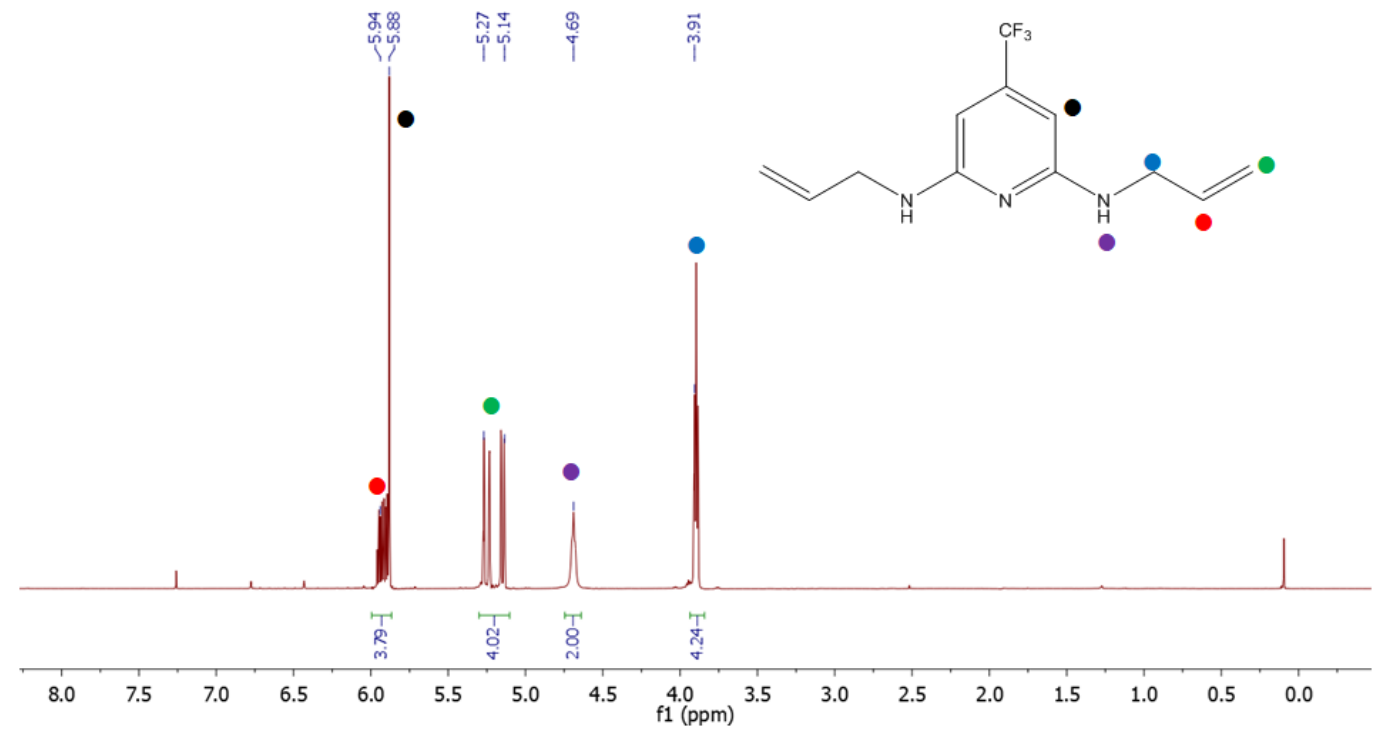

Figure S20. $500 \mathrm{MHz}{ }^{1} \mathrm{H}$ NMR spectrum of $\mathbf{B}$ in $\mathrm{CDCl}_{3}$.

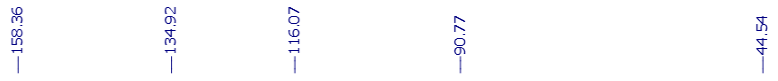

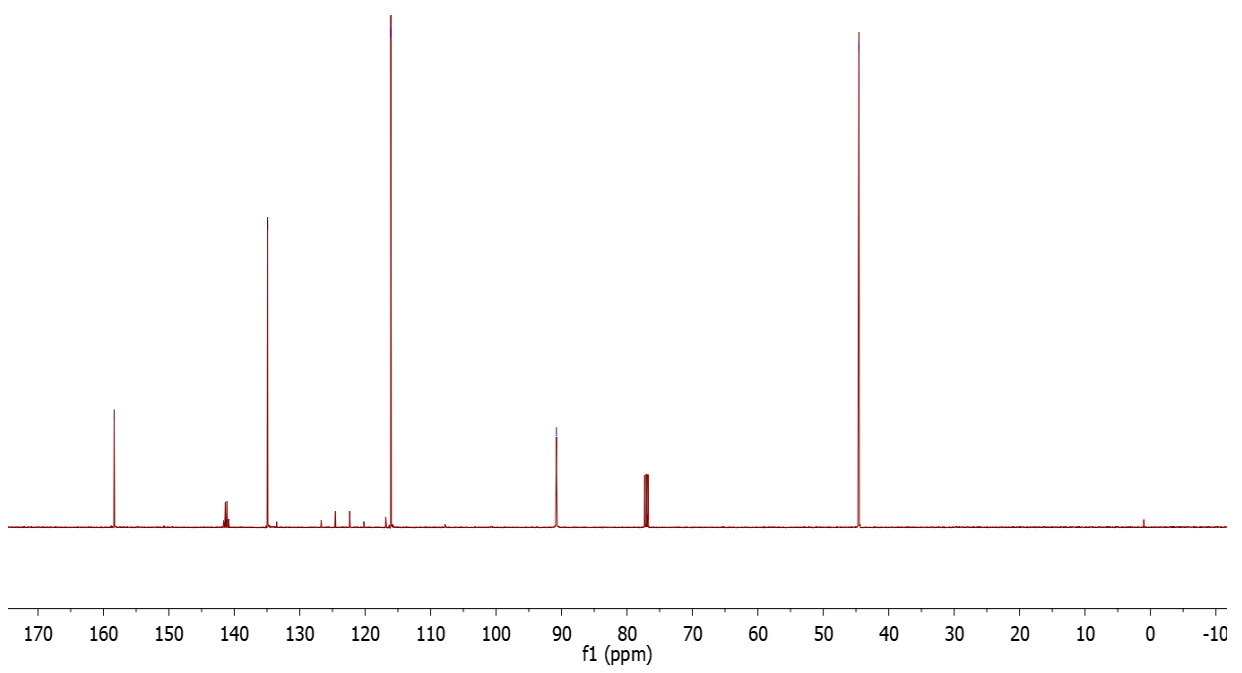

Figure S21. $126 \mathrm{MHz}{ }^{13} \mathrm{C}\left\{{ }^{1} \mathrm{H}\right\} \mathrm{NMR}$ spectrum of $\mathbf{B}$ in $\mathrm{CDCl}_{3}$. 


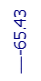

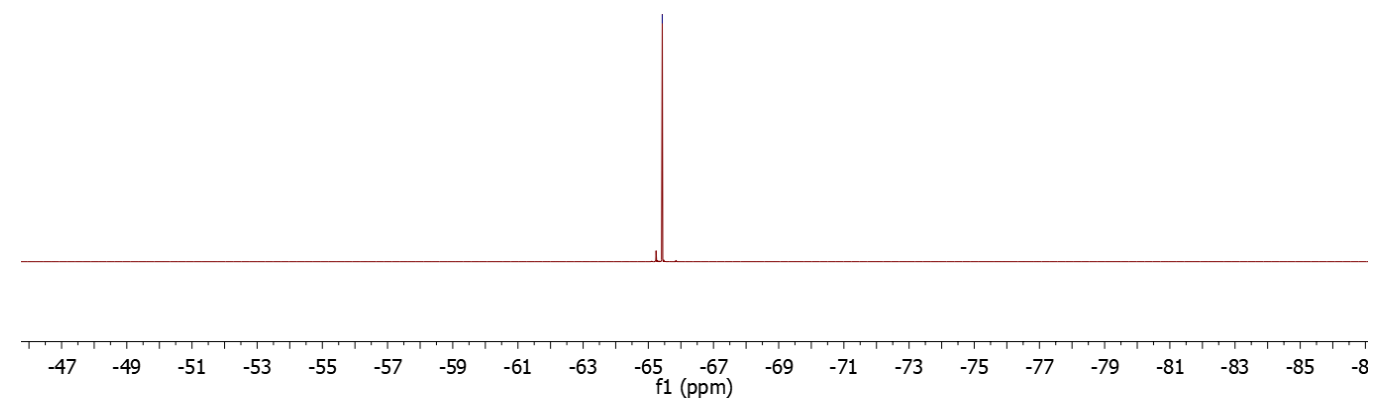

Figure S22. $470 \mathrm{MHz}{ }^{19} \mathrm{~F}\left\{{ }^{1} \mathrm{H}\right\} \mathrm{NMR}$ spectrum of $\mathbf{B}$ in $\mathrm{CDCl}_{3}$.

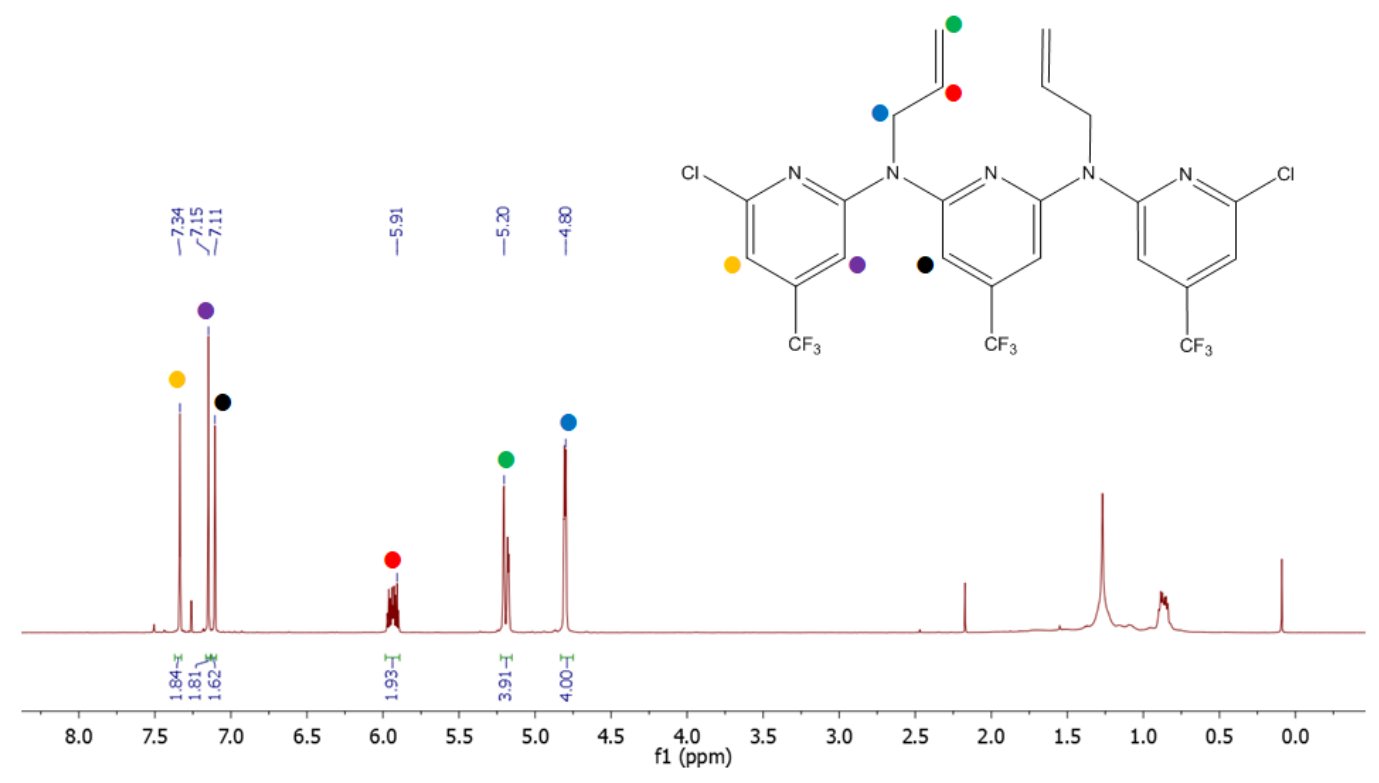

Figure S23. $500 \mathrm{MHz}{ }^{1} \mathrm{H} \mathrm{NMR}$ spectrum of $\mathbf{C}$ in $\mathrm{CDCl}_{3}$. 


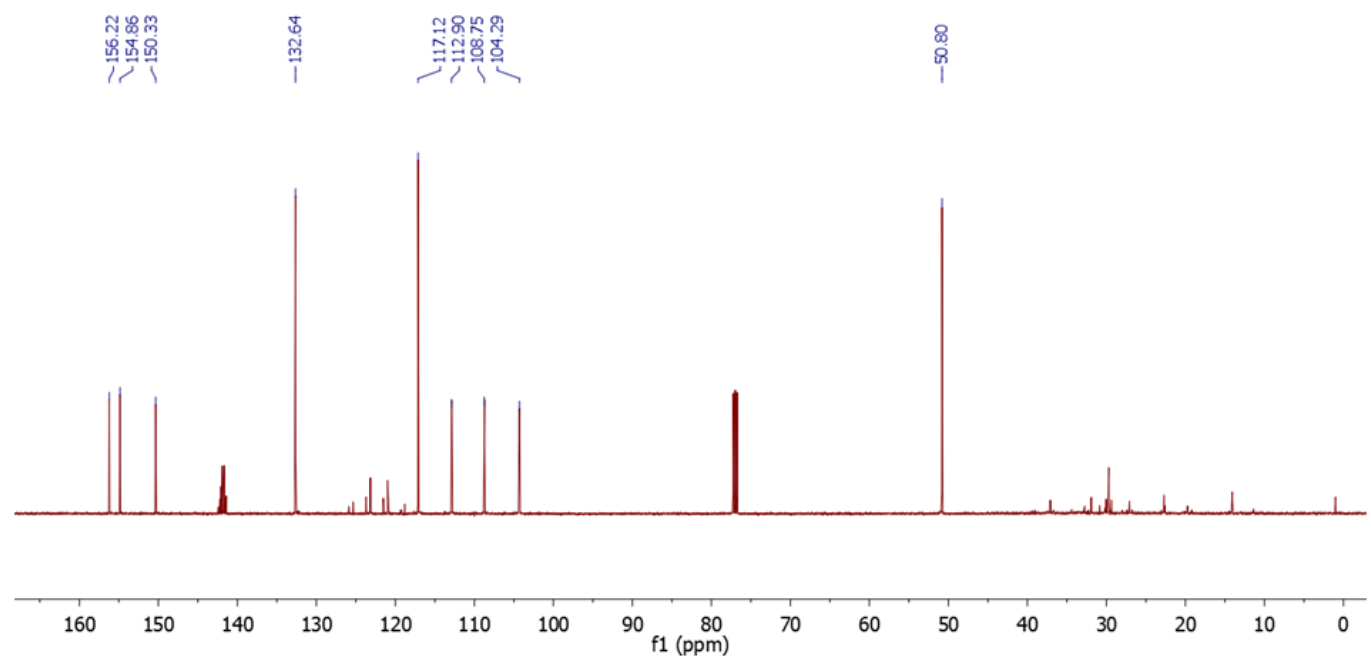

Figure S24. $126 \mathrm{MHz}{ }^{13} \mathrm{C}\left\{{ }^{1} \mathrm{H}\right\} \mathrm{NMR}$ spectrum of $\mathbf{C}$ in $\mathrm{CDCl}_{3}$.<smiles>C=CCN(c1cc([18O])cc(Cl)c1)c1cc([18O])cc(Cl)n1</smiles>
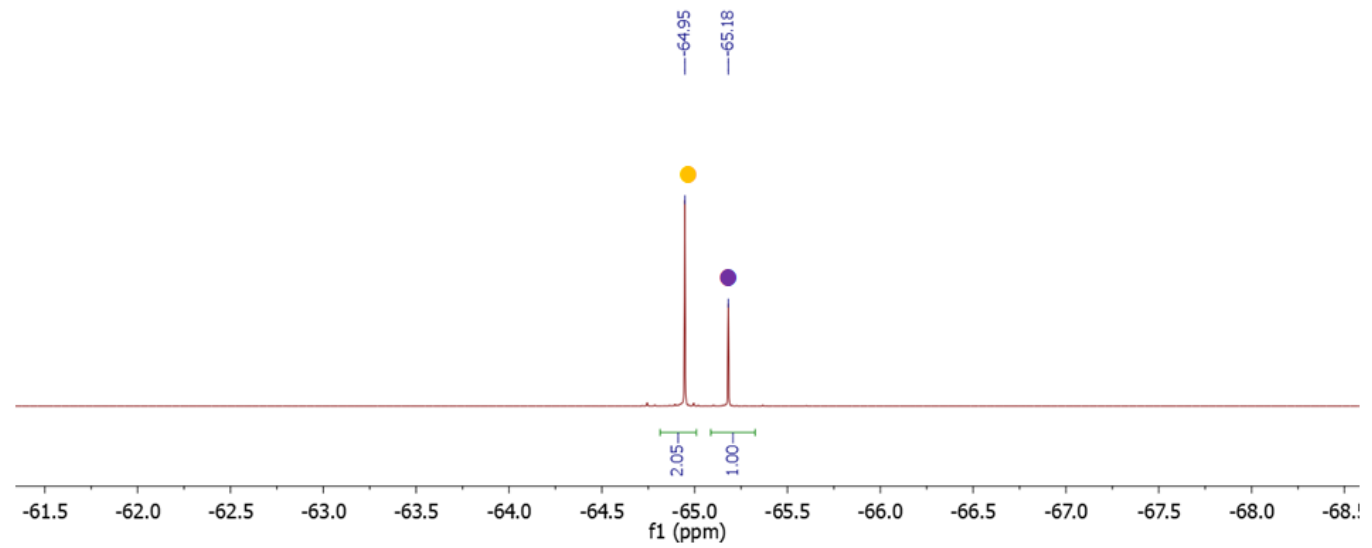

Figure S25. $470 \mathrm{MHz}{ }^{19} \mathrm{~F}\left\{{ }^{1} \mathrm{H}\right\} \mathrm{NMR}$ spectrum of $\mathbf{C}$ in $\mathrm{CDCl}_{3}$. 


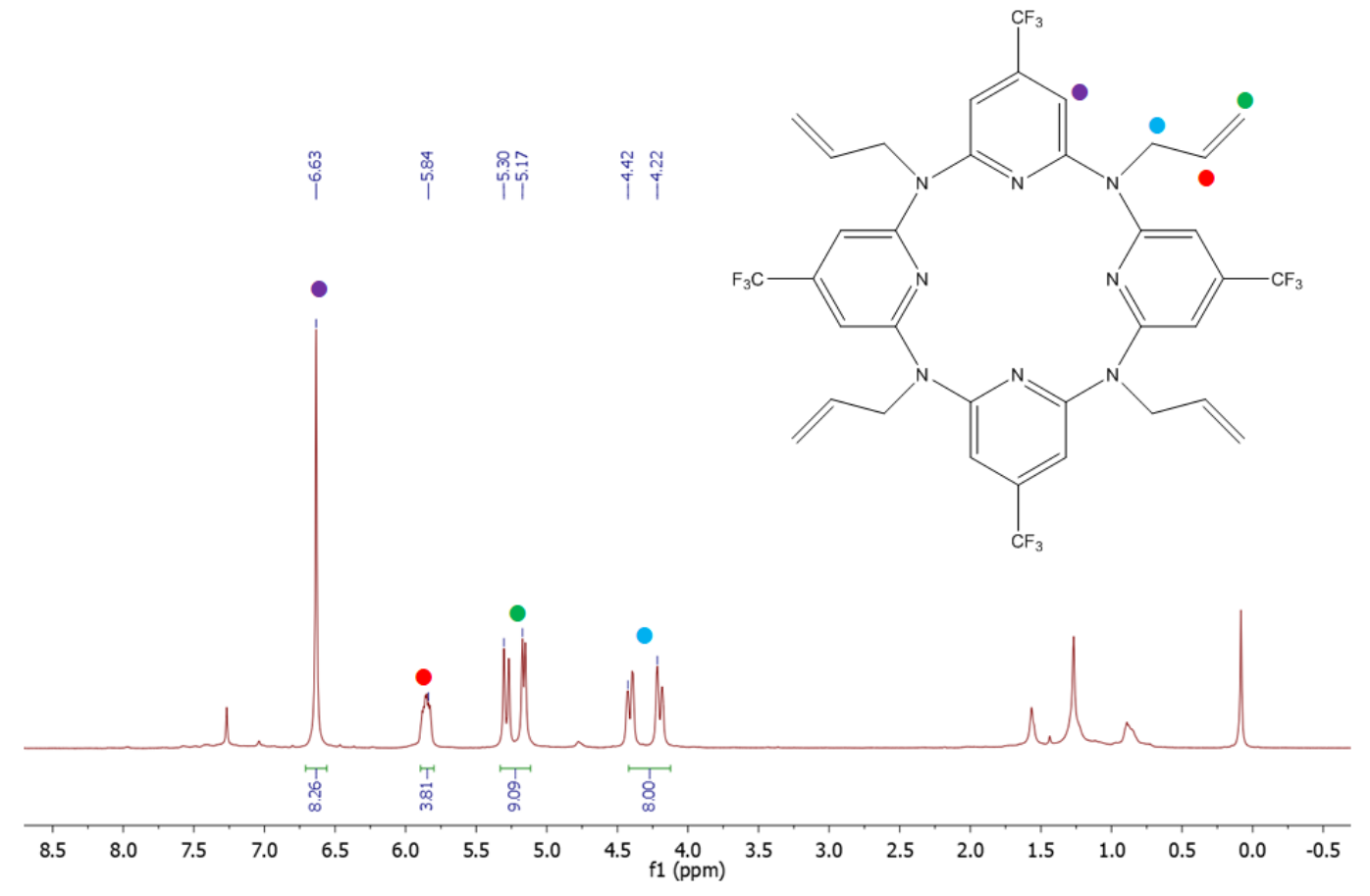

Figure S26. $500 \mathrm{MHz}{ }^{1} \mathrm{H}$ NMR spectrum of $\mathbf{D}$ in $\mathrm{CDCl}_{3}$.
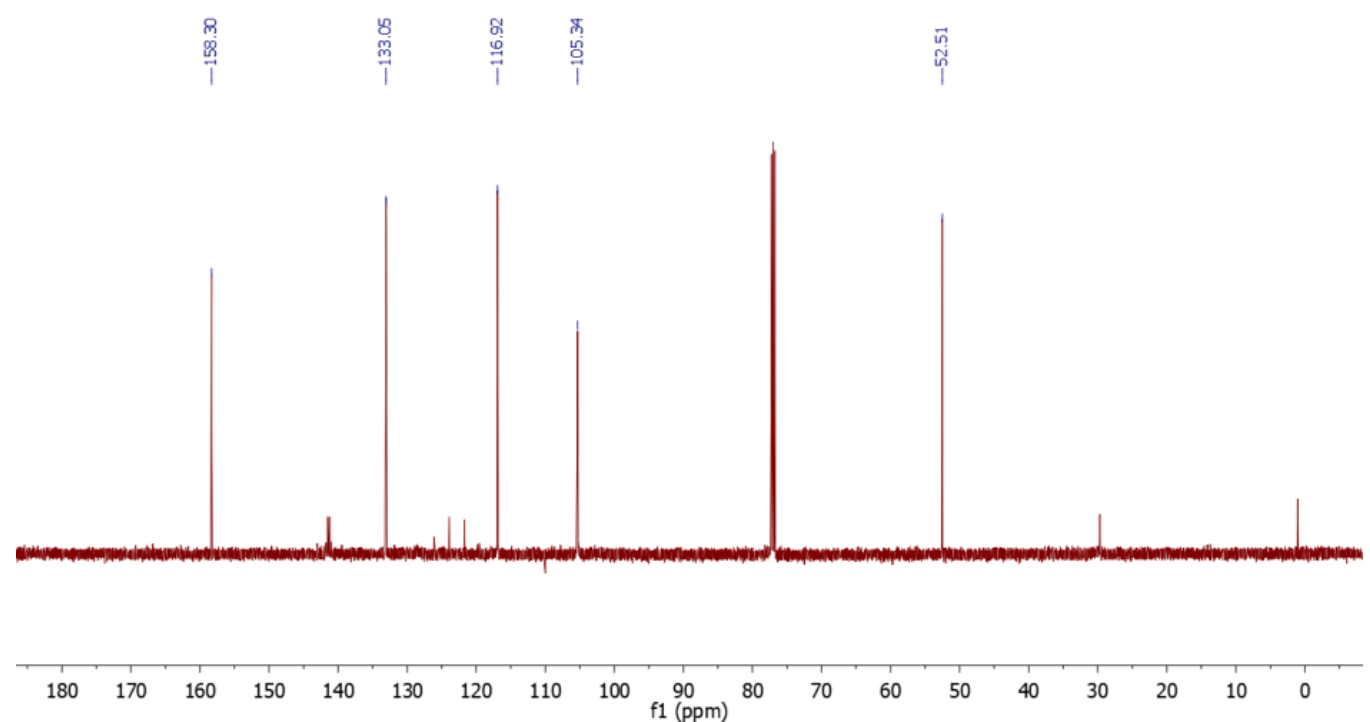

Figure S27. $126 \mathrm{MHz}{ }^{13} \mathrm{C}\left\{{ }^{1} \mathrm{H}\right\} \mathrm{NMR}$ spectrum of $\mathbf{D}$ in $\mathrm{CDCl}_{3}$. 

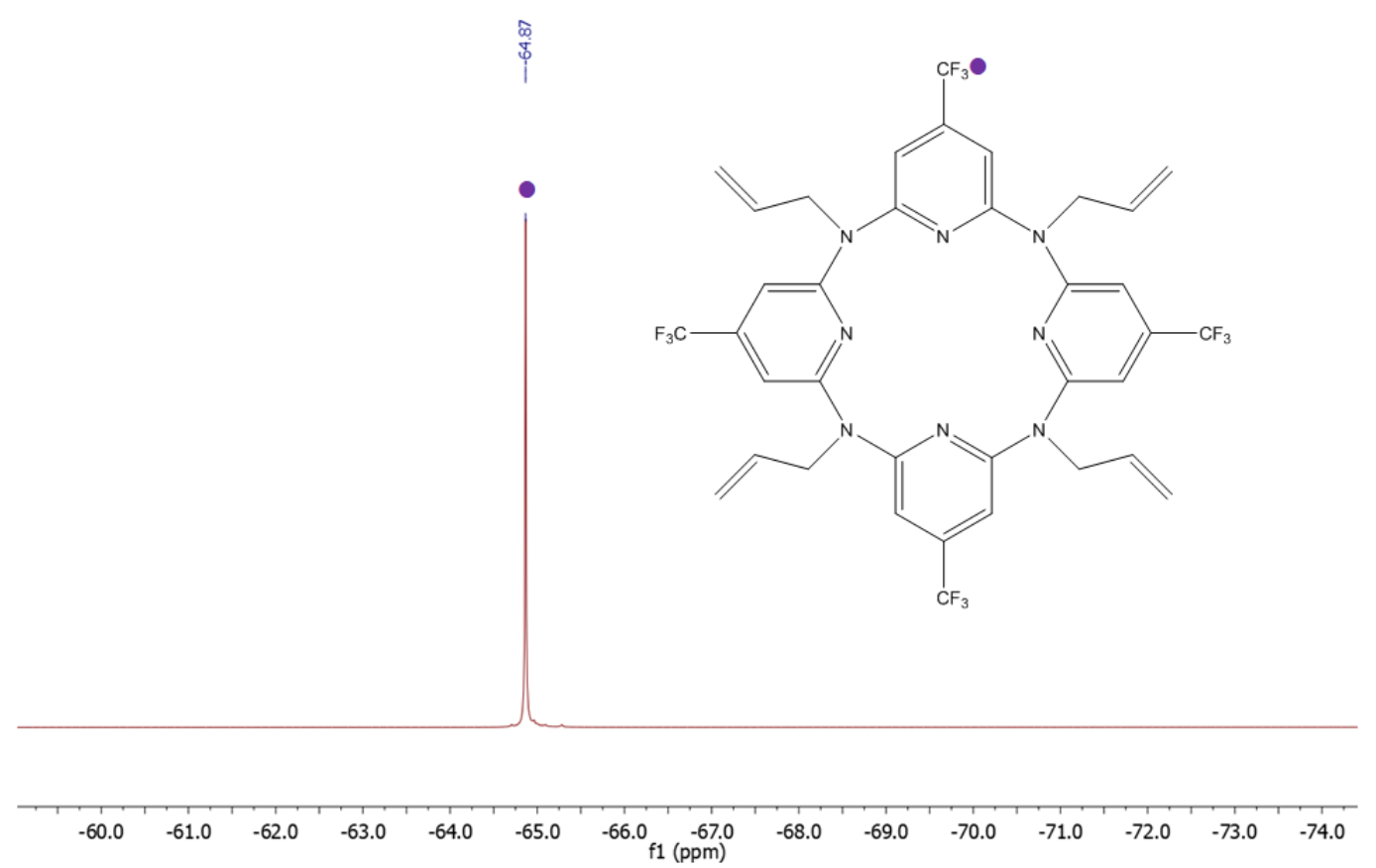

Figure S28. $470 \mathrm{MHz}{ }^{19} \mathrm{~F}\left\{{ }^{1} \mathrm{H}\right\}$ NMR spectrum of $\mathbf{D}$ in $\mathrm{CDCl}_{3}$.

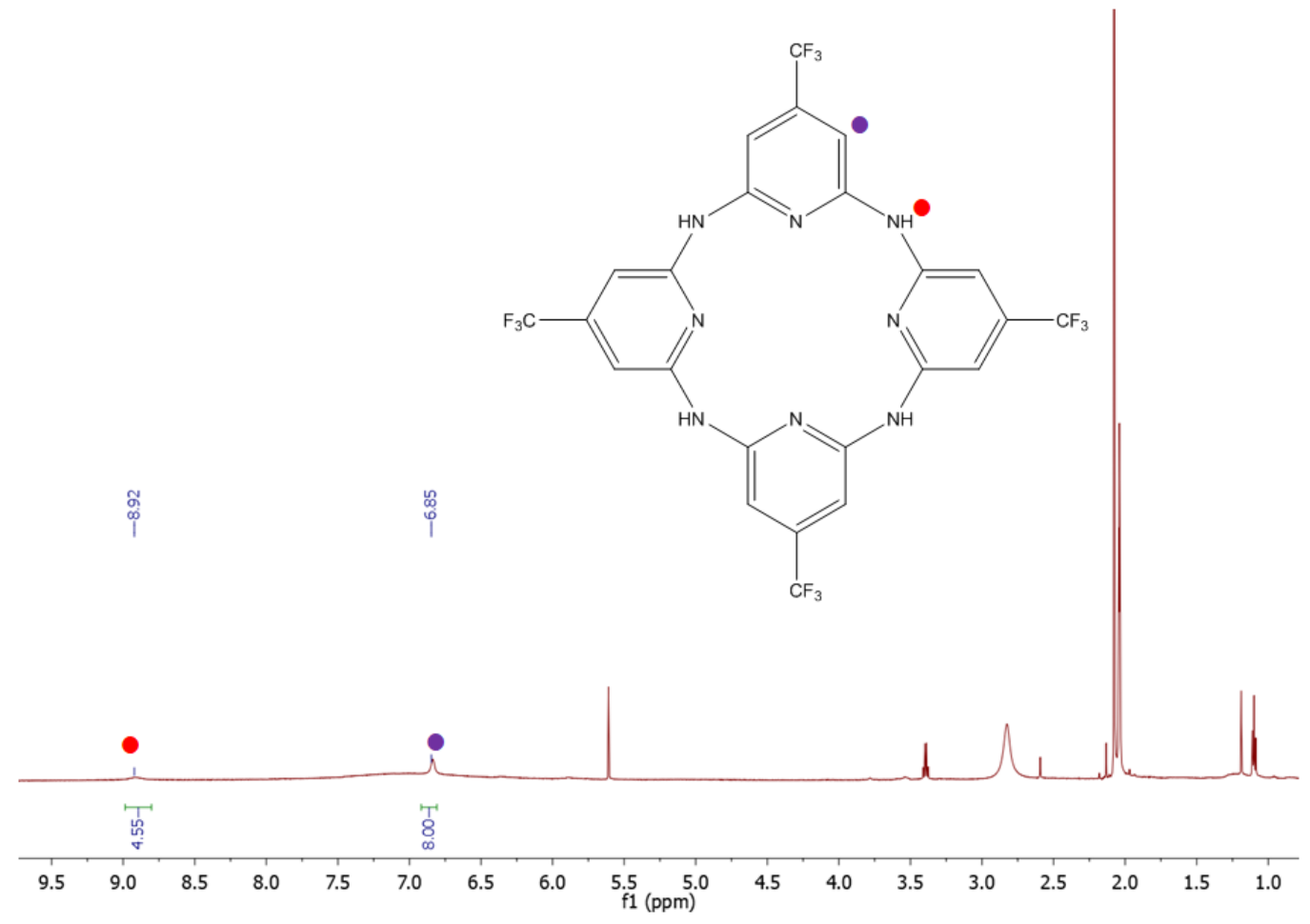

Figure S29. $500 \mathrm{MHz}{ }^{1} \mathrm{H}$ NMR spectrum of ${ }^{\mathbf{C F}} \mathbf{L}$ in acetone- $d_{6}$. 

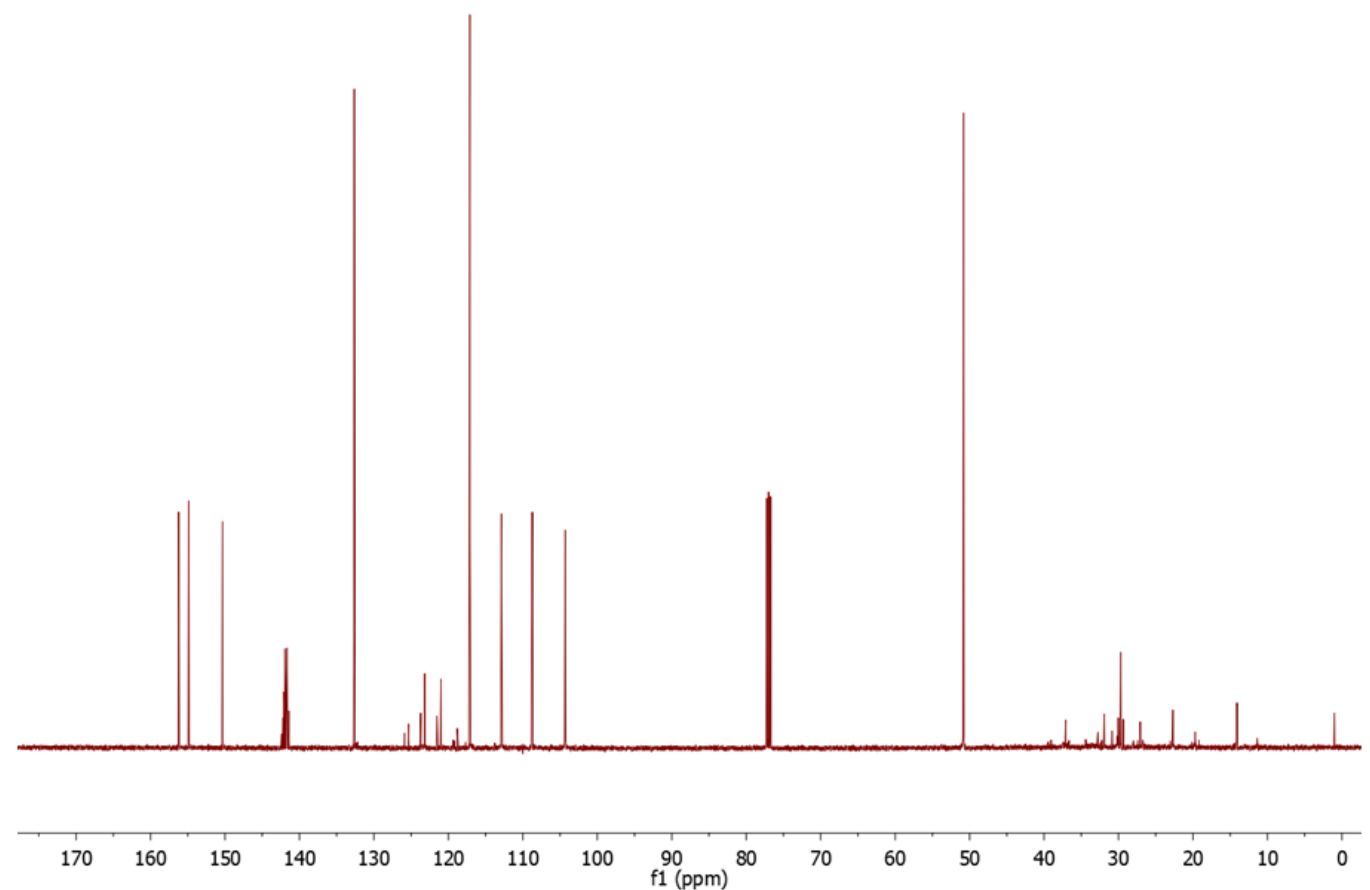

Figure S30. $126 \mathrm{MHz}{ }^{13} \mathrm{C}\left\{{ }^{1} \mathrm{H}\right\}$ NMR spectrum of ${ }^{\mathbf{C F}} \mathbf{L}$ in acetone- $d_{6}$.

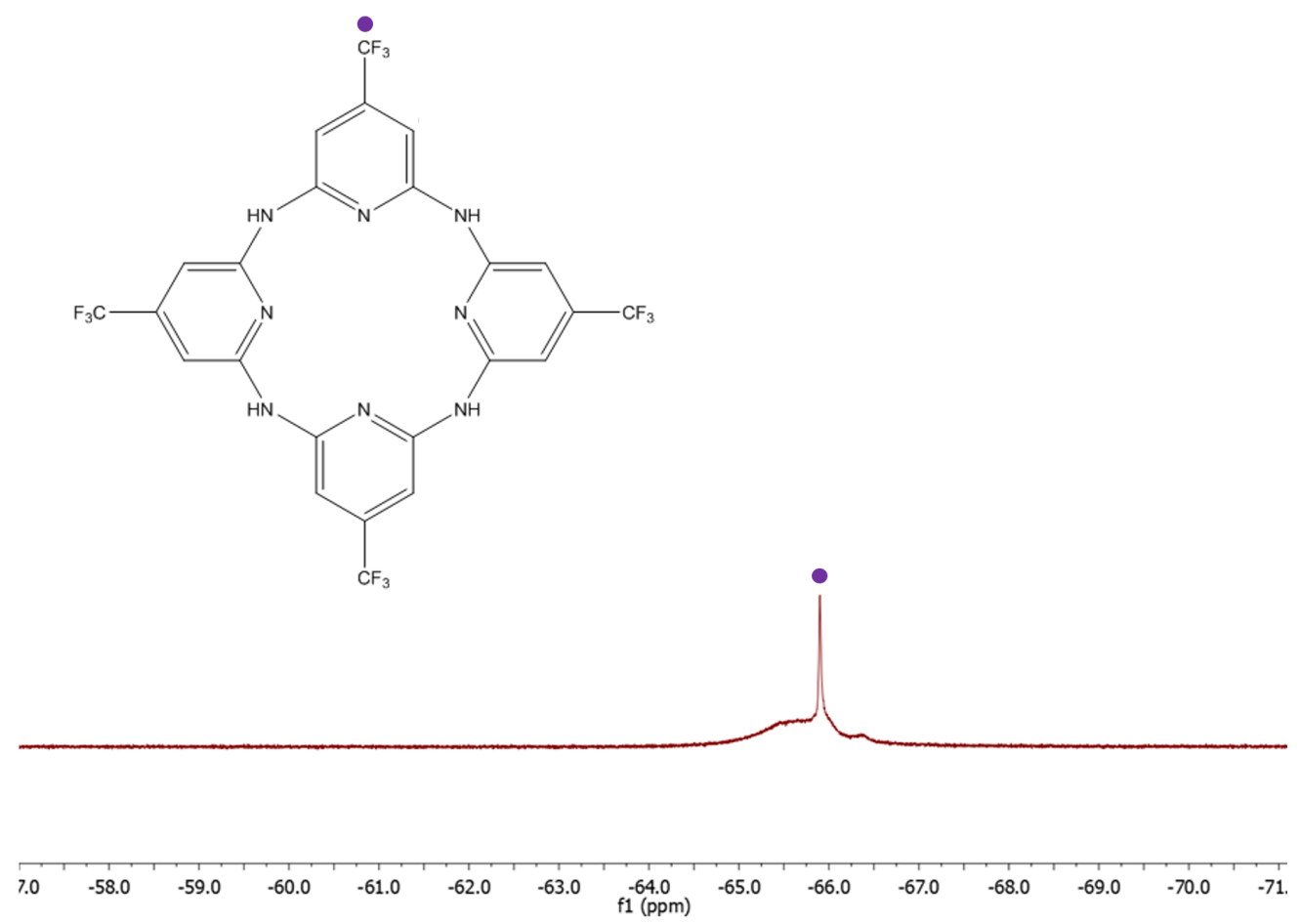

Figure S31. $470 \mathrm{MHz}{ }^{19} \mathrm{~F}\left\{{ }^{1} \mathrm{H}\right\}$ NMR spectrum of ${ }^{\mathbf{C F} 3} \mathbf{L}$ in acetone-d $d_{6}$. 


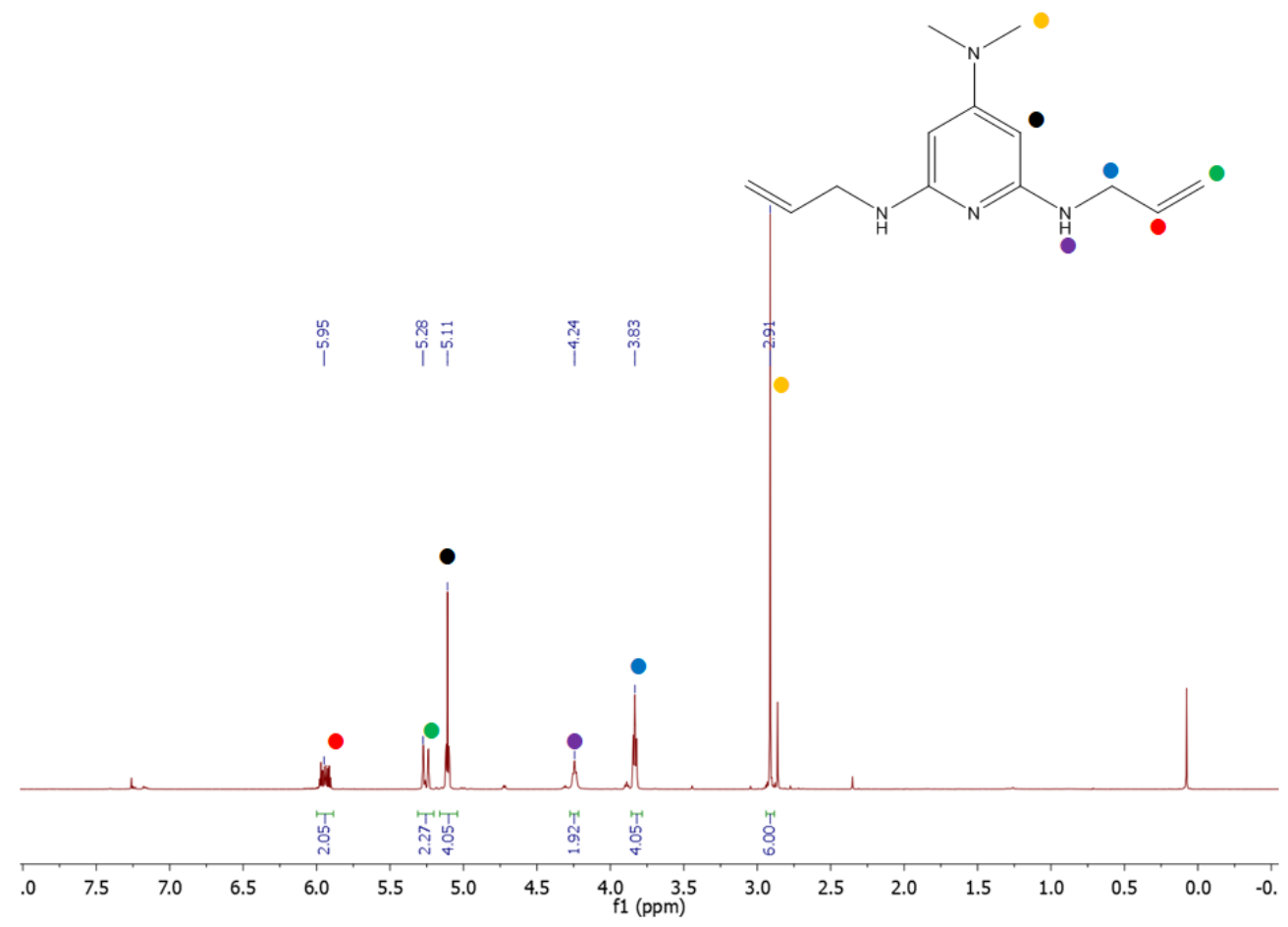

Figure S32. $500 \mathrm{MHz}{ }^{1} \mathrm{H} \mathrm{NMR}$ spectrum of $\mathbf{F}$ in $\mathrm{CDCl}_{3}$.

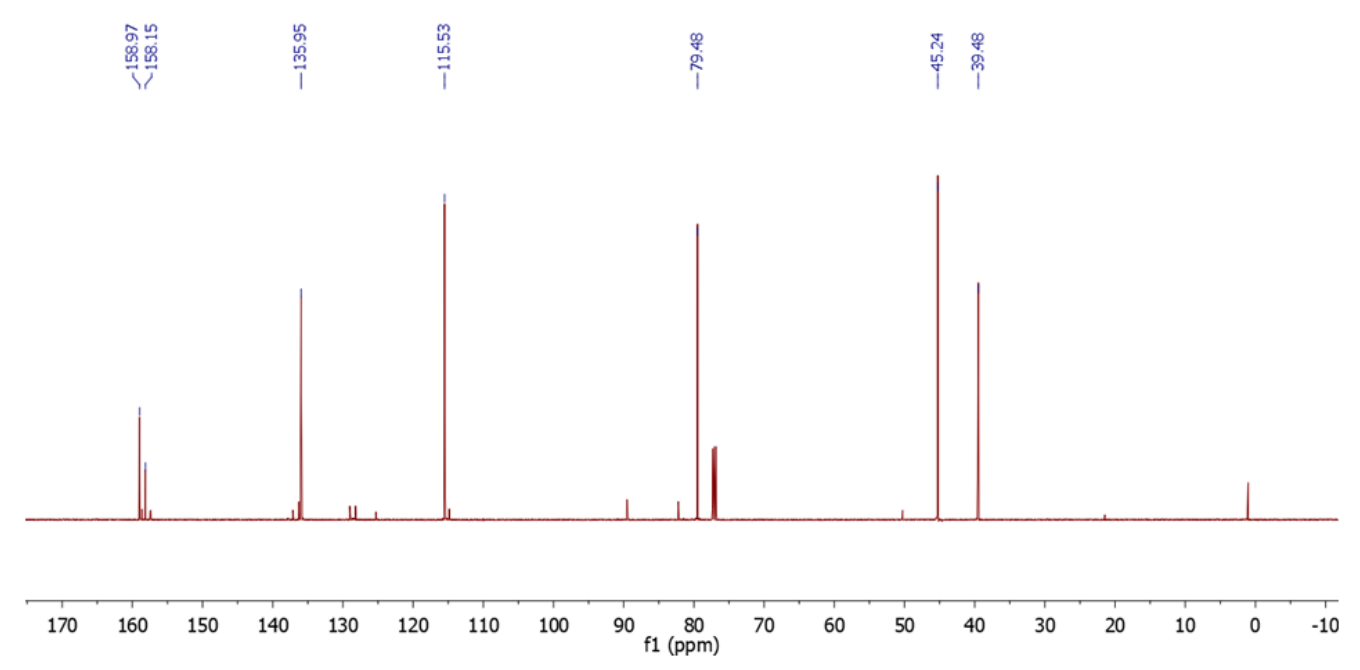

Figure S33. $126 \mathrm{MHz}{ }^{13} \mathrm{C}\left\{{ }^{1} \mathrm{H}\right\} \mathrm{NMR}$ spectrum of $\mathbf{F}$ in $\mathrm{CDCl}_{3}$. 


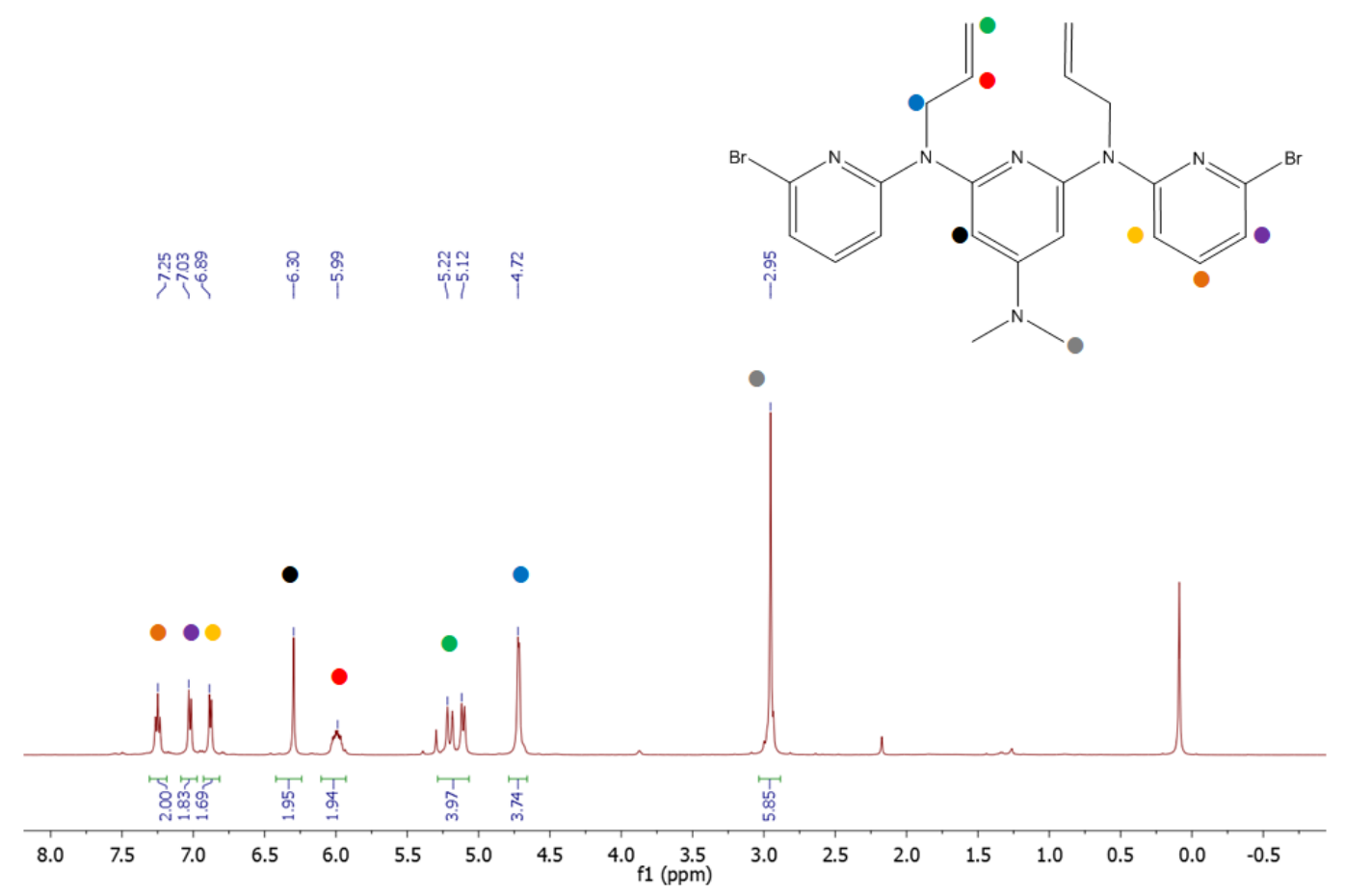

Figure S34. $500 \mathrm{MHz}{ }^{1} \mathrm{H}$ NMR spectrum of $\mathbf{G}$ in $\mathrm{CDCl}_{3}$.
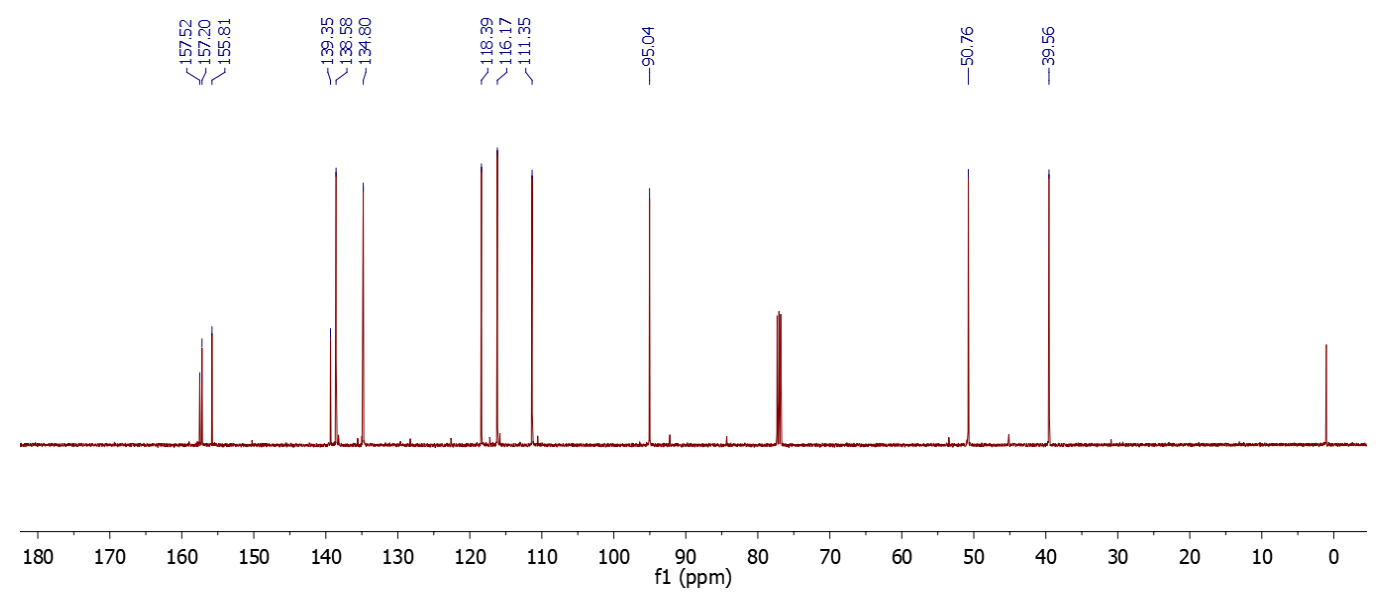

Figure S35. $126 \mathrm{MHz}{ }^{13} \mathrm{C}\left\{{ }^{1} \mathrm{H}\right\}$ NMR spectrum of $\mathbf{G}$ in $\mathrm{CDCl}_{3}$. 


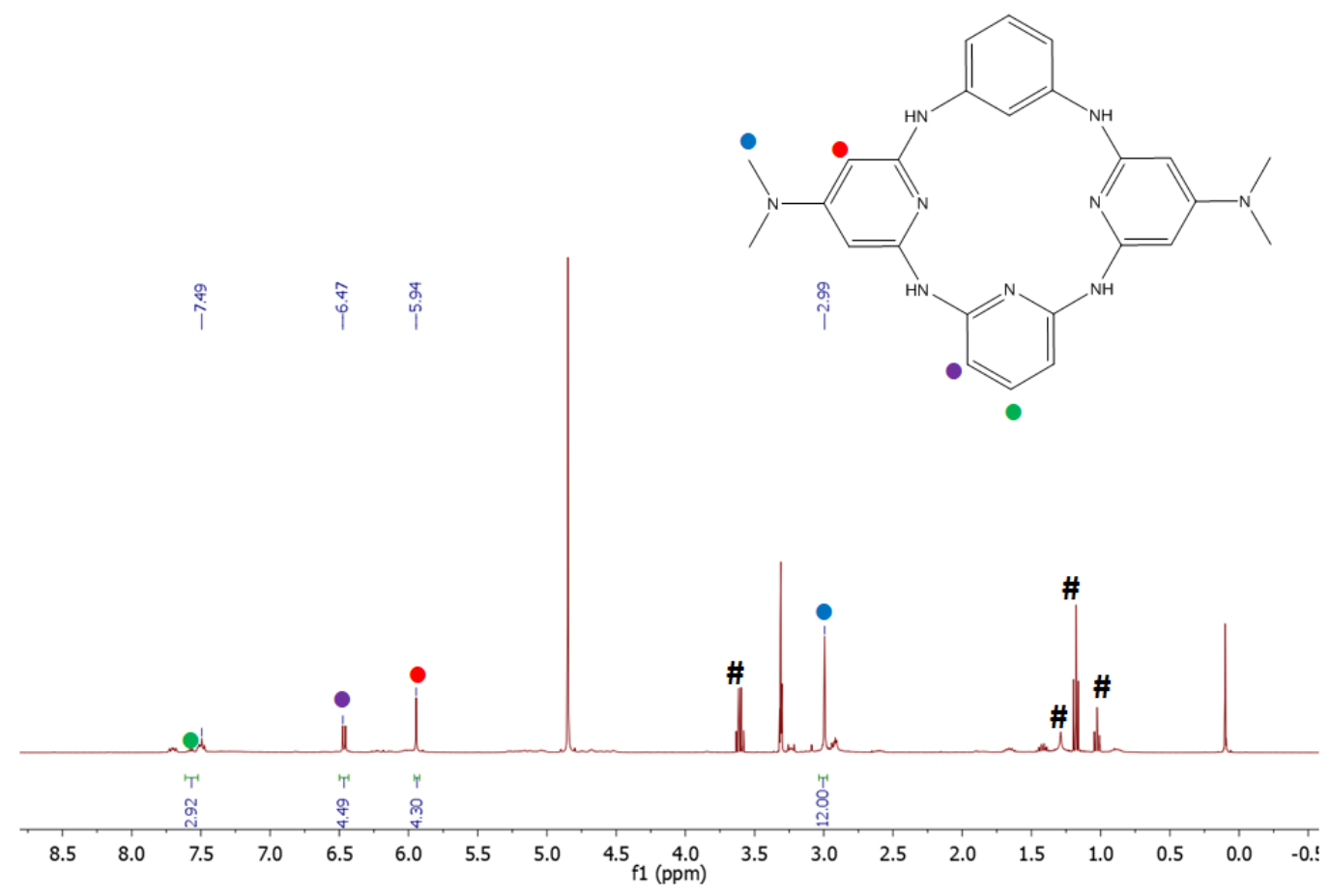

Figure S36. $500 \mathrm{MHz}{ }^{1} \mathrm{H}$ NMR spectrum of ${ }^{\mathbf{N M e} 2} \mathbf{L}$ in $\mathrm{CD}_{3} \mathrm{OD}$. Adventitious solvent peaks are designated with a hash (\#) symbol.

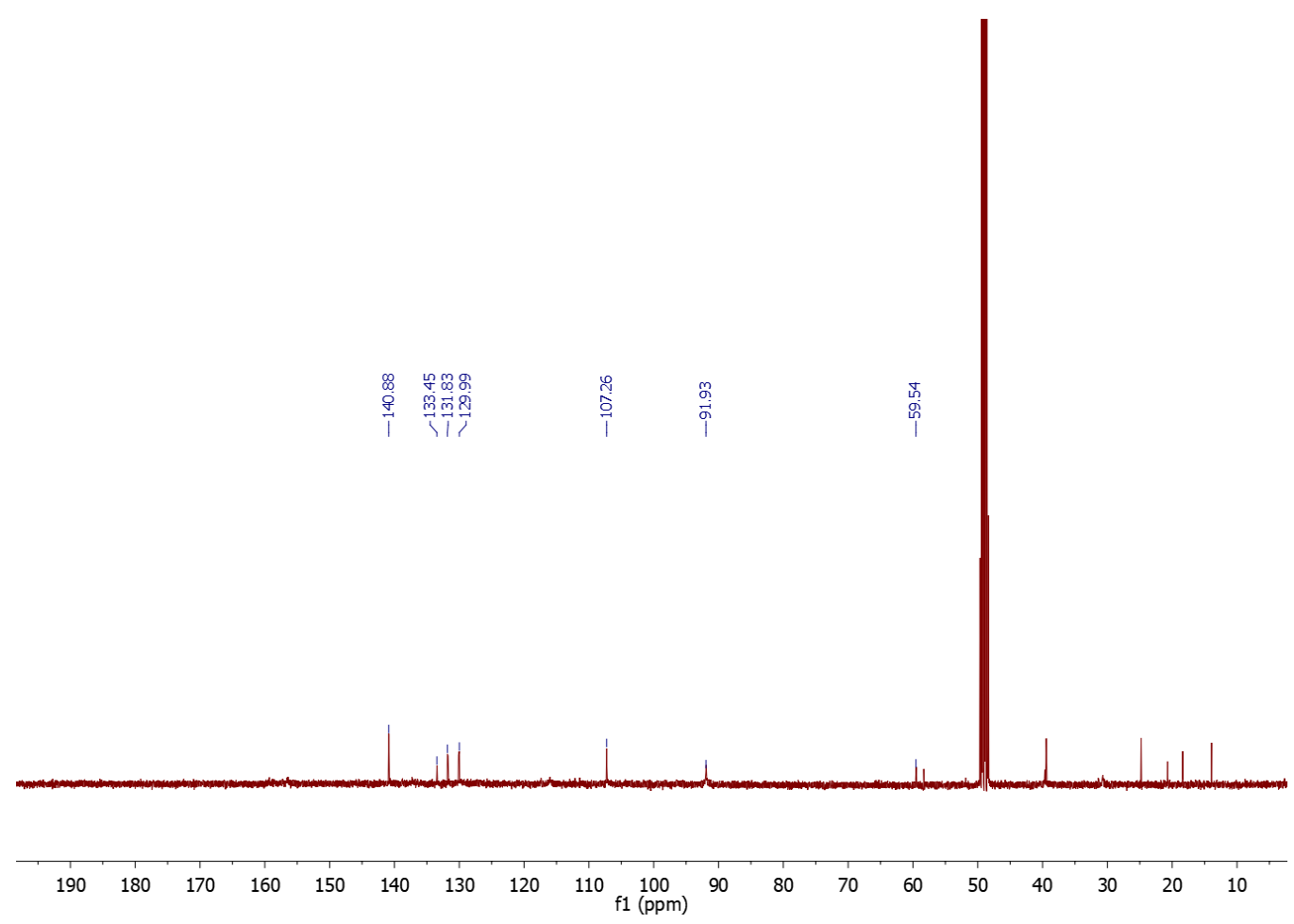

Figure S37. $126 \mathrm{MHz}{ }^{13} \mathrm{C}\left\{{ }^{1} \mathrm{H}\right\}$ NMR spectrum of ${ }^{\mathbf{N M e} 2} \mathbf{L}$ in $\mathrm{CD}_{3} \mathrm{OD}$. 


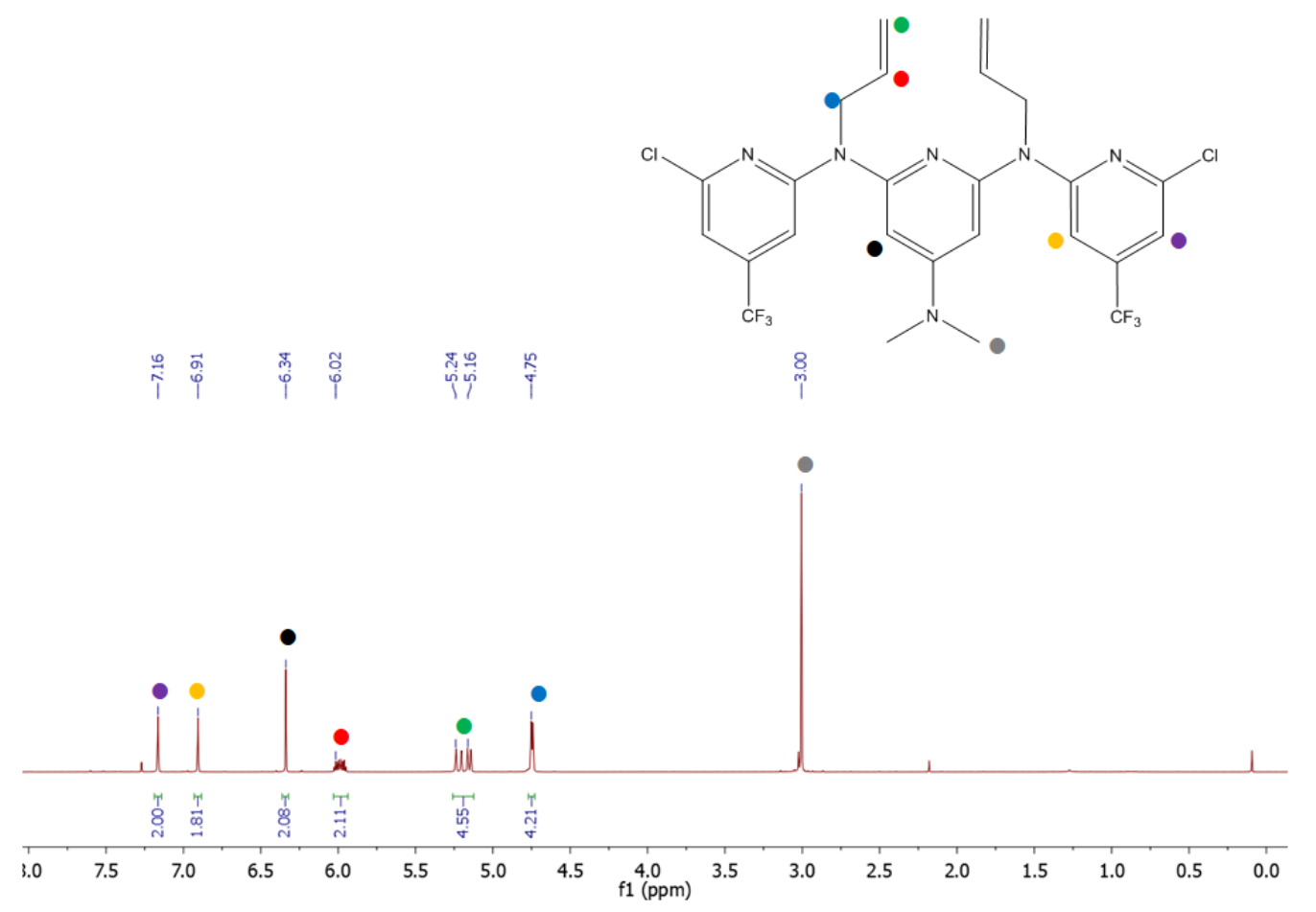

Figure S38. $500 \mathrm{MHz}{ }^{1} \mathrm{H}$ NMR spectrum of $\mathbf{I}$ in $\mathrm{CDCl}_{3}$.

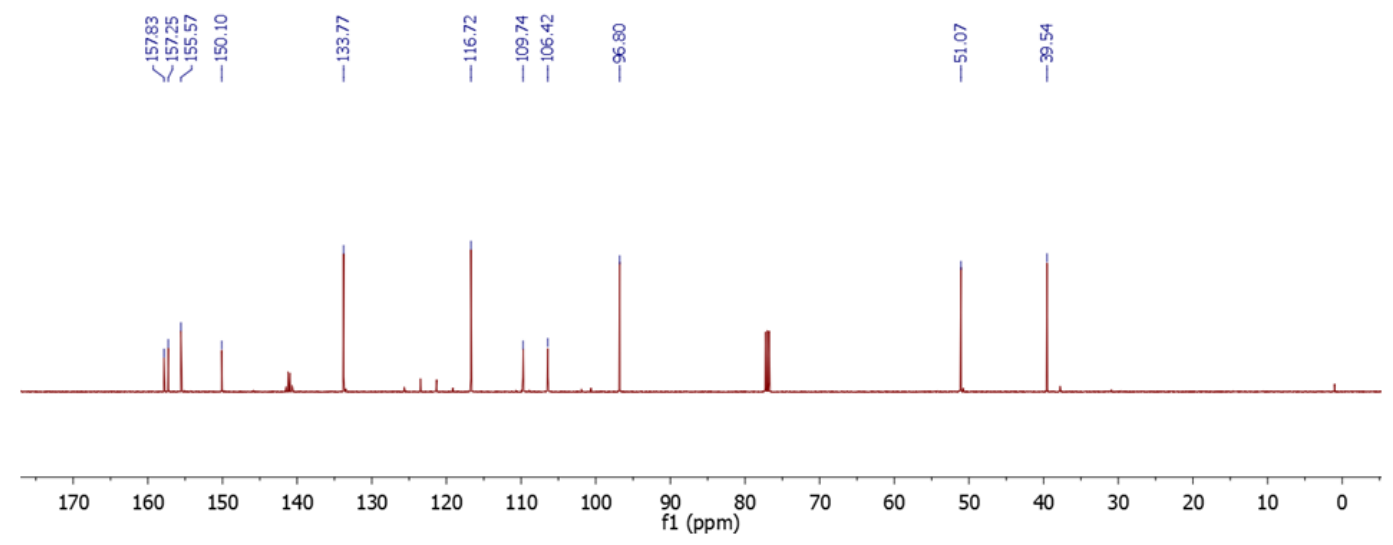

Figure S39. $126 \mathrm{MHz}{ }^{13} \mathrm{C}\left\{{ }^{1} \mathrm{H}\right\} \mathrm{NMR}$ spectrum of $\mathbf{I}$ in $\mathrm{CDCl}_{3}$. 


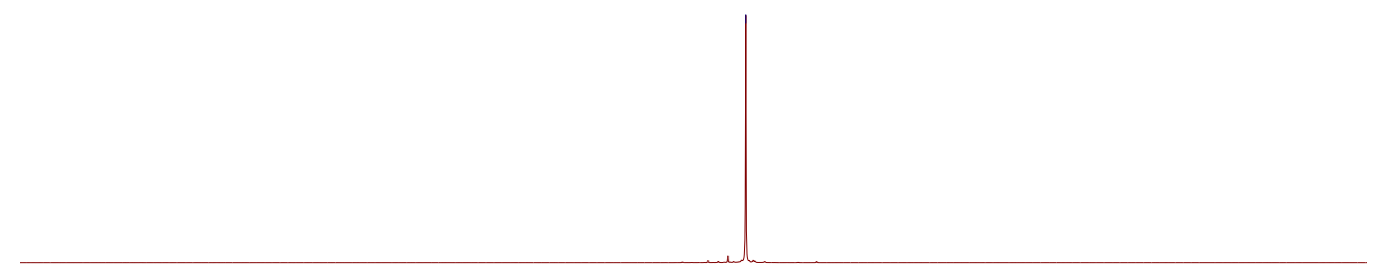

$\begin{array}{lllllllllllllllll}-61.0 & -61.5 & -62.0 & -62.5 & -63.0 & -63.5 & -64.0 & -64.5 & -65.0 & -65.5 & -66.0 & -66.5 & -67.0 & -67.5 & -68.0 & -68.1\end{array}$

Figure S40. $470 \mathrm{MHz}{ }^{19} \mathrm{~F}\left\{{ }^{1} \mathrm{H}\right\}$ NMR spectrum of $\mathbf{I}$ in $\mathrm{CDCl}_{3}$.

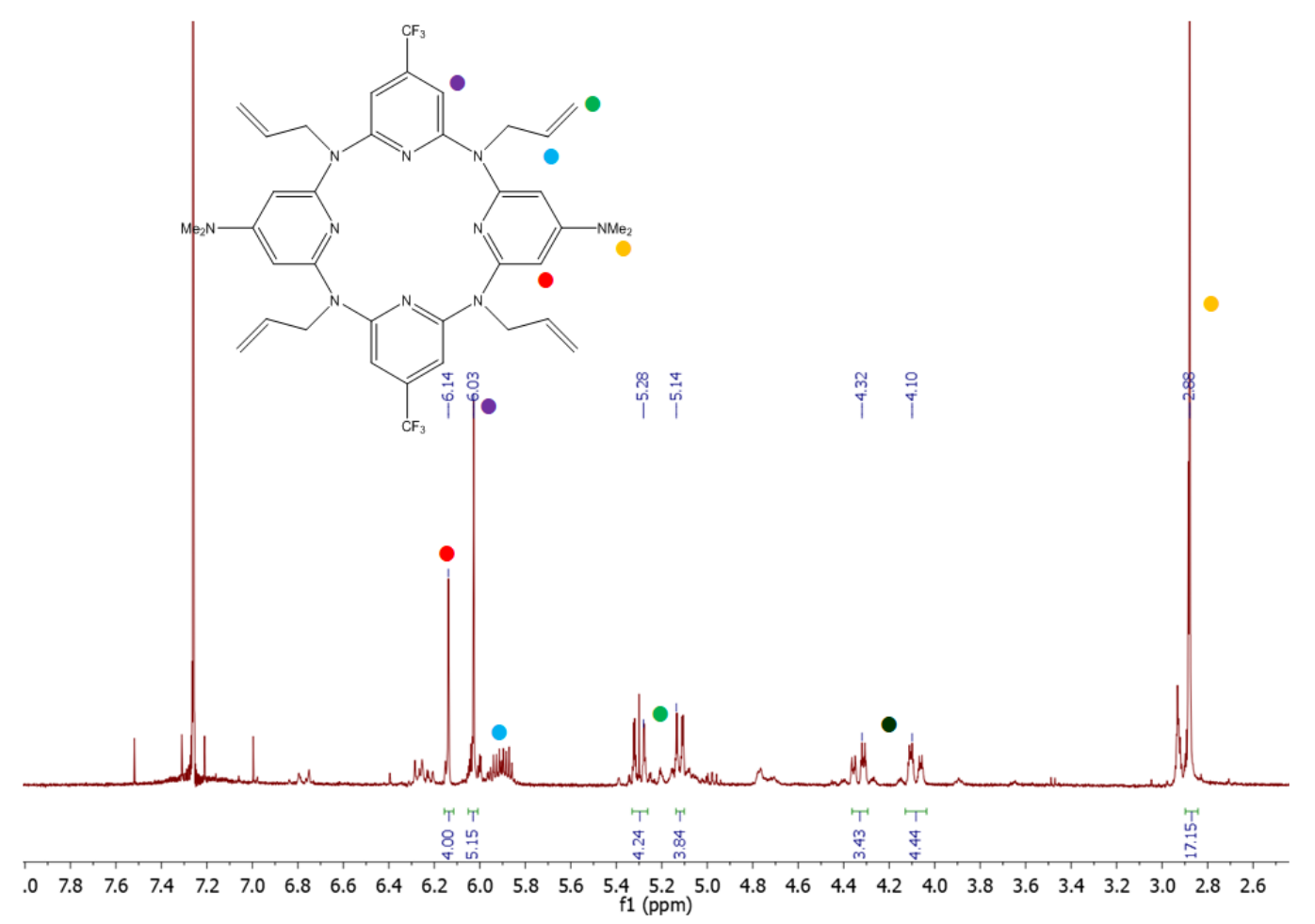

Figure S41. $500 \mathrm{MHz}{ }^{1} \mathrm{H}$ NMR spectrum of $\mathbf{J}$ in $\mathrm{CDCl}_{3}$. The impurities in the spectrum correspond to cycles bearing isomerized allyl groups. 


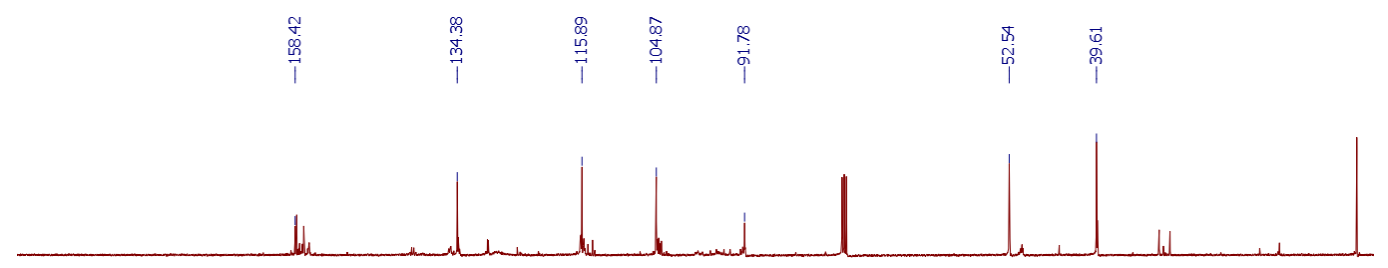

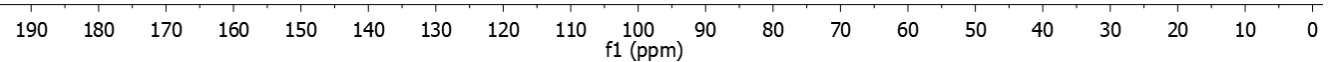

Figure $\mathbf{S 4 2 .} 126 \mathrm{MHz}{ }^{13} \mathrm{C}\left\{{ }^{1} \mathrm{H}\right\} \mathrm{NMR}$ spectrum of $\mathbf{J}$ in $\mathrm{CDCl}_{3}$.

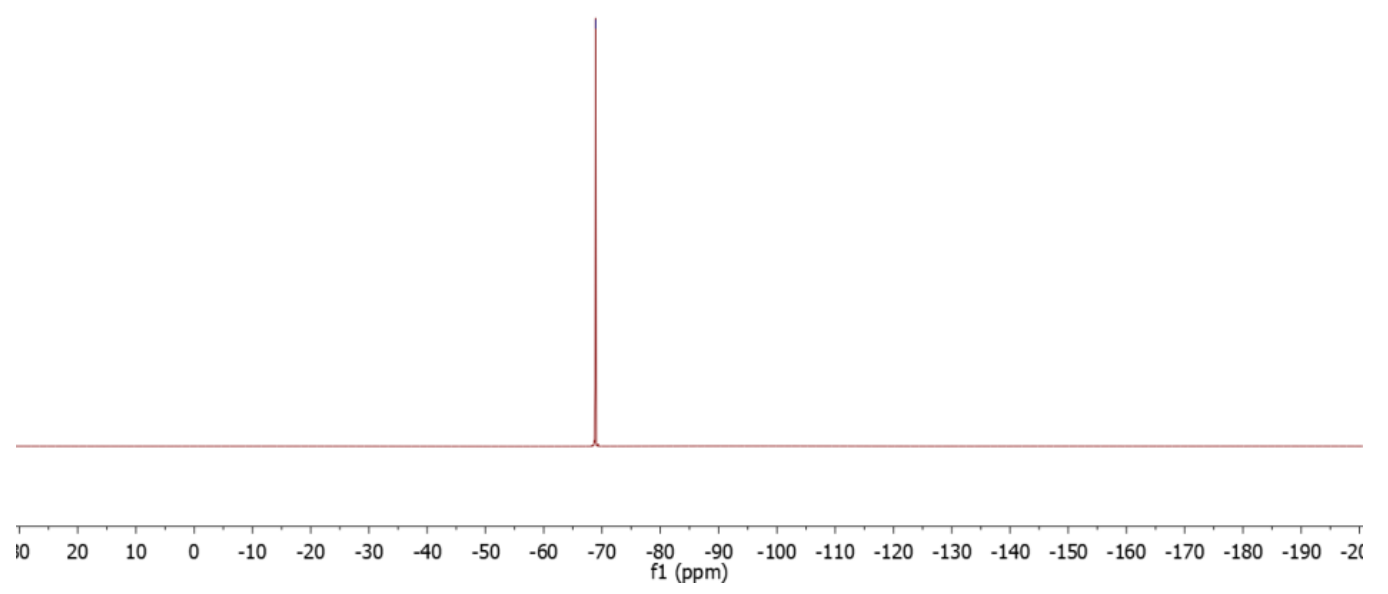

Figure $\mathbf{S 4 3 .} 470 \mathrm{MHz}{ }^{19} \mathrm{~F}\left\{{ }^{1} \mathrm{H}\right\}$ NMR spectrum of $\mathbf{J}$ in $\mathrm{CDCl}_{3}$. 


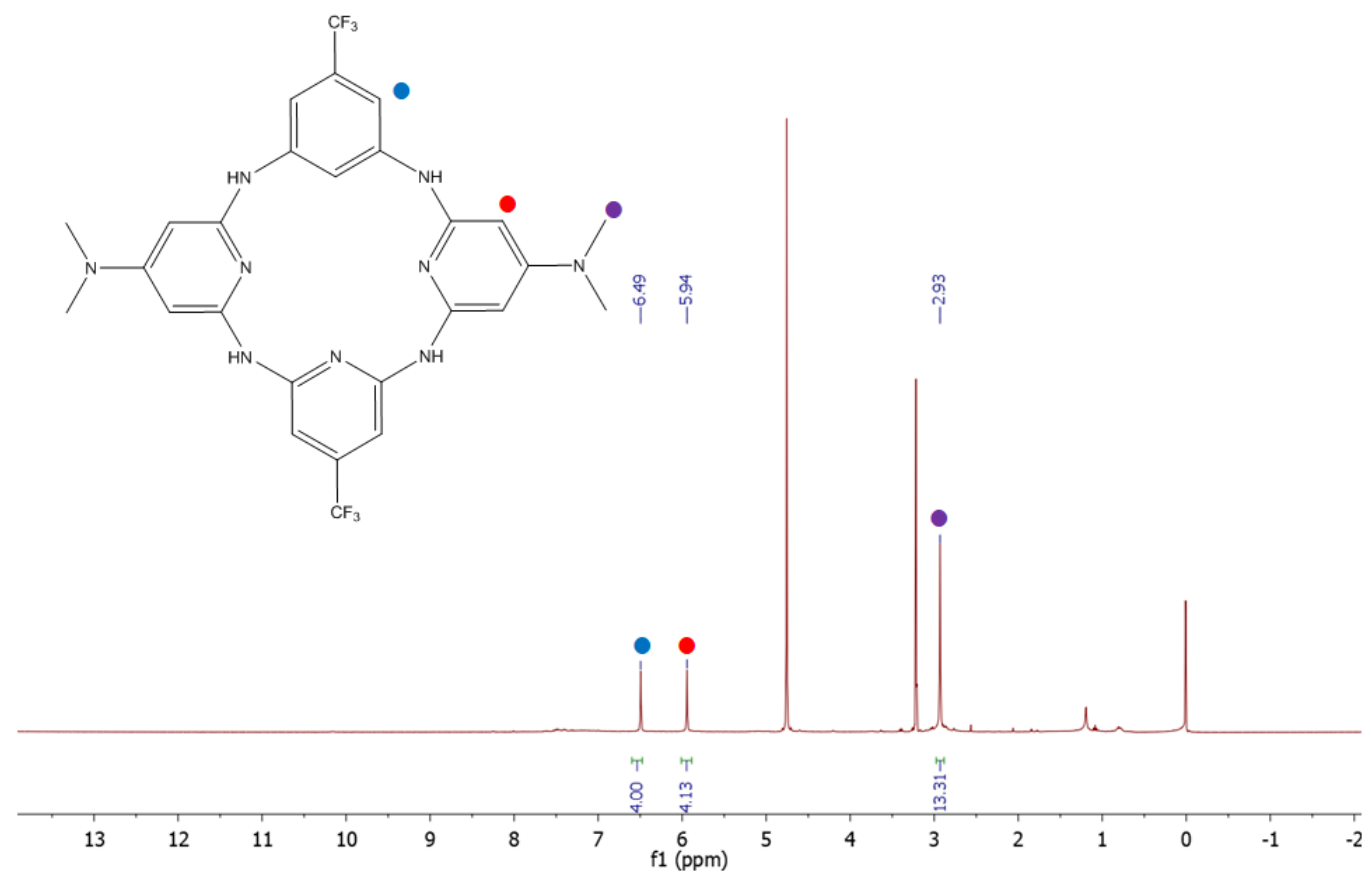

Figure S44. $500 \mathrm{MHz}{ }^{1} \mathrm{H}$ NMR spectrum of ${ }^{\mathbf{M i x}} \mathbf{L}$ in $\mathrm{CD}_{3} \mathrm{OD}$.

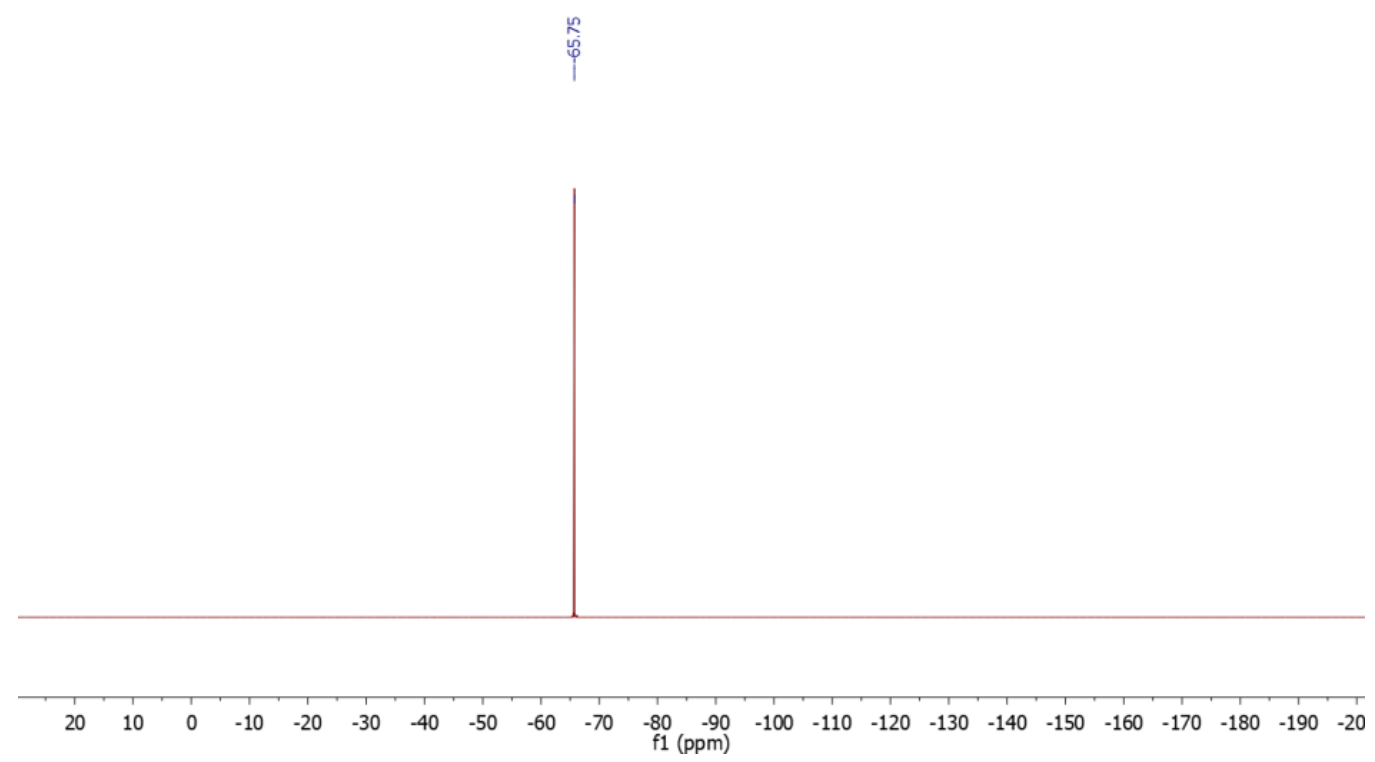

Figure S45. $470 \mathrm{MHz}{ }^{19} \mathrm{~F}\left\{{ }^{1} \mathrm{H}\right\}$ NMR spectrum of ${ }^{\mathbf{M i x}} \mathbf{L}$ in $\mathrm{CD}_{3} \mathrm{OD}$. 


\begin{tabular}{|c|c|c|c|c|c|c|c|c|}
\hline 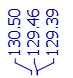 & $\begin{array}{l}0 \\
0 \\
0 \\
\stackrel{0}{0} \\
\end{array}$ & $\begin{array}{l}8 \\
\infty \\
\infty \\
\infty\end{array}$ & $\stackrel{\infty}{\stackrel{\infty}{*}}$ & \begin{tabular}{l} 
L \\
\multirow{0}{0}{} \\
0 \\
1
\end{tabular} & $\begin{array}{l}8 \\
\text { g } \\
\end{array}$ & $\begin{array}{l}\stackrel{\leftrightarrow}{\infty} \\
\stackrel{\sim}{\sim} \\
\uparrow\end{array}$ & $\frac{\alpha}{\stackrel{\gamma}{\not}}$ & $\stackrel{8}{0}$ \\
\hline
\end{tabular}

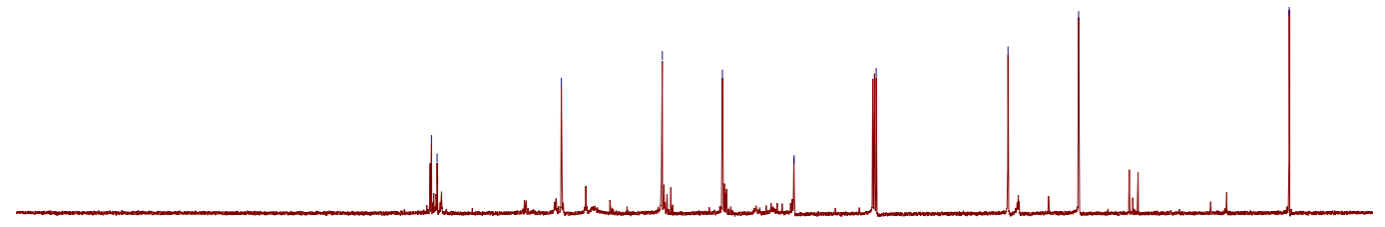

$\begin{array}{llllllllllllllllllllllllll}200 & 190 & 180 & 170 & 160 & 150 & 140 & 130 & 120 & 110 & 100 & \begin{array}{c}90 \\ \mathrm{f} 1\end{array}\left(\begin{array}{cc}\mathrm{ppm}) \\ 70\end{array}\right. & 60 & 50 & 40 & 30 & 20 & 10 & 0 & -10 & -20 & -30 & -4 \mathrm{C}\end{array}$

Figure S46. $126 \mathrm{MHz}{ }^{13} \mathrm{C}\left\{{ }^{1} \mathrm{H}\right\}$ NMR spectrum of ${ }^{\mathbf{M i x}} \mathbf{L}$ in $\mathrm{CD}_{3} \mathrm{OD}$. 


\section{Evans Method Experiments}

In a scintillation vial, a pre-weighted quantity of the cobalt complex $(5.6,3.1,3.6$, and $1.1 \mathrm{mg}$ for complexes 1-3, and 4-Cl, respectively) was dissolved in $0.7 \mathrm{~mL} \mathrm{DMSO}-d_{6}$. The solution was transferred to an NMR tube and a sealed capillary containing pure DMSO- $d_{6}$ was inserted into the cobalt solution. A ${ }^{1} \mathrm{H}$ NMR spectrum was then collected on a $500 \mathrm{MHz}$ spectrometer at $298 \mathrm{~K}$. The corrected molar susceptibility $\left(X_{\mathrm{P}}\right)$ was calculated based on the shift of the residual solvent resonances in the solution of the complex $v s$. that found in the internal capillary using the equation below where $\Delta f$ is the observed ${ }^{1} \mathrm{H}$ NMR shift of the reference standard in $\mathrm{Hz}, \mathrm{C}$ is the concentration of the sample in mol/L, $f$ is the proton Larmor frequency $(500,000,000 \mathrm{~Hz})$, and $X_{\mathrm{D}}$ is the diamagnetic susceptibility correction factor (calc. $-4.32 \times 10^{-5} \mu_{\mathrm{B}}$ ).

$$
\mathrm{X}_{P}=\frac{3000 \times \Delta f}{4 \pi C f}-\mathrm{X}_{D}
$$

The effective magnetic moment was calculated using the equation below where $\mathrm{T}$ is the temperature in Kelvin, $X_{P}$ is the corrected molar susceptibility, and $\mu_{\mathrm{eff}}$ is the effective magnetic moment in Bohr Magnetons.

$$
\mu_{e f f}=2.84 \sqrt{T \times \mathrm{X}_{P}}
$$

The observed magnetic moments for complexes $2-4$ (4.78, 4.52 and $4.97 \mu_{\mathrm{B}}$, respectively) are consistent with a high-spin $\mathrm{Co}^{2+}$ center $\left(\mathrm{d}^{7}, \mathrm{~S}=3 / 2\right)$ possessing three unpaired spins. The same result was found for the unsubstituted cobalt aminopyridine complex, 1 (ACS Cent. Sci., 2018, 4, 397-404).

Table S6. Summary of Evans method experiments for complexes 1-4. All experiments were conducted in DMSO- $d_{6}$ solvent at $298 \mathrm{~K}$ and in a $500 \mathrm{MHz}$ spectrometer. Measured magnetic moments fall in the range expected for a $\mathrm{S}=3 / 2 \mathrm{Co}^{2+}$ complex. ${ }^{19}$

\begin{tabular}{cccc}
\hline Complex & {$[\mathbf{C o}](\mathbf{m M})$} & $\Delta \boldsymbol{f}(\mathbf{H z})$ & $\boldsymbol{\mu}_{\text {eff }}\left(\boldsymbol{\mu}_{\mathrm{B}}\right)$ \\
\hline $\mathbf{1}$ & 10.8 & 223.5 & 4.98 \\
$\mathbf{2}$ & 4.6 & 87.5 & 4.78 \\
$\mathbf{3}$ & 6.1 & 103.0 & 4.52 \\
$\mathbf{4 - C l}$ & 1.6 & 33.0 & 4.97 \\
\hline
\end{tabular}



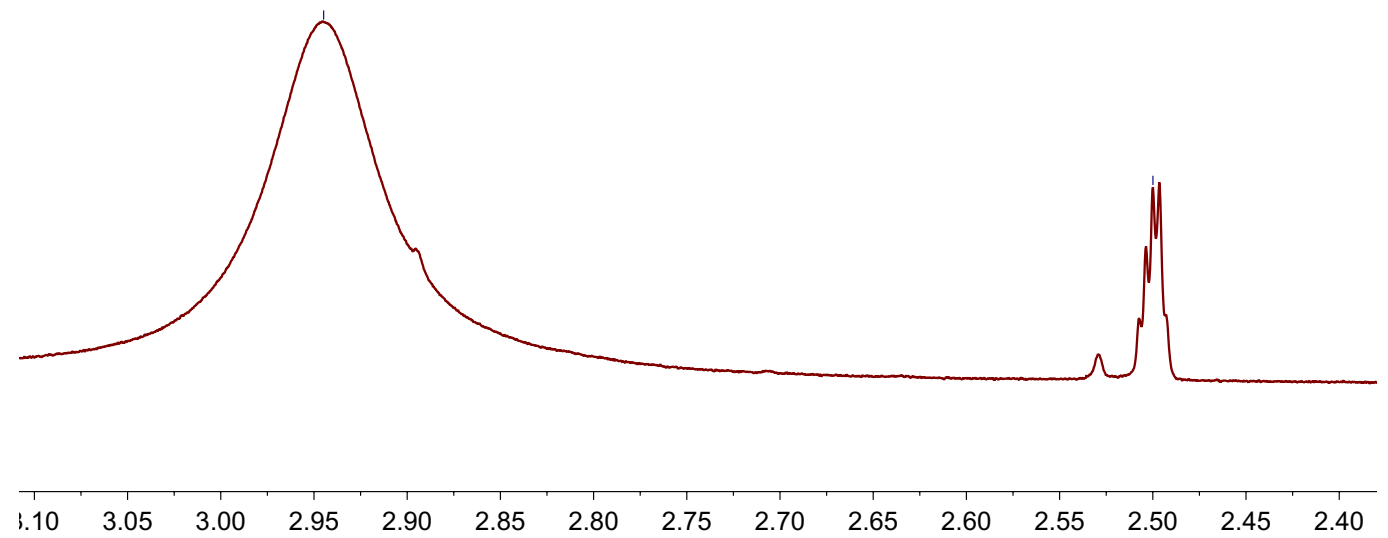

Figure S47. Selected region of the ${ }^{1} \mathrm{H}$ NMR (500 MHz) spectrum of complex 1 in DMSO- $d_{6}$ showing the paramagnetic shift of the residual solvent resonance $([\mathrm{Co}]=10.8 \mathrm{mM} ; \Delta f=223.5$ $\mathrm{Hz})$.

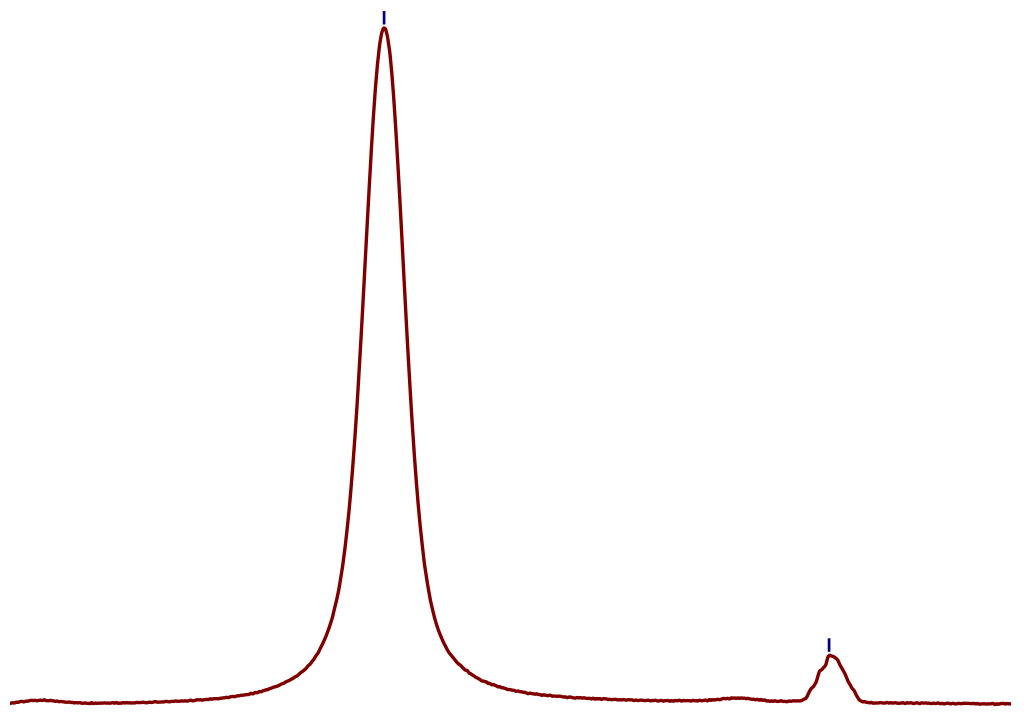

\section{$\begin{array}{llllllll}2.80 & 2.75 & 2.70 & 2.65 & 2.60 & 2.55 & 2.50 & 2.45\end{array}$}

Figure S48. Selected region of the ${ }^{1} \mathrm{H}$ NMR (500 MHz) spectrum of complex 2 in DMSO- $d_{6}$ showing the paramagnetic shift of the residual solvent resonance $([\mathrm{Co}]=4.6 \mathrm{mM} ; \Delta f=87.5 \mathrm{~Hz})$. 


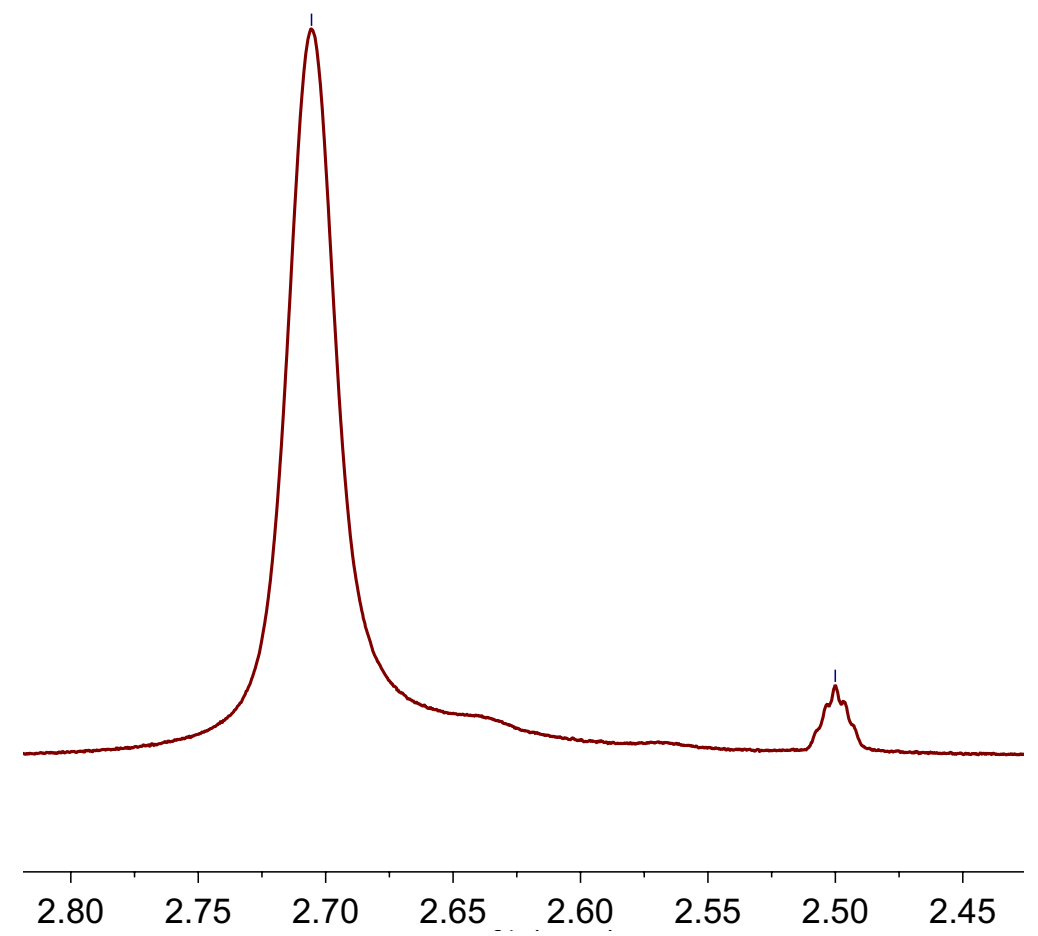

Figure S49. Selected region of the ${ }^{1} \mathrm{H}$ NMR (500 MHz) spectrum of complex 3 in DMSO- $d_{6}$ showing the paramagnetic shift of the residual solvent resonance $([\mathrm{Co}]=6.1 \mathrm{mM} ; \Delta f=103.0$ $\mathrm{Hz})$.

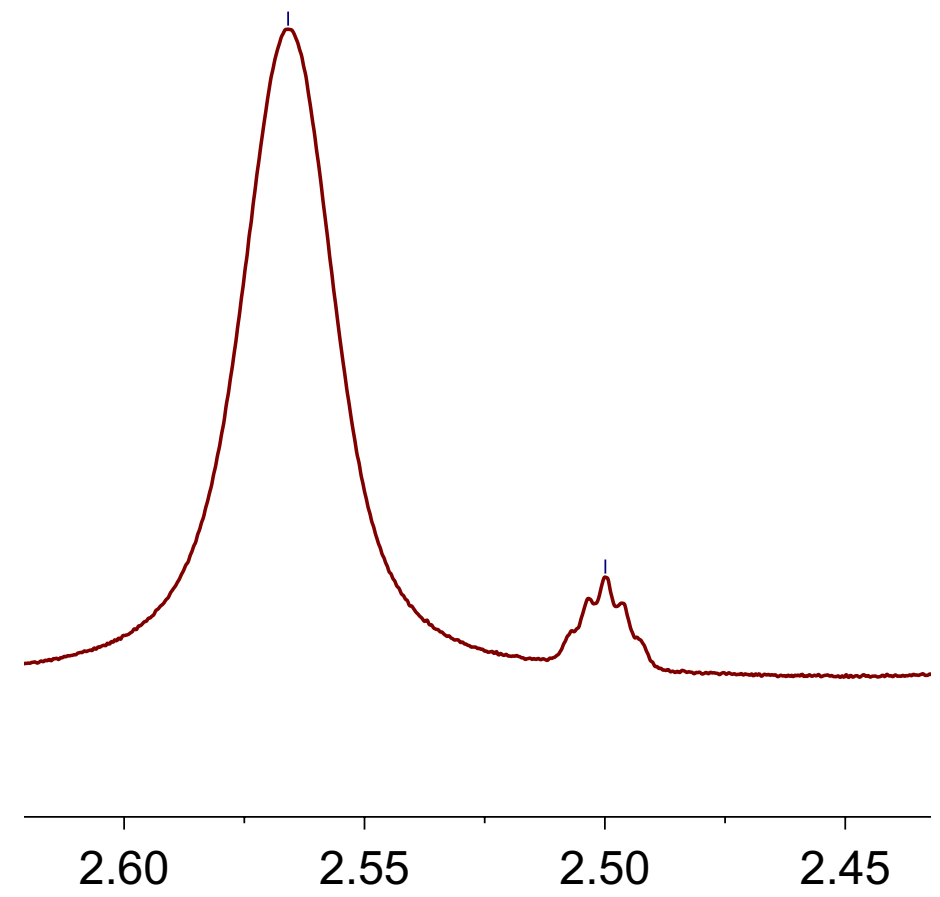

Figure S50. Selected region of the ${ }^{1} \mathrm{H}$ NMR (500 MHz) spectrum of complex 4-Cl in DMSO- $d_{6}$ showing the paramagnetic shift of the residual solvent resonance $([\mathrm{Co}]=1.6 \mathrm{mM} ; \Delta f=33.0 \mathrm{~Hz})$. 
High Scan Rate Cyclic Voltammetry for Complex 2

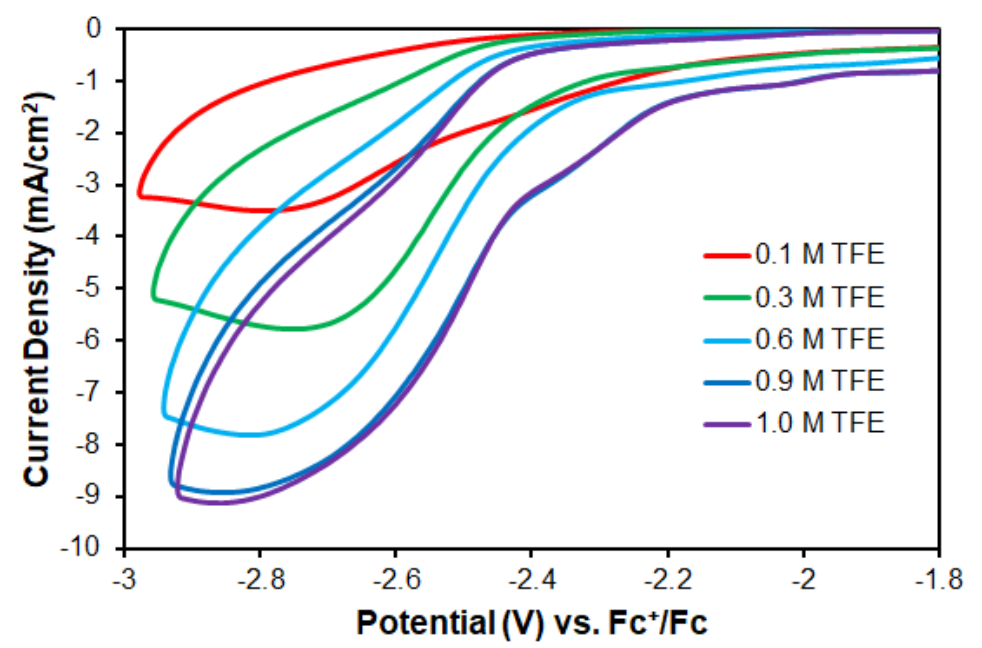

Figure S51. Cyclic Voltammetry of complex $2(0.5 \mathrm{mM})$ in a DMF solution containing $0.1 \mathrm{M}$ $\left[n \mathrm{Bu}_{4} \mathrm{~N}\right]\left[\mathrm{PF}_{6}\right]$ under $\mathrm{CO}_{2}$ atmosphere with varying amounts of TFE at $2000 \mathrm{mV} / \mathrm{s}$ scan rate.

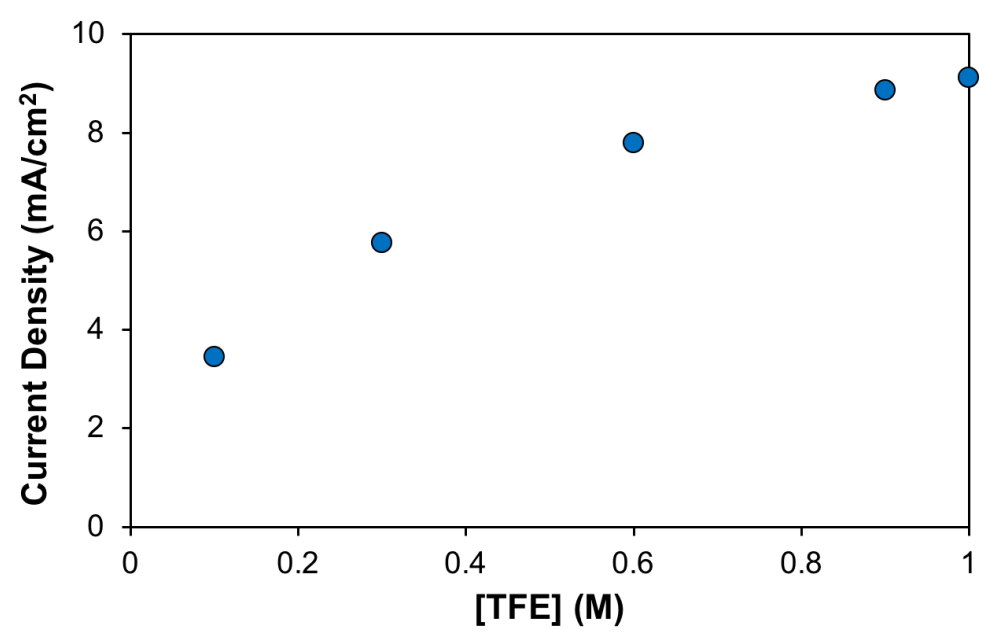

Table S7. Catalytic current for the titration of complex 2 with TFE at $v=2000 \mathrm{mV} / \mathrm{s}$.

\begin{tabular}{cc}
\hline [TFE] $(\mathbf{M})$ & $\boldsymbol{i}_{\text {cat }}\left(\mathbf{m A} / \mathbf{c m}^{\mathbf{2}}\right)$ \\
\hline $\mathbf{0 . 1}$ & 3.45 \\
$\mathbf{0 . 3}$ & 5.76 \\
$\mathbf{0 . 6}$ & 7.8 \\
$\mathbf{0 . 9}$ & 8.87 \\
$\mathbf{1}$ & 9.123 \\
\hline
\end{tabular}




\section{Supplementary Cyclic Voltammetry Titration Data}

All Titrations with TFE were performed under 1 atmosphere of $\mathrm{CO}_{2}$ and $[\mathrm{Co}]=0.5 \mathrm{mM}$ (containing $0.1 \mathrm{M}\left[n \mathrm{Bu}_{4} \mathrm{~N}\right]\left[\mathrm{PF}_{6}\right]$ electrolyte in $\mathrm{DMF}$ ), utilizing glassy carbon working electrode, $\mathrm{Pt}$ wire counter electrode and $\mathrm{Ag}$ pseudo reference electrode.

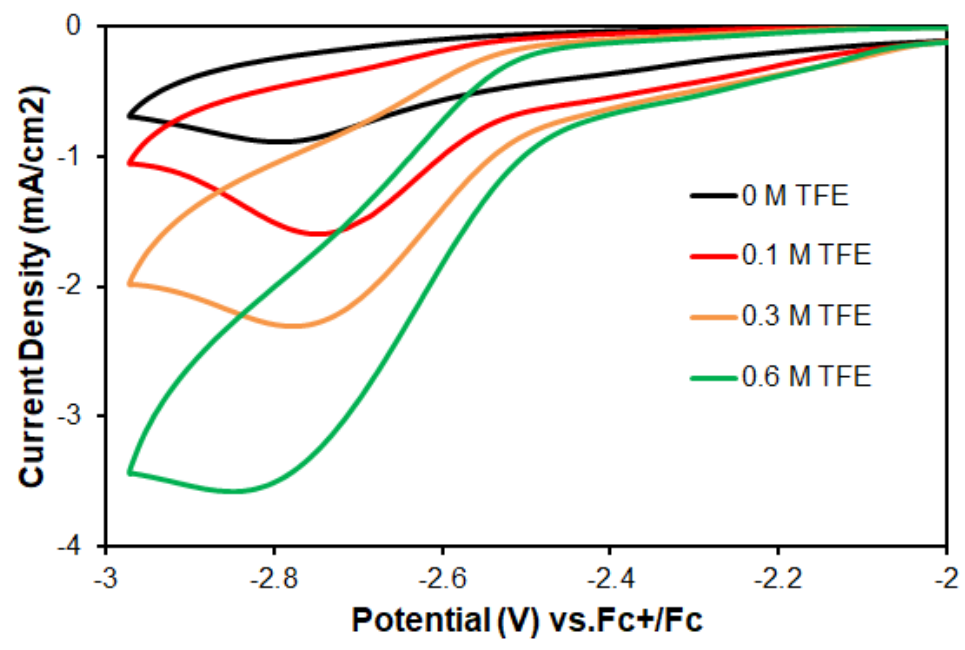

Figure S52. Cyclic Voltammetry of complex $2(0.5 \mathrm{mM})$ in a DMF solution containing $0.1 \mathrm{M}$ $\left[n \mathrm{Bu}_{4} \mathrm{~N}\right]\left[\mathrm{PF}_{6}\right]$ under $\mathrm{CO}_{2}$ atmosphere with varying amounts of TFE. Scans were collected at 100 $\mathrm{mV} / \mathrm{s}$.

Table S8. Catalytic current for the titration of complex 2 with TFE. $i_{p}=0.0177 \mathrm{~mA} / \mathrm{cm}^{2}$, extrapolated from the reversible $\mathrm{Co}^{\mathrm{II} / \mathrm{I}}$ couple.

\begin{tabular}{|c|c|c|}
\hline [TFE] (M) & $i_{c a t}\left(\mathrm{~mA} / \mathrm{cm}^{2}\right)$ & $i_{c a t} / i_{p}$ \\
\hline 0.1 & 1.59 & 89.8 \\
\hline 0.3 & 2.29 & 129.4 \\
\hline 0.6 & 3.57 & 201.7 \\
\hline
\end{tabular}




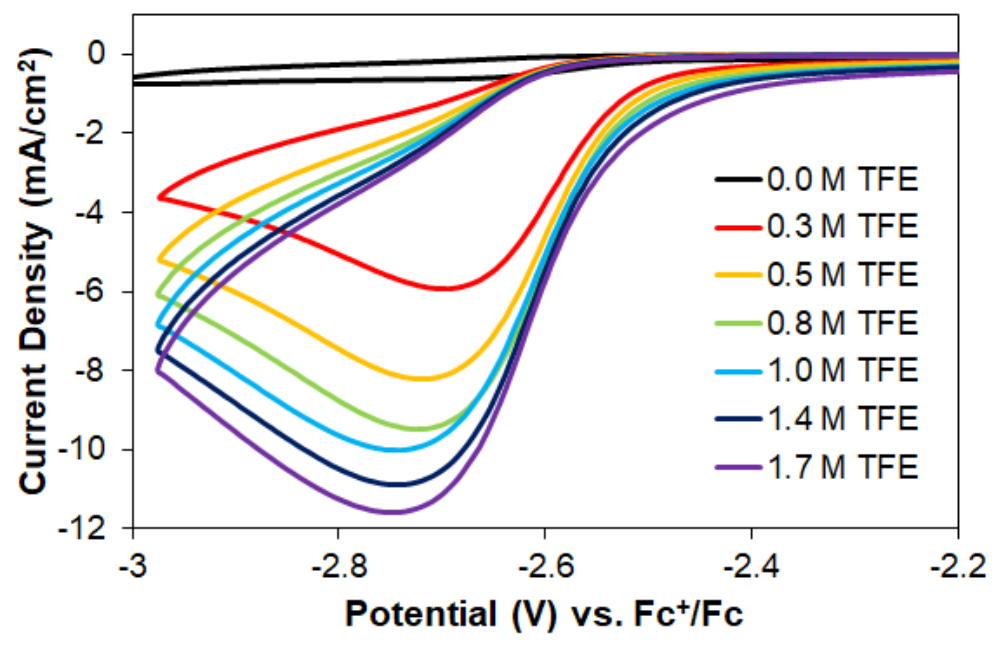

Figure S53. Cyclic Voltammetry of complex $3(0.5 \mathrm{mM})$ in a DMF solution containing $0.1 \mathrm{M}$ $\left[n \mathrm{Bu}_{4} \mathrm{~N}\right]\left[\mathrm{PF}_{6}\right]$ under $\mathrm{CO}_{2}$ atmosphere with varying amounts of TFE. Scans were collected at 100 $\mathrm{mV} / \mathrm{s}$.

Table S9. Catalytic current for the titration of complex 3 with TFE. $i_{p}=0.0140 \mathrm{~mA} / \mathrm{cm}^{2}$, extrapolated from the reversible $\mathrm{Co}^{\mathrm{II} / \mathrm{I}}$ couple.

\begin{tabular}{ccc}
\hline TFE] $\mathbf{( M )}$ & $\boldsymbol{i}_{\text {cat }}\left(\mathbf{m A} \mathbf{A} / \mathbf{c m}^{2}\right)$ & $\boldsymbol{i}_{\text {cat }} / \boldsymbol{i}_{\boldsymbol{p}}$ \\
\hline $\mathbf{0 . 3}$ & 5.92 & 423.8 \\
$\mathbf{0 . 5}$ & 8.22 & 588.4 \\
$\mathbf{0 . 8}$ & 9.45 & 676.4 \\
$\mathbf{1}$ & 9.98 & 714.0 \\
$\mathbf{1 . 4}$ & 10.85 & 776.5 \\
$\mathbf{1 . 7}$ & 11.59 & 829.8 \\
\hline
\end{tabular}




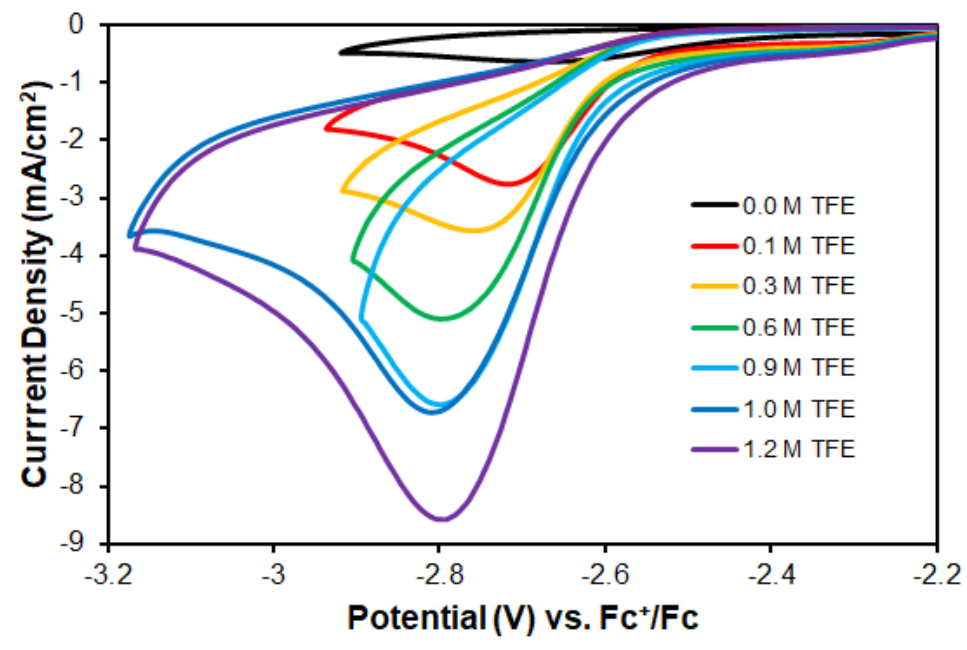

Figure S54. Cyclic Voltammetry of complex $4(0.5 \mathrm{mM})$ in a DMF solution containing $0.1 \mathrm{M}$ $\left[n \mathrm{Bu}_{4} \mathrm{~N}\right]\left[\mathrm{PF}_{6}\right]$ under $\mathrm{CO}_{2}$ atmosphere with varying amounts of TFE. Scans were collected at 100 $\mathrm{mV} / \mathrm{s}$.

Table S10. Catalytic current for the titration of complex 4 with TFE. $i_{p}=0.0357 \mathrm{~mA} / \mathrm{cm}^{2}$, extrapolated from the reversible $\mathrm{Co}^{\mathrm{I} / \mathrm{I}}$ couple.

\begin{tabular}{ccc}
\hline$[\mathrm{TFE}](\mathbf{M})$ & $\boldsymbol{i}_{\boldsymbol{c a t}}\left(\mathbf{m A} / \mathbf{c m}^{\mathbf{2}}\right)$ & $\boldsymbol{i}_{\boldsymbol{c a t}} / \boldsymbol{i}_{\boldsymbol{p}}$ \\
\hline $\mathbf{0 . 1}$ & 2.76 & 77.3 \\
$\mathbf{0 . 3}$ & 3.57 & 99.9 \\
$\mathbf{0 . 6}$ & 5.09 & 142.6 \\
$\mathbf{0 . 9}$ & 6.58 & 184.5 \\
$\mathbf{1}$ & 6.69 & 187.4 \\
$\mathbf{1 . 2}$ & 8.54 & 239.3 \\
\hline
\end{tabular}




\section{Supplementary CPE Data}
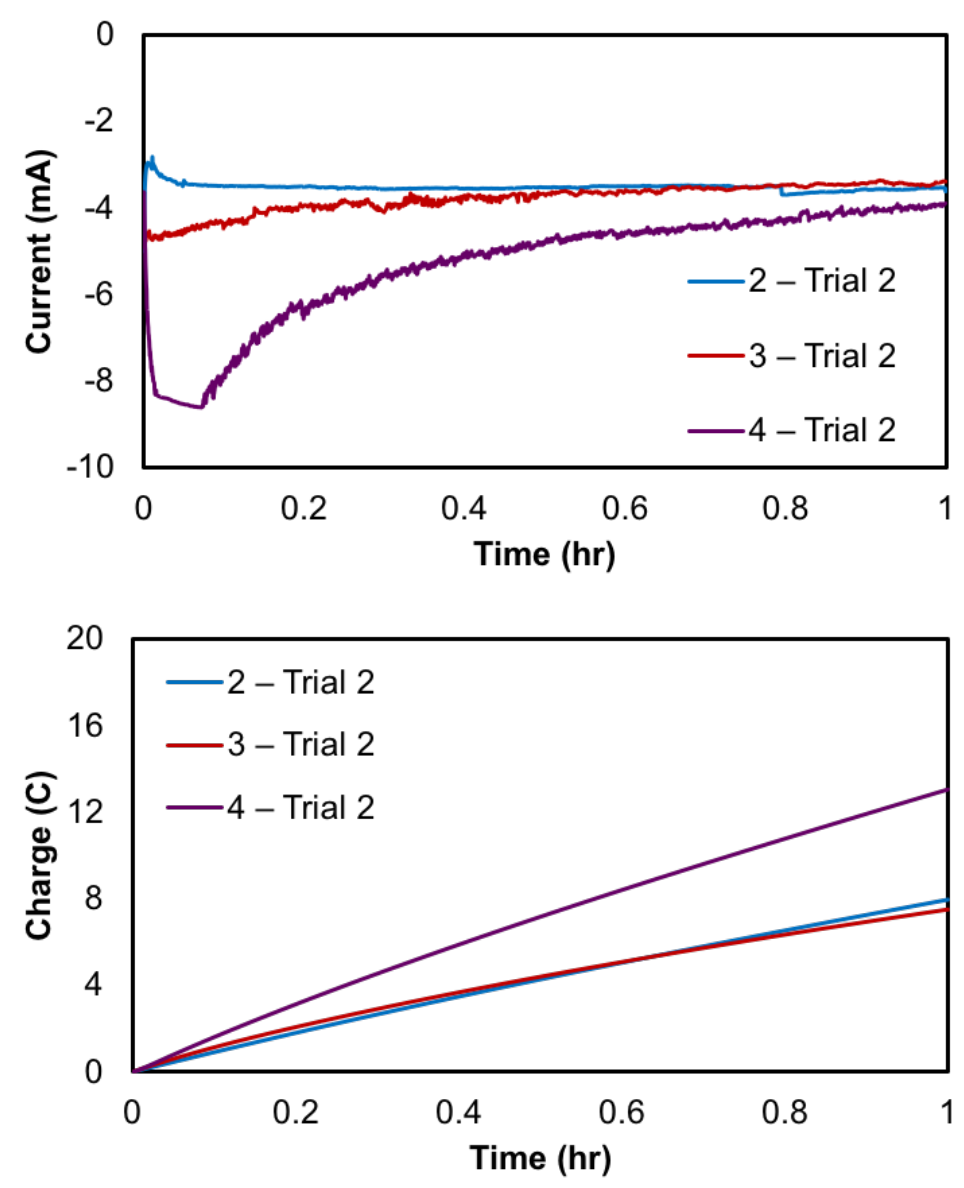

Figure S55. Replicate bulk electrolysis data for complex $2-4$ measured at $-2.75 \mathrm{~V} \mathrm{vs.} \mathrm{Fc}^{+/ 0}$ over one hour. Electrochemical studies are performed in DMF solutions containing $0.1 \mathrm{M}\left[n \mathrm{Bu}_{4} \mathrm{~N}_{[}\left[\mathrm{PF}_{6}\right]\right.$ under an atmosphere of $\mathrm{CO}_{2}$ and in the presence of 2,2,2-trifluoroethanol $(1.3 \mathrm{M})$ and catalyst $(0.5$ $\mathrm{mM})$.

Table S11. Summary of the bulk electrolysis data from Figures S12 and S57. The average error in a typical experiment for $\mathrm{CO}_{2}$ and $\mathrm{H}_{2}$ detection based on standard calibration curve is $10 \%$.

\begin{tabular}{|l|ccc|}
\hline Complex & Charge $(\mathrm{C})$ & $\mathrm{FE} \mathrm{CO}(\%)$ & $\mathrm{FE} \mathrm{H}(\%)$ \\
\hline 2 - Trial 1 & 7.95 & 15.3 & 12.7 \\
2- Trial 2 & 12.66 & 14.1 & 17.7 \\
2- Average & $\mathbf{1 0 . 3 1}$ & $\mathbf{1 4 . 7}$ & $\mathbf{1 5 . 2}$ \\
3 - Trial 1 & 7.47 & 88.4 & $<5$ \\
3- Trial 2 & 13.61 & 82.0 & $<5$ \\
3 - Average & $\mathbf{1 0 . 5 4}$ & $\mathbf{8 5 . 2}$ & $<\mathbf{5}$ \\
4- Trial 1 & 13.05 & 43.1 & $<5$ \\
4- Trial 2 & 19.07 & 46.9 & $<5$ \\
4- Average & $\mathbf{1 6 . 0 6}$ & $\mathbf{4 5 . 0}$ & $<\mathbf{5}$ \\
\hline
\end{tabular}


Faradic Efficiency Corrected $\left(i_{c a} / i_{p}\right)^{2}$ Plots

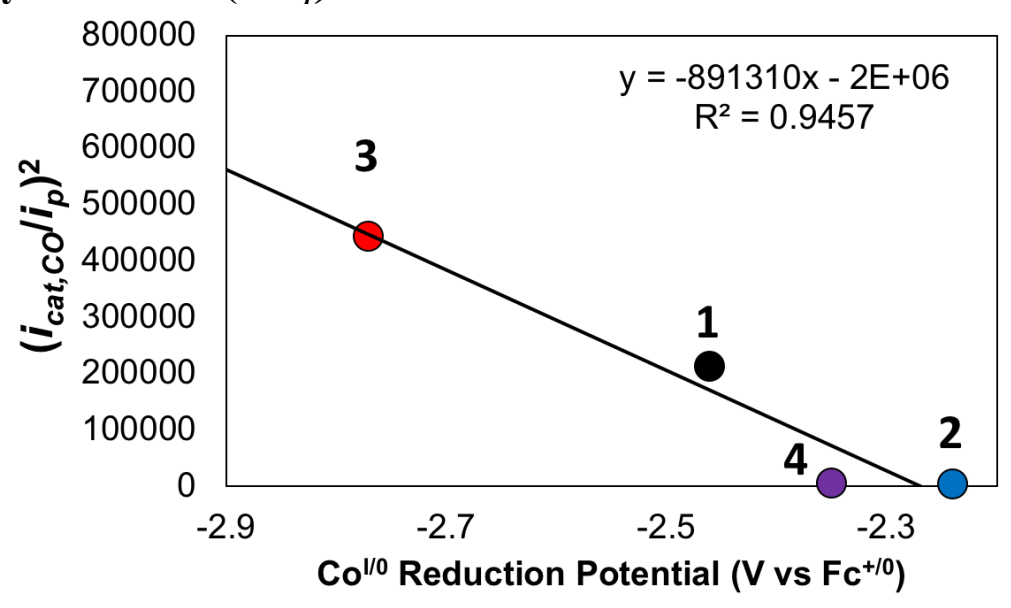

Figure S56. A plot of $\left(i_{c a t, C o} / i_{p}\right)^{2} v s$. the $\mathrm{Co}^{\mathrm{I} / 0}$ reduction potential and its linear fit. The Faradic efficiency corrected current, $i_{\text {cat, } C O}$ was calculated by multiplying $i_{\text {cat }}$ (measured in $1.5 \mathrm{M} \mathrm{TFE}$ under a $\mathrm{CO}_{2}$ atmosphere) by the Faradic efficiency obtained from CPE experiments.

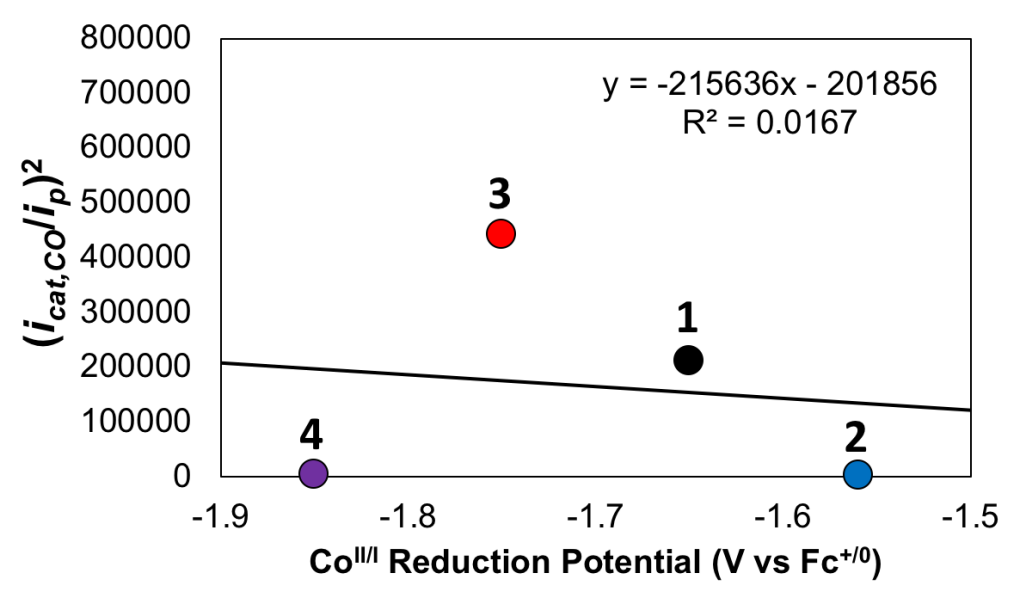

Figure S57. A plot of $\left(i_{c a t, C O} / i_{p}\right)^{2} v s$. the $\mathrm{Co}{ }^{\mathrm{I} / \mathrm{I}}$ reduction potential and its linear fit. The Faradic efficiency corrected current, $i_{\text {cat, } C O}$ was calculated by multiplying $i_{\text {cat }}$ (measured in $1.5 \mathrm{M} \mathrm{TFE}$ under a $\mathrm{CO}_{2}$ atmosphere) by the Faradic efficiency obtained from CPE experiments. 


\section{${ }^{1}$ H NMR of Complex 4 with DCM}

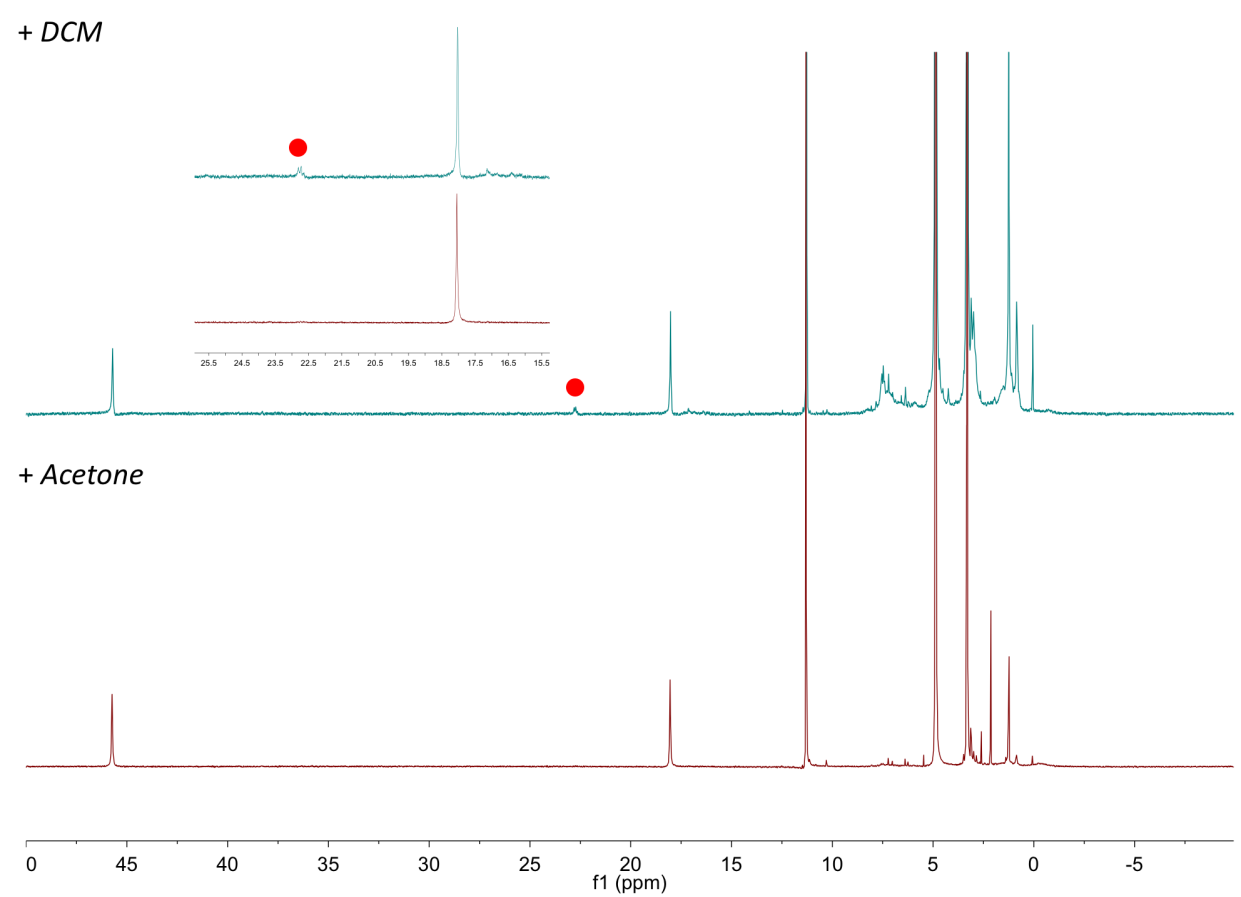

Figure S58. ${ }^{1} \mathrm{H}$ NMR spectra of complex 4 taken in $\mathrm{MeOH}-d_{4}$ after exposure of the solid material to acetone (bottom), or DCM (followed by trituration with acetone) (top). The red circle indicates a new paramagnetic feature emerging in the presence of DCM. 


\section{TFE Titration of Complex 1}

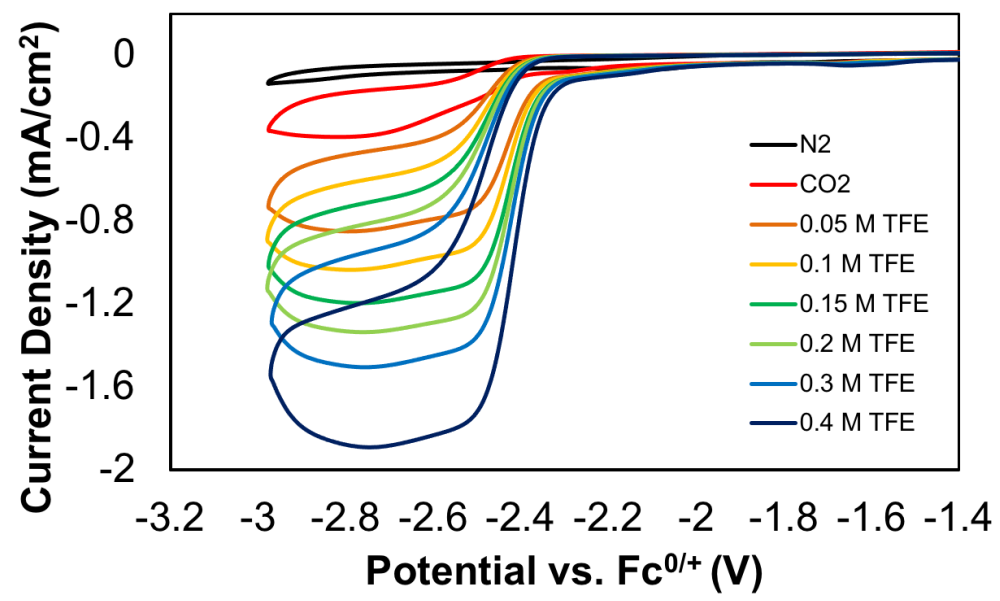

Figure S59. Cyclic voltammetry of complex $1(0.1 \mathrm{mM})$ in a DMF solution containing $0.1 \mathrm{M}$ $\left[n \mathrm{Bu}_{4} \mathrm{~N}\right]\left[\mathrm{PF}_{6}\right]$ under $\mathrm{CO}_{2}$ atmosphere with varying amounts of TFE. Scans were collected at 100 $\mathrm{mV} / \mathrm{s}$.

Table S12. Catalytic current for the titration of complex $1(0.1 \mathrm{mM})$ with TFE. $i_{p}=0.007$ $\mathrm{mA} / \mathrm{cm}^{2}$, extrapolated from the reversible $\mathrm{Co}^{\mathrm{II} / \mathrm{I}}$ couple.

\begin{tabular}{ccc}
\hline TFE $(\mathbf{M})$ & $\boldsymbol{i}_{\text {cat }}\left(\mathbf{m A} / \mathbf{c m}^{\mathbf{2}}\right)$ & $\boldsymbol{i}_{\text {cat }} / \boldsymbol{i}_{\boldsymbol{p}}$ \\
\hline $\mathbf{0}$ & 0.42 & 61.1 \\
$\mathbf{0 . 0 5}$ & 0.80 & 116.2 \\
$\mathbf{0 . 1}$ & 0.97 & 140.3 \\
$\mathbf{0 . 1 5}$ & 1.12 & 162.5 \\
$\mathbf{0 . 2}$ & 1.25 & 180.6 \\
$\mathbf{0 . 3}$ & 1.40 & 203.1 \\
$\mathbf{0 . 4}$ & 1.77 & 256.9 \\
\hline
\end{tabular}

\section{Calculation of Diffusion Coefficients for Complexes 2-4}

Diffusion coefficients were calculated from the reversible $\mathrm{Co}^{\mathrm{II} / \mathrm{I}}$ couple based on the RandlesSevcik equation (below).

$$
i_{p}=0.4463 \times n F A C \sqrt{\frac{n F v D}{R T}}
$$

$i_{p}$ is the peak current, $\mathrm{n}$ the number of electrons transferred $\left(\mathrm{n}=1\right.$ for the $\mathrm{Co}^{\mathrm{II} / \mathrm{I}}$ couple), $\mathrm{F}$ is Faraday's constant $(96,485 \mathrm{C} / \mathrm{mol}), \mathrm{A}$ is the area of the electrode $\left(0.07065 \mathrm{~cm}^{2}\right), \mathrm{C}$ is the concentration of catalyst $\left(5 \times 10^{-7} \mathrm{~mol} / \mathrm{cm}^{3}\right)$, $\mathrm{n}$ the scan rate $(0.1 \mathrm{~V} / \mathrm{s}), \mathrm{R}$ is the gas law constant (8.314 $\left.\mathrm{J} \mathrm{mol}^{-1} \mathrm{~K}^{-1}\right), \mathrm{T}$ is the absolute temperature $(298.15 \mathrm{~K})$ and $\mathrm{D}$ is the diffusion coefficient $\left(\mathrm{cm}^{2} / \mathrm{s}\right)$. By plotting $i_{p}$ as a function of $v^{1 / 2}$, the diffusion coefficient can be extrapolated. 


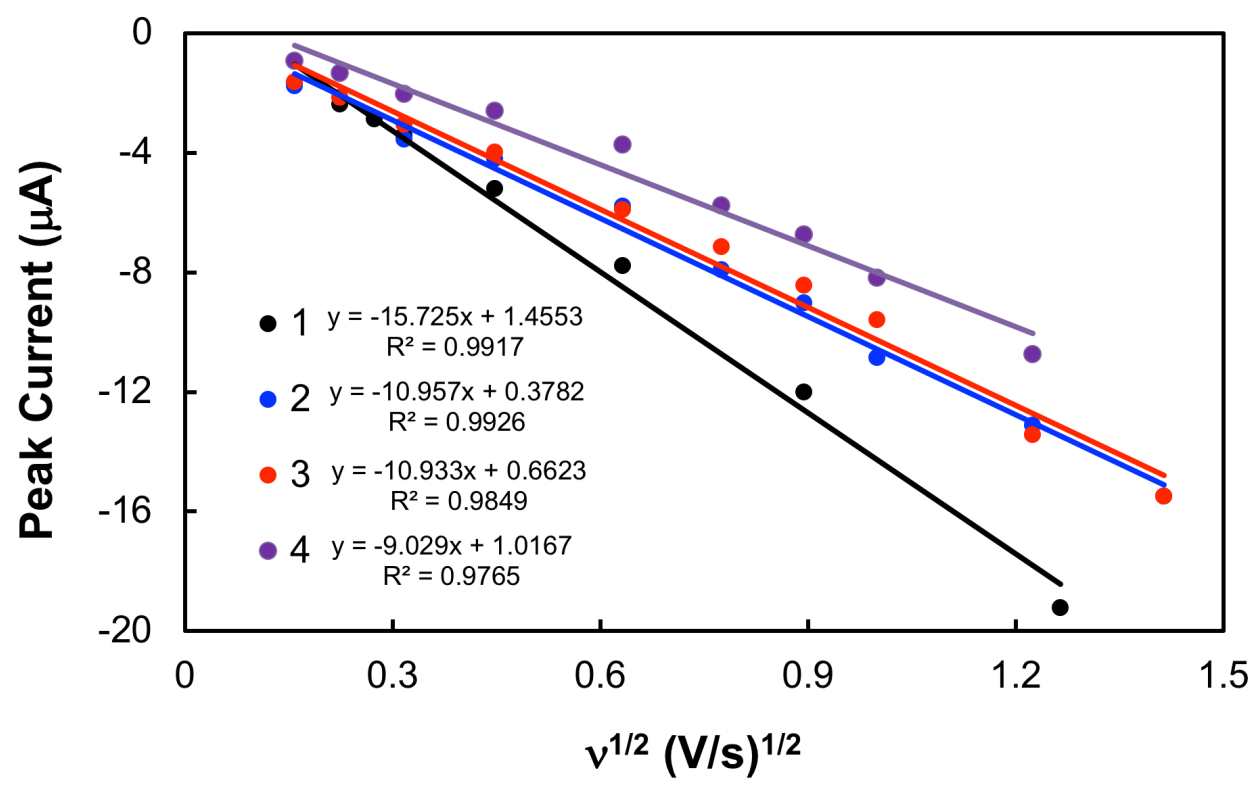

Figure S60. Linear fits of the peak current from the $\mathrm{Co}{ }^{\mathrm{II} / \mathrm{I}}$ couple as a function of the square-root of the scan rate for complex 1-4. Diffusion coefficients for each complex was extrapolated from the slope and tabulated below.

Table S13. Tabulated diffusion constants measured for complexes 2-4 based on the VSR experiments found in Figures S2, S4, and S6.

\begin{tabular}{ccc}
\hline Complex & Slope $\left(\mathbf{A} \times \mathbf{s ~ s}^{\mathbf{1} / \mathbf{2}} \times \mathbf{V}^{\mathbf{- 1 / 2}}\right)$ & $\mathbf{D}\left(\mathbf{c m}^{\mathbf{2}} / \mathbf{s}\right)$ \\
\hline $\mathbf{1}$ & $-1.53 \times 10^{-5}$ & $2.73 \times 10^{-6}$ \\
$\mathbf{2}$ & $-1.10 \times 10^{-6}$ & $1.33 \times 10^{-6}$ \\
$\mathbf{3}$ & $-1.09 \times 10^{-6}$ & $1.33 \times 10^{-6}$ \\
$\mathbf{4}$ & $-9.03 \times 10^{-7}$ & $0.91 \times 10^{-6}$ \\
\hline
\end{tabular}




\section{Coordinates of Intermediates Examined in Density Functional Theory Studies}

Listing S1. Coordinates of $\mathbf{1}^{(\mathrm{II})}-\mathrm{CO}_{2}$.

$\begin{array}{lrrrlrrr}\mathrm{H} & 2.754712 & 0.001466 & 3.714494 & \mathrm{C} & 2.388539 & -0.53111 & -5.30434 \\ \mathrm{C} & 1.948436 & 0.343141 & 3.071947 & \mathrm{H} & 3.272125 & -0.25352 & -5.87147 \\ \mathrm{C} & 0.946962 & 1.179339 & 3.556688 & \mathrm{C} & 2.33132 & -0.28813 & -3.92342 \\ \mathrm{H} & 0.939415 & 1.486093 & 4.598725 & \mathrm{H} & 5.583479 & -0.78961 & 1.295062 \\ \mathrm{C} & -0.04181 & 1.617105 & 2.68514 & \mathrm{C} & 5.16541 & -0.56648 & 0.31771 \\ \mathrm{H} & -0.85204 & 2.254752 & 3.026693 & \mathrm{C} & 3.778429 & -0.53724 & 0.132325 \\ \mathrm{C} & 0.003842 & 1.191297 & 1.348917 & \mathrm{~N} & 3.188969 & -0.24478 & -1.04284 \\ \mathrm{~N} & 0.977539 & 0.39882 & 0.854292 & \mathrm{C} & 4.002482 & 0.035392 & -2.08156 \\ \mathrm{C} & 1.928551 & -0.00819 & 1.717018 & \mathrm{C} & 5.402217 & 0.060351 & -1.98174 \\ \mathrm{C} & -1.66404 & 0.889015 & -0.49799 & \mathrm{H} & 6.007352 & 0.292377 & -2.85316 \\ \mathrm{C} & -3.04576 & 1.08098 & -0.65072 & \mathrm{C} & 5.986531 & -0.25052 & -0.76096 \\ \mathrm{H} & -3.57308 & 1.779989 & -0.00802 & \mathrm{H} & 7.067071 & -0.24553 & -0.64938 \\ \mathrm{C} & -3.71777 & 0.337389 & -1.61191 & \mathrm{~N} & -0.89071 & -1.56392 & -2.99692 \\ \mathrm{H} & -4.78806 & 0.457179 & -1.75376 & \mathrm{H} & -1.52717 & -2.13004 & -3.54473 \\ \mathrm{C} & -2.99657 & -0.56182 & -2.39224 & \mathrm{~N} & 3.438521 & 0.308332 & -3.32525 \\ \mathrm{H} & -3.48048 & -1.14187 & -3.17276 & \mathrm{H} & 4.121508 & 0.625156 & -4.00011 \\ \mathrm{C} & -1.61528 & -0.66422 & -2.18987 & \mathrm{~N} & 2.954112 & -0.8439 & 1.233238 \\ \mathrm{~N} & -0.94338 & 0.040396 & -1.25952 & \mathrm{~N} & -1.01731 & 1.6126 & 0.500768 \\ \mathrm{~N} & 1.267856 & -0.60732 & -3.15696 & \mathrm{H} & -1.61718 & 2.304815 & 0.928616 \\ \mathrm{C} & 0.232207 & -1.21118 & -3.7714 & \mathrm{Co} & 1.139465 & 0.10811 & -1.20273 \\ \mathrm{C} & 0.212827 & -1.51776 & -5.13714 & \mathrm{H} & 3.513474 & -1.19205 & 2.002501 \\ \mathrm{H} & -0.66109 & -1.98567 & -5.58136 & \mathrm{C} & 1.305331 & 2.102196 & -1.69085 \\ \mathrm{C} & 1.31067 & -1.15978 & -5.91407 & \mathrm{O} & 2.1219 & 2.694236 & -0.96769 \\ \mathrm{H} & 1.323649 & -1.36635 & -6.98045 & \mathrm{O} & 0.565107 & 2.412483 & -2.63767\end{array}$


Listing S2. Coordinates of $1^{(\mathrm{II})}-\mathrm{CO}_{2} \mathrm{H}$.

$\begin{array}{lrrrlrrr}\mathrm{H} & 2.752012 & -0.2642 & 3.806903 & \mathrm{H} & 3.407629 & -0.0522 & -5.6673 \\ \mathrm{C} & 2.026413 & 0.184615 & 3.136553 & \mathrm{C} & 2.494093 & -0.12172 & -3.71424 \\ \mathrm{C} & 1.088954 & 1.104162 & 3.599393 & \mathrm{H} & 5.66096 & -1.0982 & 1.332681 \\ \mathrm{H} & 1.056153 & 1.373982 & 4.65056 & \mathrm{C} & 5.251421 & -0.73127 & 0.397121 \\ \mathrm{C} & 0.194158 & 1.667376 & 2.700483 & \mathrm{C} & 3.869944 & -0.63193 & 0.228527 \\ \mathrm{H} & -0.57131 & 2.364085 & 3.026805 & \mathrm{~N} & 3.29397 & -0.17145 & -0.90351 \\ \mathrm{C} & 0.262327 & 1.283088 & 1.357003 & \mathrm{C} & 4.114863 & 0.202074 & -1.91058 \\ \mathrm{~N} & 1.189664 & 0.42101 & 0.882406 & \mathrm{C} & 5.50994 & 0.17687 & -1.80651 \\ \mathrm{C} & 2.050243 & -0.11674 & 1.774312 & \mathrm{H} & 6.122277 & 0.490686 & -2.64564 \\ \mathrm{C} & -1.35528 & 0.968802 & -0.45175 & \mathrm{C} & 6.080883 & -0.30296 & -0.63589 \\ \mathrm{C} & -2.74118 & 1.102199 & -0.58673 & \mathrm{H} & 7.160359 & -0.34788 & -0.52845 \\ \mathrm{H} & -3.27252 & 1.852223 & -0.00981 & \mathrm{~N} & -0.54618 & -1.71063 & -2.68463 \\ \mathrm{C} & -3.4135 & 0.23122 & -1.43254 & \mathrm{H} & -1.13516 & -2.38898 & -3.15379 \\ \mathrm{H} & -4.49018 & 0.302379 & -1.55279 & \mathrm{~N} & 3.527985 & 0.591664 & -3.11148 \\ \mathrm{C} & -2.68932 & -0.73628 & -2.12385 & \mathrm{H} & 4.187868 & 0.979736 & -3.77433 \\ \mathrm{H} & -3.1775 & -1.42213 & -2.80847 & \mathrm{~N} & 3.01438 & -1.00716 & 1.276639 \\ \mathrm{C} & -1.30397 & -0.77562 & -1.9618 & \mathrm{~N} & -0.68005 & 1.77723 & 0.459578 \\ \mathrm{~N} & -0.63105 & 0.060254 & -1.14203 & \mathrm{H} & -1.25814 & 2.511832 & 0.848305 \\ \mathrm{~N} & 1.476286 & -0.53507 & -2.92722 & \mathrm{Co} & 1.343512 & 0.103143 & -1.06099 \\ \mathrm{C} & 0.519014 & -1.29752 & -3.49975 & \mathrm{H} & 3.519968 & -1.46879 & 2.024076 \\ \mathrm{C} & 0.541306 & -1.66893 & -4.84464 & \mathrm{C} & 1.445001 & 2.088574 & -1.59047 \\ \mathrm{H} & -0.26028 & -2.27414 & -5.25561 & \mathrm{O} & 0.818261 & 2.635127 & -2.48738 \\ \mathrm{C} & 1.578542 & -1.20277 & -5.64716 & \mathrm{O} & 2.323913 & 2.867081 & -0.84296 \\ \mathrm{H} & 1.613269 & -1.45569 & -6.70244 & \mathrm{H} & 2.275662 & 3.780855 & -1.20079 \\ \mathrm{C} & 2.568643 & -0.41175 & -5.0807 & & & & \\ & & & & & & & \end{array}$


Listing S3. Coordinates of $2^{(\mathrm{II})}-\mathrm{CO}_{2}$.

$\begin{array}{lrrrrrrr}\mathrm{H} & 2.53163 & 0.018261 & 3.719313 & \mathrm{~N} & 3.198896 & -0.02395 & -1.08356 \\ \mathrm{C} & 1.785032 & 0.426054 & 3.045449 & \mathrm{C} & 4.033871 & 0.128107 & -2.13641 \\ \mathrm{C} & 0.746539 & 1.212098 & 3.52468 & \mathrm{C} & 5.41497 & -0.06179 & -2.06702 \\ \mathrm{C} & 0.658134 & 1.51894 & 4.996077 & \mathrm{H} & 6.035139 & 0.073285 & -2.94607 \\ \mathrm{C} & -0.18222 & 1.735509 & 2.619908 & \mathrm{C} & 5.966683 & -0.45532 & -0.84437 \\ \mathrm{H} & -1.02957 & 2.320179 & 2.958302 & \mathrm{C} & 7.444367 & -0.7278 & -0.73844 \\ \mathrm{C} & -0.01585 & 1.448201 & 1.265081 & \mathrm{~N} & -0.93494 & -1.19388 & -3.19439 \\ \mathrm{~N} & 0.999027 & 0.704118 & 0.768418 & \mathrm{H} & -1.56935 & -1.76514 & -3.73691 \\ \mathrm{C} & 1.882873 & 0.20839 & 1.664029 & \mathrm{~N} & 3.484258 & 0.509886 & -3.36401 \\ \mathrm{C} & -1.65439 & 1.100608 & -0.52688 & \mathrm{H} & 4.200881 & 0.765765 & -4.03181 \\ \mathrm{C} & -3.03972 & 1.080339 & -0.46344 & \mathrm{~N} & 2.958278 & -0.56127 & 1.218886 \\ \mathrm{H} & -3.56684 & 1.688141 & 0.26405 & \mathrm{~N} & -0.949 & 1.949851 & 0.348338 \\ \mathrm{C} & -3.73625 & 0.229133 & -1.34181 & \mathrm{H} & -1.56463 & 2.629842 & 0.778182 \\ \mathrm{C} & -5.23491 & 0.171433 & -1.28597 & \mathrm{Co} & 1.154055 & 0.469716 & -1.31944 \\ \mathrm{C} & -3.01168 & -0.54893 & -2.22823 & \mathrm{H} & 3.485884 & -0.942 & 1.993782 \\ \mathrm{H} & -3.51382 & -1.20023 & -2.93556 & \mathrm{C} & 1.418012 & 2.530235 & -1.84292 \\ \mathrm{C} & -1.61086 & -0.44315 & -2.23749 & \mathrm{O} & 2.242431 & 3.00835 & -1.07988 \\ \mathrm{~N} & -0.91564 & 0.352128 & -1.38594 & \mathrm{O} & 0.699304 & 2.774566 & -2.79757 \\ \mathrm{~N} & 1.280897 & -0.32518 & -3.25348 & \mathrm{~F} & -0.57255 & 1.949665 & 5.35641 \\ \mathrm{C} & 0.251299 & -0.95207 & -3.87598 & \mathrm{~F} & 1.539225 & 2.486445 & 5.361908 \\ \mathrm{C} & 0.311595 & -1.38841 & -5.211 & \mathrm{~F} & 0.944263 & 0.43044 & 5.754528 \\ \mathrm{H} & -0.55024 & -1.86043 & -5.67088 & \mathrm{~F} & 8.174571 & 0.152082 & -1.46337 \\ \mathrm{C} & 1.461628 & -1.14541 & -5.94122 & \mathrm{~F} & 7.753714 & -1.96755 & -1.20545 \\ \mathrm{C} & 1.579875 & -1.61967 & -7.36392 & \mathrm{~F} & 7.886516 & -0.67042 & 0.539251 \\ \mathrm{C} & 2.541852 & -0.50365 & -5.319 & \mathrm{~F} & 2.34232 & -0.78998 & -8.11472 \\ \mathrm{H} & 3.467626 & -0.3193 & -5.85194 & \mathrm{~F} & 0.374463 & -1.72646 & -7.97167 \\ \mathrm{C} & 2.401092 & -0.12674 & -3.98555 & \mathrm{~F} & 2.160969 & -2.8496 & -7.43276 \\ \mathrm{H} & 5.533568 & -0.92302 & 1.212916 & \mathrm{~F} & -5.75745 & -0.67405 & -2.20482 \\ \mathrm{C} & 5.132087 & -0.64318 & 0.245048 & \mathrm{~F} & -5.79803 & 1.390172 & -1.49408 \\ \mathrm{C} & 3.757543 & -0.39851 & 0.089047 & \mathrm{~F} & -5.67364 & -0.24573 & -0.06677\end{array}$


Listing S4. Coordinates of $2^{(\mathrm{II})}-\mathrm{CO}_{2} \mathrm{H}$.

\begin{tabular}{|c|c|c|c|c|c|c|c|}
\hline $\mathrm{H}$ & 2.734002 & -0.28255 & 3.745501 & $\mathrm{C}$ & 4.084788 & 0.207982 & -1.96692 \\
\hline $\mathrm{C}$ & 2.010138 & 0.168927 & 3.075701 & $\mathrm{C}$ & 5.480793 & 0.180271 & -1.86563 \\
\hline $\mathrm{C}$ & 1.076278 & 1.092775 & 3.542385 & $\mathrm{H}$ & 6.097932 & 0.491246 & -2.7007 \\
\hline $\mathrm{C}$ & 1.050506 & 1.438452 & 5.01817 & $\mathrm{C}$ & 6.045572 & -0.30561 & -0.69678 \\
\hline $\mathrm{C}$ & 0.181712 & 1.666575 & 2.653575 & $\mathrm{C}$ & 7.549544 & -0.3574 & -0.51369 \\
\hline $\mathrm{H}$ & -0.57684 & 2.363374 & 2.991074 & $\mathrm{~N}$ & -0.58702 & -1.67699 & -2.74906 \\
\hline $\mathrm{C}$ & 0.246729 & 1.286875 & 1.307497 & $\mathrm{H}$ & -1.17777 & -2.35829 & -3.21242 \\
\hline $\mathrm{N}$ & 1.166506 & 0.422497 & 0.826603 & $\mathrm{~N}$ & 3.502789 & 0.600066 & -3.16808 \\
\hline $\mathrm{C}$ & 2.026759 & -0.12571 & 1.714917 & $\mathrm{H}$ & 4.161507 & 0.993291 & -3.82979 \\
\hline $\mathrm{C}$ & -1.37476 & 0.993323 & -0.49835 & $\mathrm{~N}$ & 2.982002 & -1.02032 & 1.210046 \\
\hline $\mathrm{C}$ & -2.75732 & 1.136402 & -0.63063 & $\mathrm{~N}$ & -0.69636 & 1.791382 & 0.418981 \\
\hline $\mathrm{H}$ & -3.28893 & 1.88191 & -0.04874 & $\mathrm{H}$ & -1.26592 & 2.532639 & 0.808893 \\
\hline $\mathrm{C}$ & -3.43257 & 0.274028 & -1.48528 & Co & 1.316333 & 0.110418 & -1.11466 \\
\hline $\mathrm{C}$ & -4.93676 & 0.399349 & -1.6318 & $\mathrm{H}$ & 3.479563 & -1.50265 & 1.950356 \\
\hline $\mathrm{C}$ & -2.71946 & -0.69283 & -2.18411 & $\mathrm{C}$ & 1.426955 & 2.090371 & -1.63367 \\
\hline $\mathrm{H}$ & -3.21528 & -1.36534 & -2.87432 & $\mathrm{O}$ & 0.799666 & 2.635092 & -2.5287 \\
\hline $\mathrm{C}$ & -1.33374 & -0.74141 & -2.01909 & $\mathrm{O}$ & 2.30858 & 2.85376 & -0.88199 \\
\hline $\mathrm{N}$ & -0.65565 & 0.083831 & -1.19501 & $\mathrm{H}$ & 2.27193 & 3.772757 & -1.22766 \\
\hline $\mathrm{N}$ & 1.444295 & -0.51438 & -2.98361 & $\mathrm{~F}$ & 0.125987 & 2.375834 & 5.300824 \\
\hline $\mathrm{C}$ & 0.482378 & -1.27089 & -3.55959 & $\mathrm{~F}$ & 2.25267 & 1.903033 & 5.422411 \\
\hline $\mathrm{C}$ & 0.504586 & -1.64204 & -4.90198 & $\mathrm{~F}$ & 0.771223 & 0.342035 & 5.757922 \\
\hline $\mathrm{H}$ & -0.29747 & -2.2409 & -5.32022 & $\mathrm{~F}$ & 8.206063 & -0.09891 & -1.66112 \\
\hline $\mathrm{C}$ & 1.549961 & -1.18097 & -5.69927 & $\mathrm{~F}$ & 7.938347 & -1.57473 & -0.07608 \\
\hline $\mathrm{C}$ & 1.589665 & -1.56448 & -7.16567 & $\mathrm{~F}$ & 7.947437 & 0.549575 & 0.405258 \\
\hline $\mathrm{C}$ & 2.542196 & -0.39449 & -5.13577 & $\mathrm{~F}$ & 2.620201 & -0.98433 & -7.80919 \\
\hline $\mathrm{H}$ & 3.381184 & -0.04194 & -5.72418 & $\mathrm{~F}$ & 0.448791 & -1.20021 & -7.78926 \\
\hline $\mathrm{C}$ & 2.46344 & -0.10528 & -3.76841 & $\mathrm{~F}$ & 1.715102 & -2.90393 & -7.30191 \\
\hline $\mathrm{H}$ & 5.630825 & -1.11203 & 1.267638 & $\mathrm{~F}$ & -5.42811 & -0.47817 & -2.52803 \\
\hline $\mathrm{C}$ & 5.217297 & -0.73912 & 0.336763 & $\mathrm{~F}$ & -5.27814 & 1.64134 & -2.03363 \\
\hline $\mathrm{C}$ & 3.838823 & -0.63732 & 0.167158 & $\mathrm{~F}$ & -5.5519 & 0.172402 & -0.44927 \\
\hline $\mathrm{N}$ & 3.263392 & -0.16792 & -0.96316 & & & & \\
\hline
\end{tabular}


Listing S5. Coordinates of $3^{(\mathrm{II})}-\mathrm{CO}_{2}$.

\begin{tabular}{|c|c|c|c|c|c|c|c|}
\hline $\mathrm{H}$ & 2.806205 & -0.5819 & 3.645752 & $\mathrm{~N}$ & -1.05625 & -0.67054 & -3.12889 \\
\hline $\mathrm{C}$ & 2.029284 & -0.0641 & 3.097784 & $\mathrm{H}$ & -1.76916 & -1.16007 & -3.65269 \\
\hline $\mathrm{C}$ & 0.888214 & 0.446335 & 3.744808 & $\mathrm{~N}$ & 3.323025 & 0.992459 & -3.43496 \\
\hline $\mathrm{C}$ & -0.03759 & 1.138632 & 2.934361 & $\mathrm{H}$ & 3.984458 & 1.245062 & -4.15774 \\
\hline $\mathrm{H}$ & -0.96203 & 1.530847 & 3.338551 & $\mathrm{~N}$ & 3.322553 & -0.37983 & 1.113208 \\
\hline $\mathrm{C}$ & 0.203134 & 1.246216 & 1.565156 & $\mathrm{~N}$ & -0.71928 & 1.983402 & 0.797304 \\
\hline $\mathrm{N}$ & 1.267019 & 0.725746 & 0.934714 & $\mathrm{H}$ & -1.31279 & 2.547284 & 1.391835 \\
\hline $\mathrm{C}$ & 2.168251 & 0.10683 & 1.717377 & $\mathrm{Co}$ & 1.202725 & 0.218395 & -1.12325 \\
\hline $\mathrm{C}$ & -1.43226 & 1.525001 & -0.31642 & $\mathrm{H}$ & 3.96182 & -0.80034 & 1.774286 \\
\hline $\mathrm{C}$ & -2.76297 & 1.951627 & -0.43619 & $\mathrm{~N}$ & 0.689459 & 0.285456 & 5.098147 \\
\hline $\mathrm{H}$ & -3.18957 & 2.609694 & 0.316245 & $\mathrm{~N}$ & 1.572251 & -1.7325 & -7.02613 \\
\hline $\mathrm{C}$ & -3.5282 & 1.483625 & -1.4973 & $\mathrm{C}$ & 1.555229 & -0.61568 & 5.846879 \\
\hline $\mathrm{C}$ & -2.93657 & 0.607769 & -2.40426 & $\mathrm{H}$ & 2.596345 & -0.27035 & 5.825131 \\
\hline $\mathrm{H}$ & -3.49109 & 0.220053 & -3.25371 & $\mathrm{H}$ & 1.522256 & -1.64404 & 5.45665 \\
\hline $\mathrm{C}$ & -1.59679 & 0.247241 & -2.22295 & $\mathrm{H}$ & 1.234586 & -0.63277 & 6.890047 \\
\hline $\mathrm{N}$ & -0.82004 & 0.709623 & -1.20802 & $\mathrm{C}$ & -0.57301 & 0.695697 & 5.695776 \\
\hline $\mathrm{N}$ & 1.156258 & 0.092328 & -3.23619 & $\mathrm{H}$ & -0.7574 & 1.763245 & 5.525884 \\
\hline $\mathrm{C}$ & 0.151716 & -0.5897 & -3.81293 & $\mathrm{H}$ & -0.52445 & 0.53795 & 6.774869 \\
\hline $\mathrm{C}$ & 0.234028 & -1.20819 & -5.06409 & $\mathrm{H}$ & -1.42871 & 0.126948 & 5.299924 \\
\hline $\mathrm{H}$ & -0.6279 & -1.74091 & -5.44552 & $\mathrm{C}$ & 2.873955 & -1.7484 & -7.67845 \\
\hline $\mathrm{C}$ & 1.430095 & -1.11928 & -5.80048 & $\mathrm{C}$ & 0.571887 & -2.69961 & -7.45961 \\
\hline $\mathrm{C}$ & 2.472397 & -0.36476 & -5.21899 & $\mathrm{H}$ & 3.623036 & -2.32214 & -7.11033 \\
\hline $\mathrm{H}$ & 3.443398 & -0.28096 & -5.68983 & $\mathrm{H}$ & 3.251044 & -0.729 & -7.8186 \\
\hline $\mathrm{C}$ & 2.279241 & 0.208355 & -3.96258 & $\mathrm{H}$ & 2.769727 & -2.1989 & -8.66728 \\
\hline $\mathrm{H}$ & 5.862429 & 0.16213 & 1.045754 & $\mathrm{H}$ & 0.46409 & -3.53141 & -6.74753 \\
\hline $\mathrm{C}$ & 5.359734 & 0.350289 & 0.10161 & $\mathrm{H}$ & 0.868641 & -3.10888 & -8.42703 \\
\hline $\mathrm{C}$ & 3.981539 & 0.143124 & -0.00581 & $\mathrm{H}$ & -0.40763 & -2.22277 & -7.58759 \\
\hline $\mathrm{N}$ & 3.264535 & 0.387333 & -1.13577 & $\mathrm{C}$ & 1.032854 & -1.8227 & -0.79453 \\
\hline $\mathrm{C}$ & 3.977872 & 0.799425 & -2.21199 & $\mathrm{O}$ & 0.236136 & -2.0759 & 0.119077 \\
\hline $\mathrm{C}$ & 5.357424 & 1.047914 & -2.184 & $\mathrm{O}$ & 1.752387 & -2.46785 & -1.56917 \\
\hline $\mathrm{H}$ & 5.865366 & 1.379805 & -3.08558 & $\mathrm{H}$ & -4.56455 & 1.787495 & -1.61244 \\
\hline $\mathrm{C}$ & 6.061274 & 0.819942 & -1.00731 & $\mathrm{H}$ & 7.131829 & 0.995341 & -0.95596 \\
\hline
\end{tabular}


Listing S6. Coordinates of $3^{(\mathrm{II})}-\mathrm{CO}_{2} \mathrm{H}$.

\begin{tabular}{|c|c|c|c|c|c|c|c|}
\hline $\mathrm{H}$ & 2.641557 & -0.46311 & 3.754952 & $\mathrm{H}$ & -1.4149 & -2.00548 & -3.49036 \\
\hline $\mathrm{C}$ & 1.895029 & 0.001622 & 3.124052 & $\mathrm{~N}$ & 3.285227 & 0.913488 & -3.06348 \\
\hline $\mathrm{C}$ & 0.892056 & 0.835913 & 3.667622 & $\mathrm{H}$ & 3.936927 & 1.340377 & -3.71144 \\
\hline $\mathrm{C}$ & 0.027819 & 1.454418 & 2.731571 & $\mathrm{~N}$ & 3.009079 & -0.96079 & 1.234958 \\
\hline $\mathrm{H}$ & -0.78599 & 2.09115 & 3.053323 & $\mathrm{~N}$ & -0.7048 & 1.811205 & 0.470185 \\
\hline $\mathrm{C}$ & 0.176514 & 1.192796 & 1.377797 & $\mathrm{H}$ & -1.27191 & 2.516384 & 0.925965 \\
\hline $\mathrm{N}$ & 1.114267 & 0.368994 & 0.858213 & $\mathrm{Co}$ & 1.179781 & -0.11417 & -1.04508 \\
\hline $\mathrm{C}$ & 1.969852 & -0.18372 & 1.74951 & $\mathrm{H}$ & 3.533849 & -1.45159 & 1.947658 \\
\hline $\mathrm{C}$ & -1.45901 & 1.049609 & -0.43456 & $\mathrm{~N}$ & 0.771182 & 1.040218 & 5.008055 \\
\hline $\mathrm{C}$ & -2.84828 & 1.185309 & -0.46409 & $\mathrm{~N}$ & 1.57952 & -1.04416 & -7.13832 \\
\hline $\mathrm{H}$ & -3.34254 & 1.878179 & 0.209376 & $\mathrm{C}$ & 1.611241 & 0.29316 & 5.941271 \\
\hline $\mathrm{C}$ & -3.57666 & 0.380914 & -1.33682 & $\mathrm{H}$ & 2.672671 & 0.542945 & 5.815019 \\
\hline $\mathrm{C}$ & -2.89975 & -0.50876 & -2.15926 & $\mathrm{H}$ & 1.484181 & -0.78949 & 5.812869 \\
\hline $\mathrm{H}$ & -3.42925 & -1.13625 & -2.86933 & $\mathrm{H}$ & 1.325489 & 0.549175 & 6.961523 \\
\hline $\mathrm{C}$ & -1.50154 & -0.55379 & -2.09431 & $\mathrm{C}$ & -0.25569 & 1.938855 & 5.528499 \\
\hline $\mathrm{N}$ & -0.78074 & 0.200277 & -1.23477 & $\mathrm{H}$ & -0.17861 & 2.932213 & 5.070842 \\
\hline $\mathrm{N}$ & 1.265751 & -0.29408 & -3.00046 & $\mathrm{H}$ & -0.11436 & 2.056415 & 6.603091 \\
\hline $\mathrm{C}$ & 0.316644 & -0.97796 & -3.6805 & $\mathrm{H}$ & -1.26752 & 1.546012 & 5.35687 \\
\hline $\mathrm{C}$ & 0.371418 & -1.25012 & -5.04103 & $\mathrm{C}$ & 2.675637 & -0.46134 & -7.90855 \\
\hline $\mathrm{H}$ & -0.45738 & -1.77122 & -5.50222 & $\mathrm{C}$ & 0.575785 & -1.85637 & -7.82116 \\
\hline $\mathrm{C}$ & 1.46643 & -0.78885 & -5.80631 & $\mathrm{H}$ & 3.649038 & -0.84209 & -7.5726 \\
\hline $\mathrm{C}$ & 2.437486 & -0.03429 & -5.10397 & $\mathrm{H}$ & 2.678609 & 0.633808 & -7.83444 \\
\hline $\mathrm{H}$ & 3.319888 & 0.344414 & -5.60309 & $\mathrm{H}$ & 2.553632 & -0.72665 & -8.95876 \\
\hline $\mathrm{C}$ & 2.296562 & 0.173241 & -3.74014 & $\mathrm{H}$ & 0.425828 & -2.81049 & -7.30312 \\
\hline $\mathrm{H}$ & 5.632731 & -1.15794 & 1.115031 & $\mathrm{H}$ & 0.922708 & -2.07638 & -8.83107 \\
\hline $\mathrm{C}$ & 5.182322 & -0.72315 & 0.228454 & $\mathrm{H}$ & -0.38956 & -1.33616 & -7.8954 \\
\hline $\mathrm{C}$ & 3.792321 & -0.57106 & 0.152581 & $\mathrm{C}$ & 1.087185 & -2.13945 & -0.73331 \\
\hline $\mathrm{N}$ & 3.169152 & -0.03864 & -0.92173 & $\mathrm{O}$ & 0.124231 & -2.56798 & 0.180804 \\
\hline $\mathrm{C}$ & 3.942756 & 0.383699 & -1.94358 & $\mathrm{O}$ & 1.783282 & -2.99666 & -1.2617 \\
\hline $\mathrm{C}$ & 5.336687 & 0.306701 & -1.93091 & $\mathrm{H}$ & 0.19356 & -3.54694 & 0.226265 \\
\hline $\mathrm{H}$ & 5.910055 & 0.652884 & -2.78474 & $\mathrm{H}$ & -4.65987 & 0.448921 & -1.37328 \\
\hline $\mathrm{C}$ & 5.960381 & -0.26842 & -0.82686 & $\mathrm{H}$ & 7.041774 & -0.36177 & -0.79272 \\
\hline
\end{tabular}


Listing S7. Coordinates of $\mathbf{4}^{(\mathrm{II})}-\mathrm{CO}_{2}$.

\begin{tabular}{|c|c|c|c|c|c|c|c|}
\hline $\mathrm{H}$ & 2.780407338 & -0.507132393 & 3.805054234 & $\mathrm{H}$ & -1.63174591 & -1.631001663 & -3.691784219 \\
\hline $\mathrm{C}$ & 1.990773621 & -0.068505397 & 3.208308962 & $\mathrm{~N}$ & 3.3994945554 & 0.648108033 & -3.27981881 \\
\hline C & 0.909140337 & 0.613679483 & 3.8042064 & $\mathrm{H}$ & 4.08768201 & 0.95606876 & -3.954389671 \\
\hline $\mathrm{C}$ & -0.02807039 & 1.194413034 & 2.922916386 & $\mathrm{~N}$ & 3.152623167 & -0.815987401 & 1.246153469 \\
\hline $\mathrm{H}$ & -0.91330238 & 1.697316986 & 3.29099542 & $\mathrm{~N}$ & -0.79557551 & 1.670342439 & 0.707206405 \\
\hline $\mathrm{C}$ & 0.148298118 & 1.052161492 & 1.545914009 & $\mathrm{H}$ & -1.39507496 & 2.293590926 & 1.232775846 \\
\hline $\mathrm{N}$ & 1.162187216 & 0.383330839 & 0.975169288 & Co & 1.199054011 & -0.208492138 & -1.07146865 \\
\hline $\mathrm{C}$ & 2.069794237 & -0.148370777 & 1.817632624 & $\mathrm{H}$ & 3.744033704 & -1.252303396 & 1.941868639 \\
\hline $\mathrm{C}$ & -1.49588989 & 1.084715958 & -0.352205129 & $\mathrm{~F}$ & 8.154339112 & 0.581546344 & -1.810530876 \\
\hline $\mathrm{C}$ & -2.85969445 & 1.375270271 & -0.449621021 & $\mathrm{~F}$ & 8.117879563 & -0.629308917 & 0.010973606 \\
\hline $\mathrm{H}$ & -3.338546 & 2.003933437 & 0.293437683 & $\mathrm{~F}$ & 7.828619471 & 1.521856349 & 0.130948312 \\
\hline $\mathrm{C}$ & -3.59983903 & 0.796553489 & -1.480343144 & $\mathrm{~F}$ & -5.72834352 & 0.116685775 & -2.274991179 \\
\hline $\mathrm{C}$ & -5.0550162 & 1.113206386 & -1.648099742 & $\mathrm{~F}$ & -5.25310206 & 2.238927756 & -2.395606826 \\
\hline $\mathrm{C}$ & -2.94445549 & -0.040212058 & -2.386241876 & $\mathrm{~F}$ & -5.67604416 & 1.334492278 & -0.461367536 \\
\hline $\mathrm{H}$ & -3.47917192 & -0.498937278 & -3.210580147 & $\mathrm{~N}$ & 0.781495155 & 0.715696356 & 5.167343714 \\
\hline $\mathrm{C}$ & -1.57647763 & -0.261856637 & -2.225787472 & $\mathrm{~N}$ & 1.554204368 & -1.386811753 & -7.242176126 \\
\hline $\mathrm{N}$ & -0.83273602 & 0.286240738 & -1.227743776 & $\mathrm{C}$ & 1.652112663 & -0.066387974 & 6.036384291 \\
\hline $\mathrm{N}$ & 1.239714014 & -0.292336142 & -3.179754909 & $\mathrm{H}$ & 2.70494131 & 0.202798515 & 5.888636667 \\
\hline $\mathrm{C}$ & 0.226829388 & -0.880420151 & -3.841853829 & $\mathrm{H}$ & 1.540710864 & -1.147267794 & 5.866106225 \\
\hline $\mathrm{C}$ & 0.272118766 & -1.255785765 & -5.183920522 & $\mathrm{H}$ & 1.399757197 & 0.145622074 & 7.076535215 \\
\hline $\mathrm{H}$ & -0.6046614 & -1.6973229 & -5.640116352 & $\mathrm{C}$ & -0.39600637 & 1.351665437 & 5.742182909 \\
\hline $\mathrm{C}$ & 1.447205076 & -1.013095774 & -5.92821873 & $\mathrm{H}$ & -0.51464506 & 2.37189988 & 5.358849727 \\
\hline $\mathrm{C}$ & 2.498678351 & -0.36204668 & -5.250762198 & $\mathrm{H}$ & -0.27223373 & 1.417946463 & 6.824429614 \\
\hline $\mathrm{H}$ & 3.446738637 & -0.169149113 & -5.736389679 & $\mathrm{H}$ & -1.31958522 & 0.79038794 & 5.533144628 \\
\hline C & 2.347548859 & -0.029536363 & -3.901108455 & $\mathrm{C}$ & 2.761251747 & -1.075546279 & -7.995266954 \\
\hline $\mathrm{H}$ & 5.733546813 & -0.442976358 & 1.265802122 & $\mathrm{C}$ & 0.480826166 & -2.138717349 & -7.878877896 \\
\hline $\mathrm{C}$ & 5.272505221 & -0.212678761 & 0.310811892 & $\mathrm{H}$ & 3.641060512 & -1.596767535 & -7.591920252 \\
\hline $\mathrm{C}$ & 3.901952564 & -0.33494228 & 0.15443551 & $\mathrm{H}$ & 2.96508446 & 0.003405812 & -7.992875231 \\
\hline $\mathrm{N}$ & 3.227339955 & -0.041177948 & -1.001648757 & $\mathrm{H}$ & 2.626336863 & -1.388571115 & -9.031593599 \\
\hline $\mathrm{C}$ & 4.006812804 & 0.364684467 & -2.04578022 & $\mathrm{H}$ & 0.243172642 & -3.050231899 & -7.315008522 \\
\hline $\mathrm{C}$ & 5.388675136 & 0.522861531 & -1.973719626 & $\mathrm{H}$ & 0.797718227 & -2.435707096 & -8.879680099 \\
\hline $\mathrm{H}$ & 5.946600518 & 0.833424312 & -2.850726151 & $\mathrm{H}$ & -0.43640949 & -1.540477341 & -7.976518406 \\
\hline $\mathrm{C}$ & 6.049826884 & 0.227129771 & -0.776729904 & $\mathrm{C}$ & 0.953322125 & -2.280570276 & -0.638510759 \\
\hline $\mathrm{C}$ & 7.518282161 & 0.418342709 & -0.622065179 & $\mathrm{O}$ & 0.06209264 & -2.443705663 & 0.184289661 \\
\hline $\mathrm{N}$ & -0.95587061 & -1.122836231 & -3.136567509 & $\mathrm{O}$ & 1.744418851 & -2.895901357 & -1.34086352 \\
\hline
\end{tabular}


Listing S8. Coordinates of $4^{(\mathrm{II})}-\mathrm{CO}_{2} \mathrm{H}$.

\begin{tabular}{|c|c|c|c|c|c|c|c|}
\hline $\mathrm{H}$ & 2.610901 & -0.45517 & 3.759682 & $\mathrm{~N}$ & 3.298379 & 0.901145 & -3.0532 \\
\hline $\mathrm{C}$ & 1.864969 & 0.00367 & 3.123806 & $\mathrm{H}$ & 3.951054 & 1.33069 & -3.69847 \\
\hline C & 0.858641 & 0.840611 & 3.659905 & $\mathrm{~N}$ & 2.991486 & -0.96412 & 1.244345 \\
\hline C & -0.00083 & 1.454369 & 2.715065 & $\mathrm{~N}$ & -0.72319 & 1.803859 & 0.449697 \\
\hline $\mathrm{H}$ & -0.81444 & 2.094964 & 3.029533 & $\mathrm{H}$ & -1.28854 & 2.514008 & 0.900303 \\
\hline $\mathrm{C}$ & 0.153163 & 1.184987 & 1.364544 & Co & 1.174042 & -0.12365 & -1.04798 \\
\hline $\mathrm{N}$ & 1.091574 & 0.355756 & 0.852858 & $\mathrm{H}$ & 3.510816 & -1.45519 & 1.961179 \\
\hline $\mathrm{C}$ & 1.944501 & -0.18868 & 1.751835 & F & 8.076147 & 0.228174 & -1.74207 \\
\hline $\mathrm{C}$ & -1.47298 & 1.039881 & -0.45343 & $\mathrm{~F}$ & 7.838589 & -1.67186 & -0.69921 \\
\hline $\mathrm{C}$ & -2.86106 & 1.162198 & -0.47811 & $\mathrm{~F}$ & 7.930011 & 0.184234 & 0.43463 \\
\hline $\mathrm{H}$ & -3.36527 & 1.844816 & 0.197557 & $\mathrm{~F}$ & -5.64529 & -0.43364 & -2.23455 \\
\hline $\mathrm{C}$ & -3.58064 & 0.350694 & -1.35457 & $\mathrm{~F}$ & -5.46939 & 1.696784 & -1.8017 \\
\hline $\mathrm{C}$ & -5.08878 & 0.462754 & -1.39461 & $\mathrm{~F}$ & -5.62478 & 0.266149 & -0.16785 \\
\hline $\mathrm{C}$ & -2.90226 & -0.53164 & -2.17998 & $\mathrm{~N}$ & 0.73214 & 1.052196 & 4.996479 \\
\hline $\mathrm{H}$ & -3.43056 & -1.16057 & -2.88737 & $\mathrm{~N}$ & 1.608814 & -1.03881 & -7.13981 \\
\hline $\mathrm{C}$ & -1.50176 & -0.56222 & -2.11525 & $\mathrm{C}$ & 1.569853 & 0.312149 & 5.938882 \\
\hline $\mathrm{N}$ & -0.78755 & 0.199455 & -1.25907 & $\mathrm{H}$ & 2.630466 & 0.568579 & 5.820803 \\
\hline $\mathrm{N}$ & 1.276349 & -0.30963 & -2.99989 & $\mathrm{H}$ & 1.44919 & -0.77101 & 5.811395 \\
\hline $\mathrm{C}$ & 0.327504 & -0.98386 & -3.69093 & $\mathrm{H}$ & 1.273068 & 0.56794 & 6.955893 \\
\hline $\mathrm{C}$ & 0.38745 & -1.24912 & -5.05104 & $\mathrm{C}$ & -0.29353 & 1.958632 & 5.508722 \\
\hline $\mathrm{H}$ & -0.4415 & -1.76326 & -5.51963 & $\mathrm{H}$ & -0.21332 & 2.947308 & 5.041977 \\
\hline $\mathrm{C}$ & 1.489136 & -0.78852 & -5.8096 & $\mathrm{H}$ & -0.15163 & 2.085709 & 6.582017 \\
\hline $\mathrm{C}$ & 2.456801 & -0.03799 & -5.09729 & $\mathrm{H}$ & -1.30548 & 1.5655 & 5.340706 \\
\hline $\mathrm{H}$ & 3.340927 & 0.344598 & -5.59025 & $\mathrm{C}$ & 2.712045 & -0.45759 & -7.90289 \\
\hline $\mathrm{C}$ & 2.309838 & 0.161699 & -3.73358 & $\mathrm{C}$ & 0.60891 & -1.84932 & -7.8324 \\
\hline $\mathrm{H}$ & 5.620628 & -1.12916 & 1.155121 & $\mathrm{H}$ & 3.681653 & -0.84343 & -7.56261 \\
\hline $\mathrm{C}$ & 5.170106 & -0.70689 & 0.26325 & $\mathrm{H}$ & 2.717414 & 0.637056 & -7.82562 \\
\hline $\mathrm{C}$ & 3.781659 & -0.56605 & 0.172585 & $\mathrm{H}$ & 2.593934 & -0.719 & -8.95435 \\
\hline $\mathrm{N}$ & 3.165622 & -0.03353 & -0.90764 & $\mathrm{H}$ & 0.453983 & -2.80381 & -7.31694 \\
\hline $\mathrm{C}$ & 3.944572 & 0.383886 & -1.92538 & $\mathrm{H}$ & 0.964449 & -2.06889 & -8.83926 \\
\hline $\mathrm{C}$ & 5.340367 & 0.316122 & -1.90278 & $\mathrm{H}$ & -0.35404 & -1.32653 & -7.91426 \\
\hline $\mathrm{H}$ & 5.922729 & 0.661181 & -2.74892 & $\mathrm{C}$ & 1.078844 & -2.1357 & -0.74034 \\
\hline $\mathrm{C}$ & 5.952316 & -0.24642 & -0.78853 & $\mathrm{O}$ & 0.105711 & -2.55893 & 0.160067 \\
\hline $\mathrm{C}$ & 7.458132 & -0.37444 & -0.70492 & $\mathrm{O}$ & 1.783253 & -2.98739 & -1.26333 \\
\hline $\mathrm{N}$ & -0.80719 & -1.39485 & -2.98134 & $\mathrm{H}$ & 0.170247 & -3.53783 & 0.211231 \\
\hline $\mathrm{H}$ & -1.40827 & -2.01211 & -3.51256 & & & & \\
\hline
\end{tabular}




\section{References}

(1) Bruker Instrument Service V2011.4.0.0, Bruker AXS, Madison, WI. 2011.

(2) SAINT+ V8.27B, Bruker AXS Madison, WI. 2011.

(3) SADABS V2012-1, Bruker AXS Madison, WI, 2012.

(4) Bruker SHELXTL V2014/7, Bruker AXS Madison, WI. 2014.

(5) Sheldrick, G. M. A Short History of SHELX. Acta Crystallogr. Sect. A Found. Crystallogr. 2008, 64, 112-122.

(6) Sheldrick, G. M. Crystal Structure Refinement with SHELXL. Acta Crystallogr. Sect. C Struct. Chem. 2015, 71, 3-8.

(7) Hübschle, C. B.; Sheldrick, G. M.; Dittrich, B. ShelXle: A Qt Graphical User Interface for SHELXL. J. Appl. Crystallogr. 2011, 44, 1281-1284.

(8) Sampson, M. D.; Nguyen, A. D.; Grice, K. A.; Moore, C. E.; Rheingold, A. L.; Kubiak, C. P. Manganese Catalysts with Bulky Bipyridine Ligands for the Electrocatalytic Reduction of Carbon Dioxide: Eliminating Dimerization and Altering Catalysis. J. Am. Chem. Soc. 2014, 136, 5460-5471.

(9) Hansch, C.; Leo, a; Taft, R. W. A Survey of Hammett Substituent Constants and Resonance and Field Parameters. Chem. Rev. 1991, 91, 165-195.

(10) Huang, S. N.; Pascal, T. A.; Goddard, W. A.; Maiti, P. K.; Lin, S. T. Absolute Entropy and Energy of Carbon Dioxide Using the Two-Phase Thermodynamic Model. J. Chem. Theory Comput. 2011, 7, 1893-1901.

(11) Becke, A. D. Density-functional Thermochemistry. III. The Role of Exact Exchange. $J$. Chem. Phys. 1993, 98, 5648-5652.

(12) Lee, C.; Yang, W.; Parr, R. G. Development of the Colle-Salvetti Correlation-Energy Formula into a Functional of the Electron Density. Phys. Rev. B 1988, 37, 785-789.

(13) Stephens, P. J.; Devlin, F. J.; Chabalowski, C. F.; Frisch, M. J. Ab Initio Calculation of Vibrational Absorption and Circular Dichroism Spectra Using Density Functional Force Fields. J. Phys. Chem. 1994, 98, 11623-11627.

(14) Vosko, S. H.; Wilk, L.; Nusair, M. Accurate Spin-Dependent Electron Liquid Correlation Energies for Local Spin Density Calculations: A Critical Analysis. Can. J. Phys. 1980, 58, $1200-1211$.

(15) Lebedev, V. I. Spherical Quadrature Formulas Exact to Orders 25-29. Sib. Math. J. 1977, $18,99-107$.

(16) Rassolov, V. A.; Ratner, M. A.; Pople, J. A.; Redfern, P. C.; Curtiss, L. A. 6-31G* Basis Set for Third-Row Atoms. J. Comput. Chem. 2001, 22, 976-984.

(17) Marenich, A. V; Cramer, C. J.; Truhlar, D. G. Universal Solvation Model Based on Solute Electron Density and on a Continuum Model of the Solvent Defined by the Bulk Dielectric Constant and Atomic Surface Tensions. J. Phys. Chem. B 2009, 113, 6378- 
6396.

(18) Chapovetsky, A.; Welborn, M.; Luna, J. M.; Haiges, R.; Miller, T. F.; Marinescu, S. C. Pendant Hydrogen-Bond Donors in Cobalt Catalysts Independently Enhance CO 2 Reduction. ACS Cent. Sci. 2018, 4, 397-404.

(19) Cotton, F. A.; Wilkinson, G. Advanced Inorganic Chemistry, 4th ed.; Wiley: New York, 1980 . 